\title{
DELTA
}

\section{Diesel Engine Light Truck Application}

\section{DE-FC05-02OR22909}

\section{FINAL REPORT}

\author{
Prepared for: \\ Department of Energy \\ March 2009
}

\section{getrout gugsen}

13400 Outer Drive, West

Detroit, Michigan 48239-4001

Detroit Diesel Corporation is a Daimler company. 


\section{DISCLAIMER}

This report was prepared as an account of work sponsored by an agency of the United States Government. Neither the United States Government nor any agency thereof, nor any of their employees, makes any warranty, express or implied, or assumes any legal liability or responsibility for the accuracy, completeness, or usefulness of any information, apparatus, product, or process disclosed, or represents that its use would not infringe privately owned rights. Reference herein to any specific commercial product, process, or service by trade name, trademark, manufacturer, or otherwise does not necessarily constitute or imply its endorsement, recommendation, or favoring by the United States Government or any agency thereof. The views and opinions of authors expressed herein do not necessarily state or reflect those of the United States Government or any agency thereof. 


\section{TABLE OF CONTENTS}

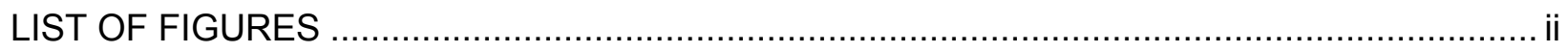

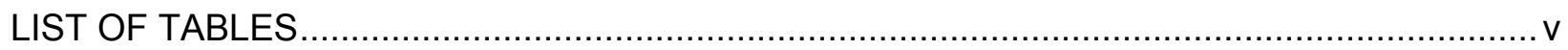

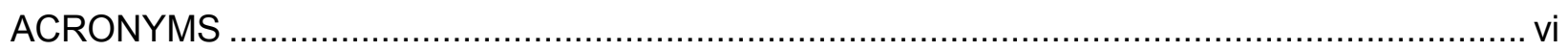

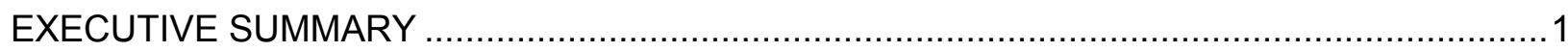

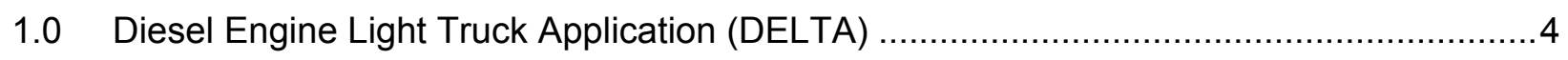

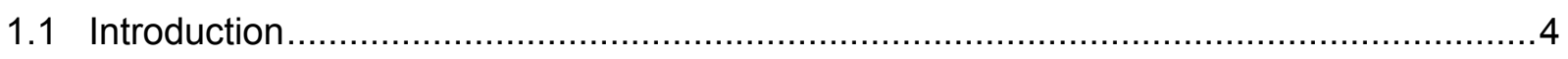

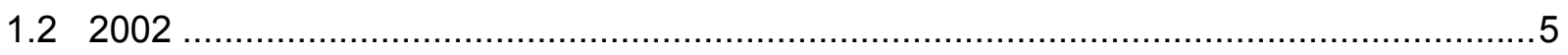

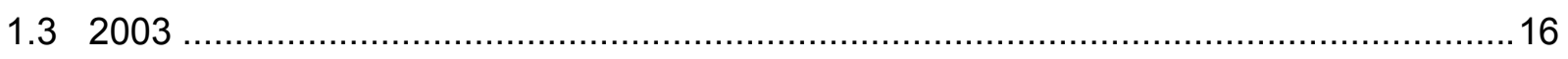

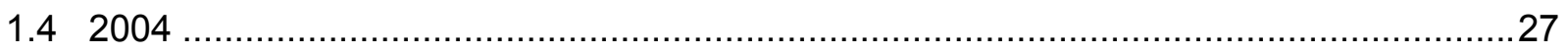

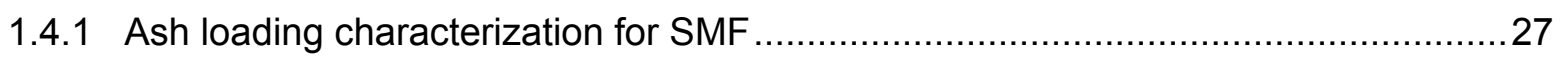

1.4.2 Fuel burner development for DPF regeneration ........................................... 36

1.4.3 DPF characterization using reactor bench................................................ 40

2.0 DPF Soot Layer Characterization and Substrate Material Assessment .......................44

2.1 DPF soot-loading exhaust leg/sampling system for miniature DPFs .........................44

2.2 Engine exhaust and PM characterization ....................................................... 47

2.3 Miniature DPF PM-loading experiments ......................................................... 50

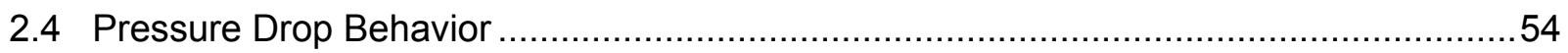

2.5 EM Characterization of a Soot-Loaded Un-Catalyzed Cordierite DPF .........................61

2.6 Micro-structural characterization of soot and ash distribution ..................................66

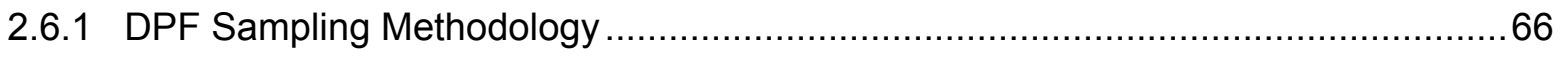

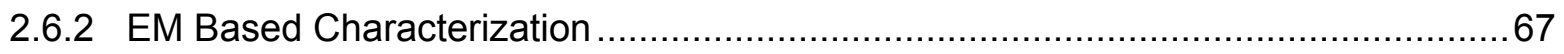

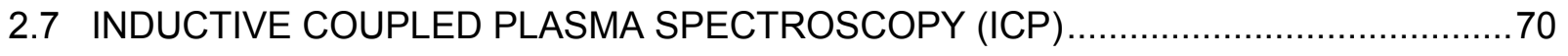

2.7.1 ICP Analysis of the First-Received Full-Sized DPF ......................................... 70

2.7.2 Comparison of ICP techniques applied to the first-received DPF ..........................74

2.7.3 ICP Analysis of the Second Full-Sized DPF ............................................. 76

2.8 Summary for DPF soot layer characterization assessment.................................... 81

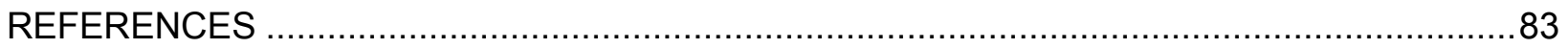




\section{LIST OF FIGURES}

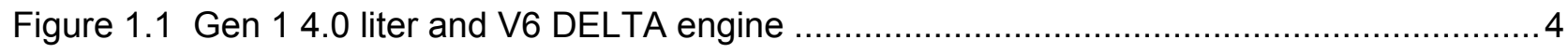

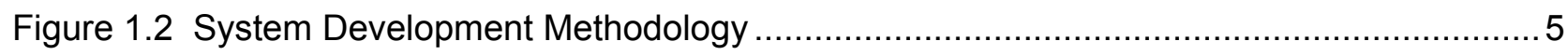

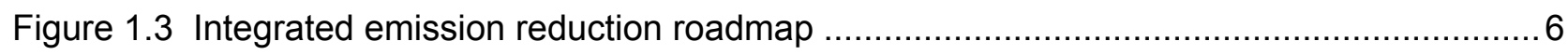

Figure 1.4 Emission reductions in vehicle chassis dynamometer...................................... 7

Figure 1.5 Forward engineering with virtual lab simulations ........................................... 8

Figure 1.6 KIVA developed engine-out emissions strategy for DELTA combustion system..........8

Figure 1.7 Integrated GT-Power/CFD simulations for improved EGR distribution and Mixing .......9

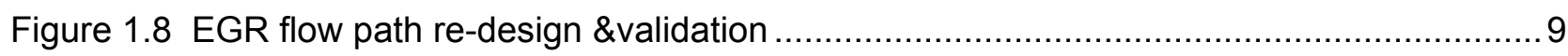

Figure 1.9 DELTA Gen 1 EGR system design............................................................. 10

Figure 1.10 Impact of more efficient EGR Cooling ...................................................... 10

Figure 1.11 Selection of steady state modals point to simulate transient operations .................11

Figure 1.12 Steady state modal and 8-mode composite NOx and PM emission results ..............12

Figure 1.13 Summary of different potential strategies for Tier 2 FTP Emissions ....................... 12

Figure 1.14 Transient testing results......................................................................... 13

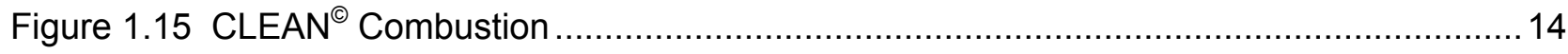

Figure $1.16 \mathrm{CO}$ and $\mathrm{HC}$ emissions of $\mathrm{CLEAN}^{\odot}$ combustion ............................................ 14

Figure 1.17 NO2/NOx emissions of $\mathrm{CLEAN}^{\circledR}$ combustion. ............................................... 15

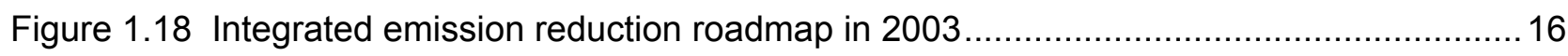

Figure 1.19 High-Squish Combustion Development ...................................................... 17

Figure 1.20 Post injection process on wetting the wall ................................................... 18

Figure 1.21 Impact of post injection quantity on combustion ........................................... 18

Figure 1.22 Impact of post injection timing on combustion .................................................. 19

Figure 1.23 Closed loop control for variable geometry turbine .........................................20

Figure 1.24 Transient boost response with closed loop control .............................................20

Figure 1.25 Exhaust temperature over a FTP75 cycle for a Neon vehicle with $1.5 \mathrm{~L}$ engine ........21

Figure 1.26 Fuel burner concept ................................................................................. 22

Figure 1.27 Ash loading in SMF (left side) and cordierite filter (right side) .............................23

Figure 1.28 Sintered Metal PM Filter (1) ........................................................................ 23

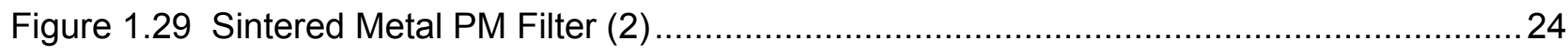

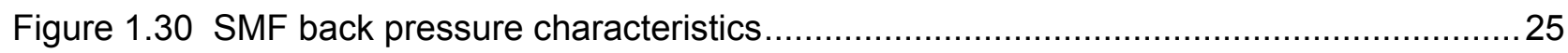

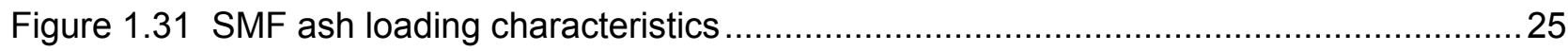

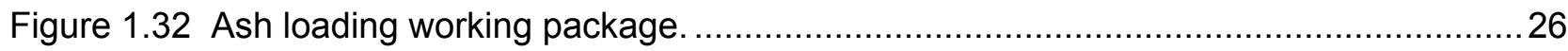

Figure 1.33 Flow diagram of aging rig with typical instrumentation shown ...........................27 


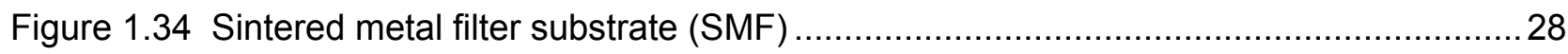

Figure 1.35 Experimental setup to determine sample flow rate by increasing pressure drop.......29

Figure 1.36 Experimental results for one sample, Coated and Uncoated ................................29

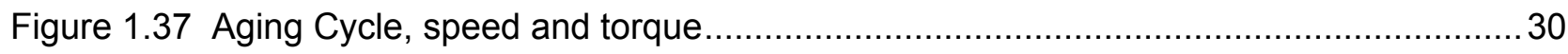

Figure 1.38 Typical Temperature Profile and Sample Pressure Drop .................................... 30

Figure 1.39 DOC Inlet Temperatures for all sample legs .................................................... 31

Figure 1.40 CSF Inlet Temperatures for all sample legs .................................................. 32

Figure 1.41 Histogram of CSF Inlet Temperatures for all sample ......................................... 32

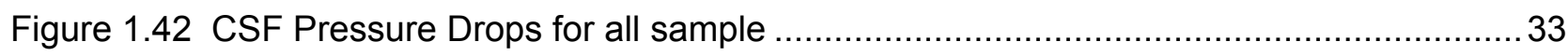

Figure 1.43 Increase in sample weights over ash accumulation .......................................... 33

Figure 1.44 Axial duct burner system configuration ...................................................... 36

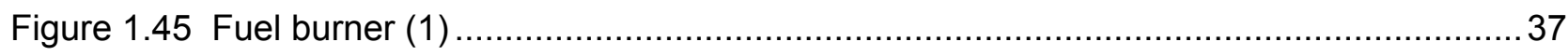

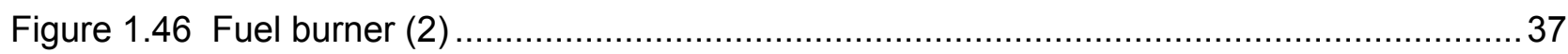

Figure 1.47 Burner performance at idle speed .............................................................. 38

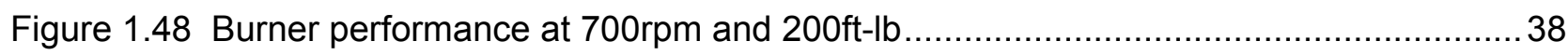

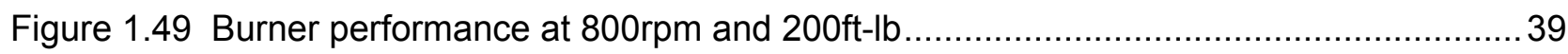

Figure 1.50 DPF Characterization Using Reactor Bench Laboratory setup .............................40

Figure 1.51 Standard tests for active regeneration ......................................................... 41

Figure 1.52 Soot consumption rate $(1 / \mathrm{s})$ at different operating conditions ...............................42

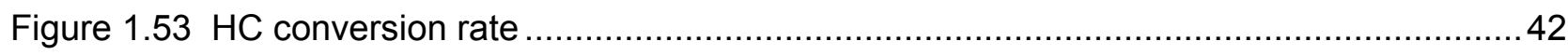

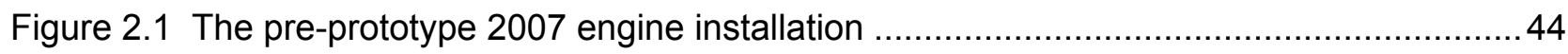

Figure 2.2 Schematic diagram of exhaust system set up with the pre-prototype 2007 DDC engine...

Figure 2.3 Small exhaust system branching off the main exhaust........................................46

Figure 2.4 Front and back view of the blower system and flow measurement system...............46

Figure 2.5 SMPS particle number based geometric mean mobility diameter ........................... 48

Figure 2.6 SMPS particle volume based geometric mean mobility diameter............................ 49

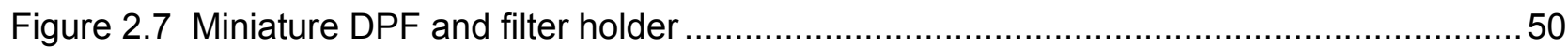

Figure $2.83 \times 6$ inch filter removed from the can after loading...........................................52

Figure 2.9 Pressure drop and other parameter behavior at 1500rpm and 40\% load.................54

Figure 2.10 Repeat of pressure drop and other parameter behavior at 1500rpm and $40 \%$ load.. 55

Figure 2.11 Pressure drop across for $3 \times 6$ inch DPFs at the $1800 \mathrm{rpm}, 100 \%$ load condition.......56

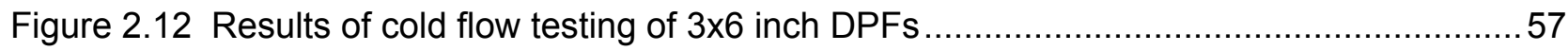

Figure 2.13 Schematic of exhaust leg for de-greening of $3 \times 6$ inch DPFs...............................57

Figure 2.14 Results of cold flow testing of $3 \times 6$ inch DPFs ................................................ 58 


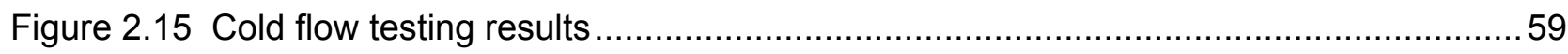

Figure 2.16 Cold flow result for several different $3 \times 6$ inch DPFs.......................................60

Figure 2.17 A composite from several overlapping images ................................................61

Figure 2.18 A highly magnified view of a pore containing soot particles from an uncatalyzed

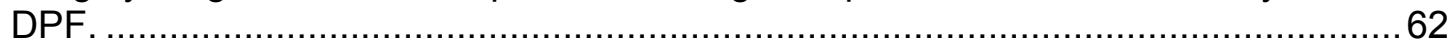

Figure 2.19 TEM comparisons of individual soot particles...............................................63

Figure 2.20 The results of soot particle size counts are shown in the above plots....................63

Figure 2.21 The soot agglomerate particles from the Hatz engine ........................................64

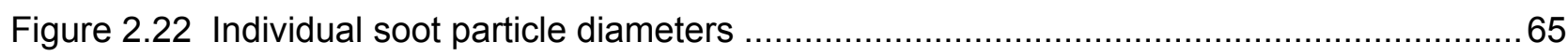

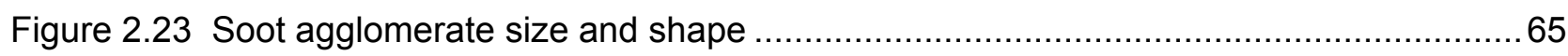

Figure 2.24 The DPF sectioning and sample positions ..................................................6

Figure 2.25 Ash+soot particle morphology for sections B-3. ........................................... 68

Figure 2.26 Ash+Soot particle morphology for section D-3 ...........................................68

Figure 2.27 Compositional profiles "within" soot layer .......................................................69

Figure 2.28 Detailed results of ICP analysis by sample location .......................................... 71

Figure 2.29 Results of ICP analysis shown as total ash metals as a function of axial position ....72

Figure 2.30 Measured refractory oxides are shown for four DPF .................................... 73

Figure 2.31 Distribution of lube oil related elements by DPF sample position..........................73

Figure 2.32 Distribution of Pd by DPF sample position. .................................................. 74

Figure 2.33 Calcium distribution for the DOC and DPF ............................................... 76

Figure 2.34 Results for all lube oil related elements for both the DOC and DPF....................77

Figure 2.35 Distribution of $\mathrm{Al} 2 \mathrm{O} 3, \mathrm{SiO} 2$, and $\mathrm{MgO}$ in the $\mathrm{DOC}$ and DPF.............................78

Figure 2.36 Distribution of $\mathrm{Ce}$, La, and $\mathrm{Zr}$ is shown for the DOC and DPF.............................79

Figure 2.37 PGM metal measurements are shown for the DOC samples. Levels appear

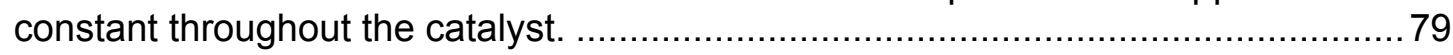

Figure 2.38 Distribution of carbon in the DOC and DPF is shown..................................... 80 


\section{LIST OF TABLES}

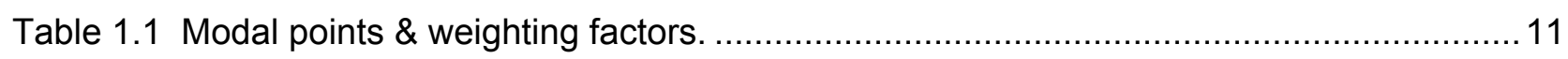

Table 1.2 Instrumentation Referenced in Figure 1.33 ....................................................... 28

Table 1.3 XRF elemental analysis of collected ash samples.................................................. 34

Table 1.4 DPF characterization using reactor bench test matrix ........................................ 40

Table 2.1 Exhaust soot characteristics at selected engine conditions...................................47

Table 2.2 SMPS results for particle number concentration................................................ 49

Table 2.3 SMPS results for volume weighted particle concentration ......................................50

Table 2.4 Initial test matrix for soot filter loading .......................................................... 51

Table 2.5 Properties of 2007 Certification Fuel (Haltermann) and ExxonMobil ULSD................52

Table 2.6 Summary of important quantities for experimental loading of $3 \times 6$ inch soot filters.......53

Table 2.6 (continued) Summary of important quantities for experimental loading of $3 \times 6$ inch

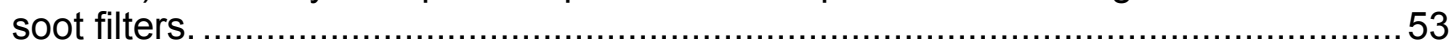

Table 2.7 Comparison of ICP results for cordierite using three digestion techniques ................75

Table 2.8 Comparison of DPF sample results using three digestion techniques...................... 75 
ACRONYMS

\begin{tabular}{|c|c|}
\hline CFD & Computational Fluid Dynamics \\
\hline CLEAN $^{\odot}$ Combustion & Controlled Low Emission Aftertreatment Nurturing Combustion \\
\hline CSF & Catalyzed soot filter \\
\hline DDC & Detroit Diesel Corporation \\
\hline DEER & Diesel Engine Emissions Reduction \\
\hline DELTA & Diesel Engine Light Truck Application \\
\hline DOE & Department of Energy \\
\hline DPF & Diesel Particulate Filter \\
\hline EGR & Exhaust Gas Recirculation \\
\hline EM & Electron Microscopy \\
\hline FEA & Finite Element Analysis \\
\hline FTP & Federal Test Procedure \\
\hline Gen & Generation \\
\hline ICP & Inductively coupled plasma \\
\hline LDT & Light Duty Truck \\
\hline MPG & Miles Per Gallon \\
\hline NOx & Nitrous Oxides \\
\hline OEM & Original Equipment Manufacturer \\
\hline ORNL & Oak Ridge National Laboratory \\
\hline PM & Particulate Matter \\
\hline SFTP & Supplemental Federal Test Procedure \\
\hline SMPS & Scanning Mobility Particle Sizer \\
\hline SS & Steady State \\
\hline SUV & Sports Utility Vehicle \\
\hline TEM & Transmission Electron Microscopy \\
\hline TPO & Turbine Outlet Pressure \\
\hline VGT & Variable Geometry Turbo \\
\hline
\end{tabular}




\section{DELTA \\ Diesel Engine Light Truck Application \\ Final Report \\ DE-FC05-02OR22909}

\section{EXECUTIVE SUMMARY}

The Diesel Engine Light Truck Application (DELTA) program consists of two major contracts with the Department of Energy (DOE). The first one under DE-FC05-97-OR22606, starting from 1997, was completed in 2001, and consequently, a final report was submitted to DOE in 2003. The second part of the contract was under DE-FC05-02OR22909, covering the program progress from 2002 to 2007 . This report is the final report of the second part of the program under contract DE-FC05-02OR22909.

During the course of this contract, the program work scope and objectives were significantly changed. From 2002 to 2004, the DELTA program continued working on light-duty engine development with the 4.0L V6 DELTA engine, following the accomplishments made from the first part of the program under DE-FC05-97-OR22606. The program work scope in 2005-2007 was changed to the DPF soot layer characterization and substrate material assessment. This final report will cover two major technical tasks.

(1) Continuation of the DELTA engine development to demonstrate production-viable diesel engine technologies and to demonstrate emissions compliance with significant fuel economy advantages, covering progress made from 2002 to 2004.

(2) DPF soot layer characterization and substrate material assessment from 2005-2007

Key accomplishments for each task are summarized as follows. 


\section{DELTA Program Milestones}

1997: DOE DELTA Funding Awarded

Gen 0 Design Initiated

DDC Quotes DELTA for NAFTA Pick Up

1998: Gen 0 Tooled, Built, and Running

Durango Repowered

1999: OEM Program (DDC Initiative)

Gen 1 Design Initiated

Twin VGT Gen 0 Developed

2000: OEM Vehicle Repowered

CLEAN Combustion ${ }^{\odot}$ Discovered

OEM Program Goals Achieved

2001: Gen 1 Engine Tooled and Assembled Gen 1 Verification Initiated

2002: Dakota Repowered

Tier 2 Bin 10 Engine Out Demonstrated Tier 2 Bin 6 Tail Pipe Out Demonstrated Gen 1 Verification Completed

2003: Cold Operating Emissions Reduced Closed Loop Air System Controls Applied Tier 2 Bin 5 Tail Pipe Out Demonstrated Tier 2 Bin 3 Tail Pipe Out Demonstrated
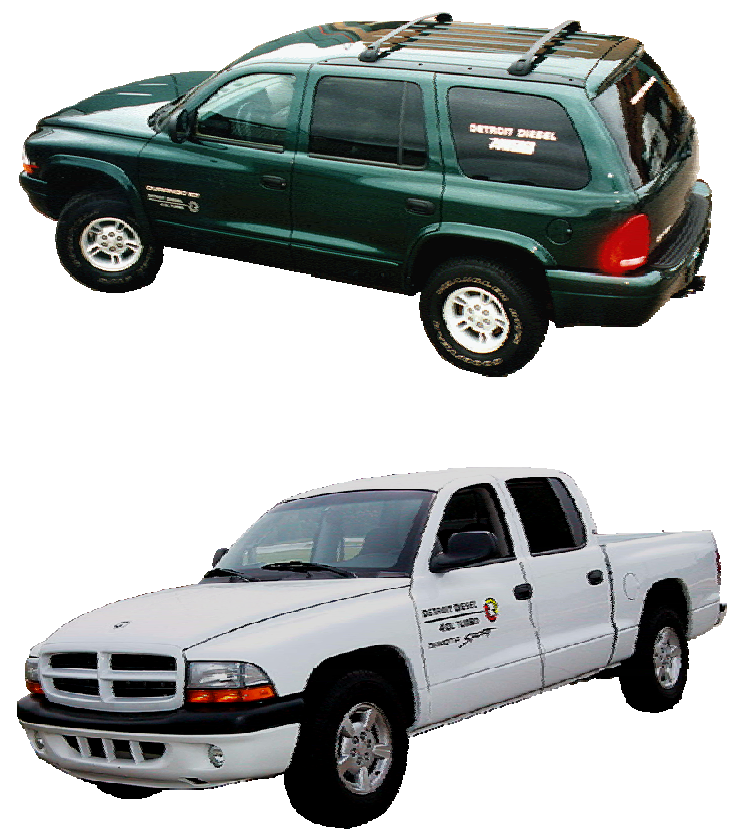

2004: Conducted ash-loading tests of sintered metal diesel particulate filters with $\mathbf{3 0 0 0}$ hours

\section{DPF Soot Layer Characterization and Substrate Material Assessment}

- Many of the general and special capabilities at ORNL were demonstrated to operate engines, characterize PM and exhaust, and load and regenerate DPFs.

- Because surrogate engines produced were likely unrepresentative of DDC products, an advanced version of a pre-prototype 2007 Series 60 engine was chosen for use in further work. Delivery and installation were accelerated to support the overall effort.

- The electron microscopy (EM) and transmission electron microscopy (TEM) techniques appear to be quite useful for imaging the details of the DPF (substrate and washcoat), soot layers, and individual soot particles. The epoxy impregnation method with microtome cutting and polishing for TEM imaging appears to work very well.

- Individual soot particle and agglomerate visual characterization is possible and size statistics can be generated using EM grids with TEM imaging. A more suitable type of EM grid was procured for future work.

- The composition and morphology of both soot and ash particles remains the same from inlet to outlet face of DPF, and only the thickness of the deposit changes. The density of the 
(ash+soot) layer does not change with increasing layer thickness and the localized composition within the deposit remains constant.

- The ICP measurements can provide a quantitative picture of metals distribution in the DOC and DPF components. Refractory oxides are hard to digest and the technique can have low accuracy without special procedures.

- Lube oil related metals were found to be concentrated at the back of both DPFs examined, consistent with ash packing. These results are also consistent with the EM analysis results and information from visual inspection.

Detailed progress of these two technical tasks will be presented in this final report. 


\subsection{Diesel Engine Light Truck Application (DELTA)}

\subsection{Introduction}

Detroit Diesel developed engine and aftertreatment technologies in support of the Department of Energy-sponsored Light-Duty Truck Diesel Engine development program. This program was split into two major contracts. The first one focused mainly on light-duty engine hardware development, which resulted in the first generation of the light-duty engine named DELTA (Figure 1.1).

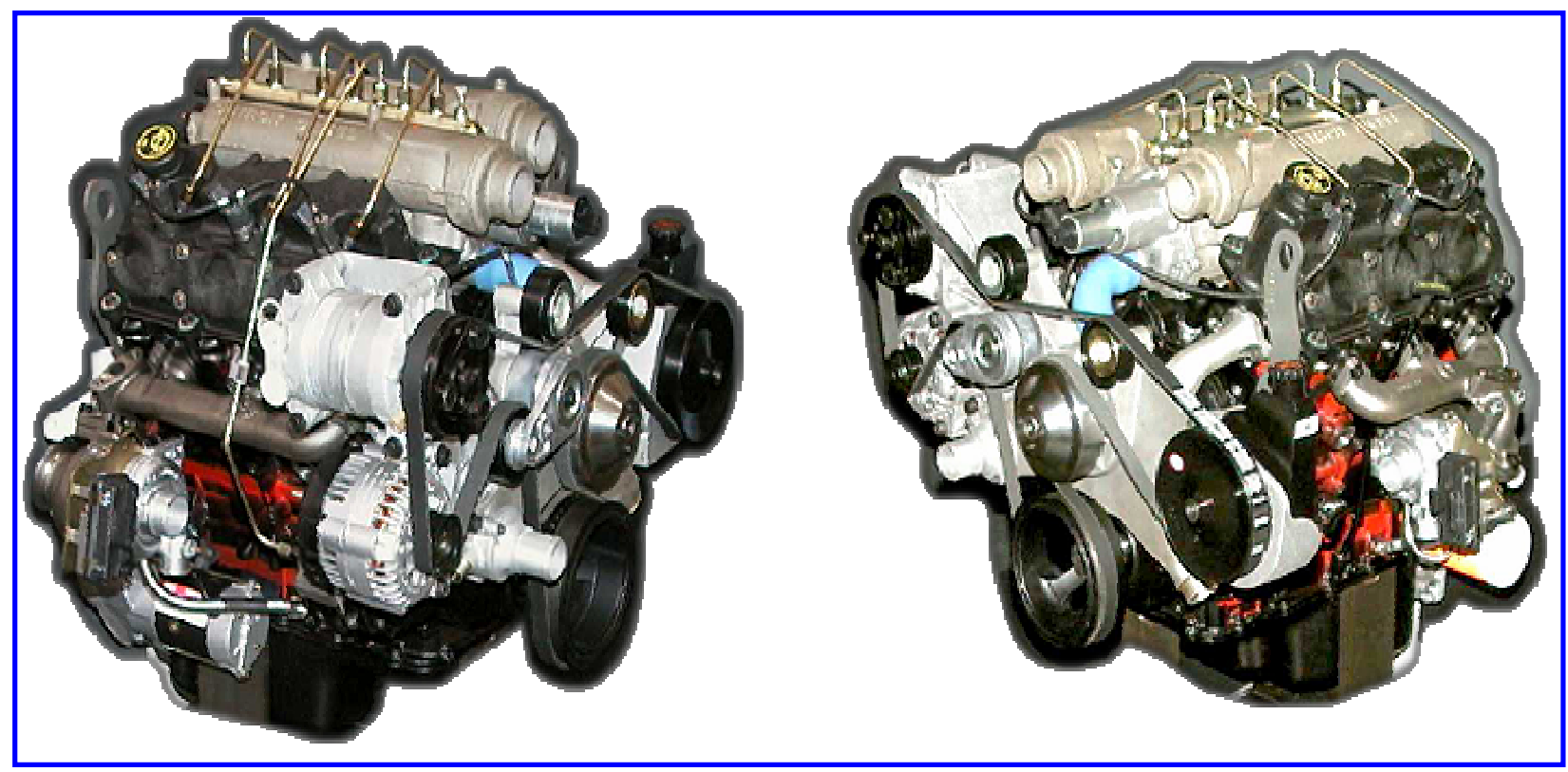

Figure 1.1 Gen 14.0 liter and V6 DELTA engine

A detailed technical report was submitted to DOE in 2003 (Reference 1). The second part of the DELTA program was the development of engine performance and emissions, which is the focus of this report.

The objective of this effort was to demonstrate production viable diesel engine technologies, which were specifically tailored for the North American light truck market. Light-duty truck diesel engines were intended for a variety of vehicle applications, which range from small and mid-size sport utility vehicles (SUVs) and passenger vans to full-size pick-ups, SUVs and vans.

This report presents a chronological outline of the main technology building blocks developed from 2002 to 2004. The technical progress made was regularly presented at the DEER conferences (References 2-5). 


\subsection{2}

Detroit Diesel developed a comprehensive System Development Methodology as shown in Figure 1.2, which was used throughout the entire program.

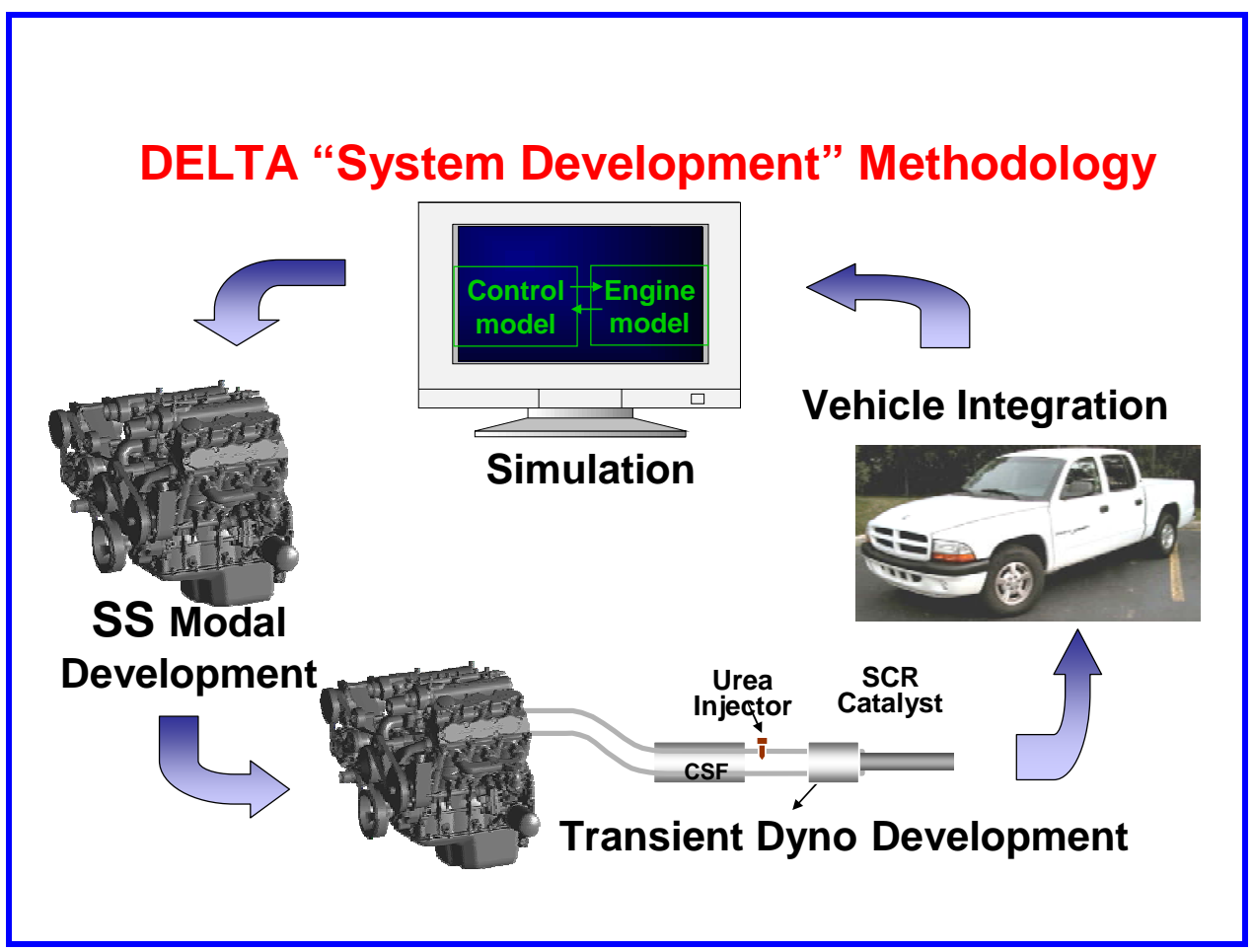

Figure 1.2 System Development Methodology

A 2001 Dakota vehicle repowered with a DELTA engine was used for the technology demonstration. The key features for this vehicle can be seen in the following paragraph. 
- 2001 Dakota Quad Cab Sport 4 x 2

- Repowered with DDC DELTA 4.0I V6 - Common Rail Injection; 235 hp @ 4000 RPM

- Integrated CSF and Urea SCR Aftertreatment

- Tier 2 - Bin 5 Emission Target

- Vehicle Instrumented to Provide Detailed On-board Measurements of System Pressures, Temperatures and NOx Emissions - "Mobile Test Cell"

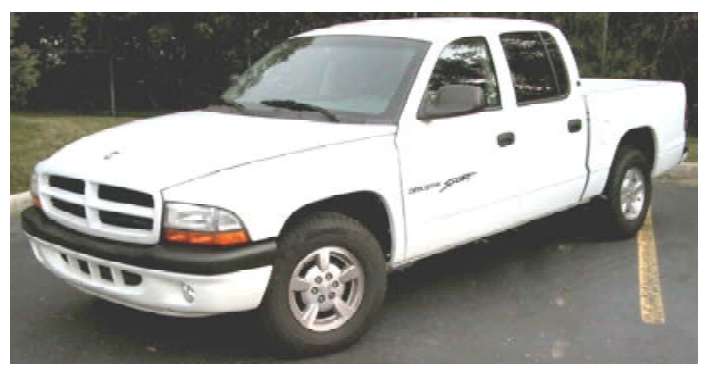

The technical road map for achieving the program goals is shown in Figure 1.3

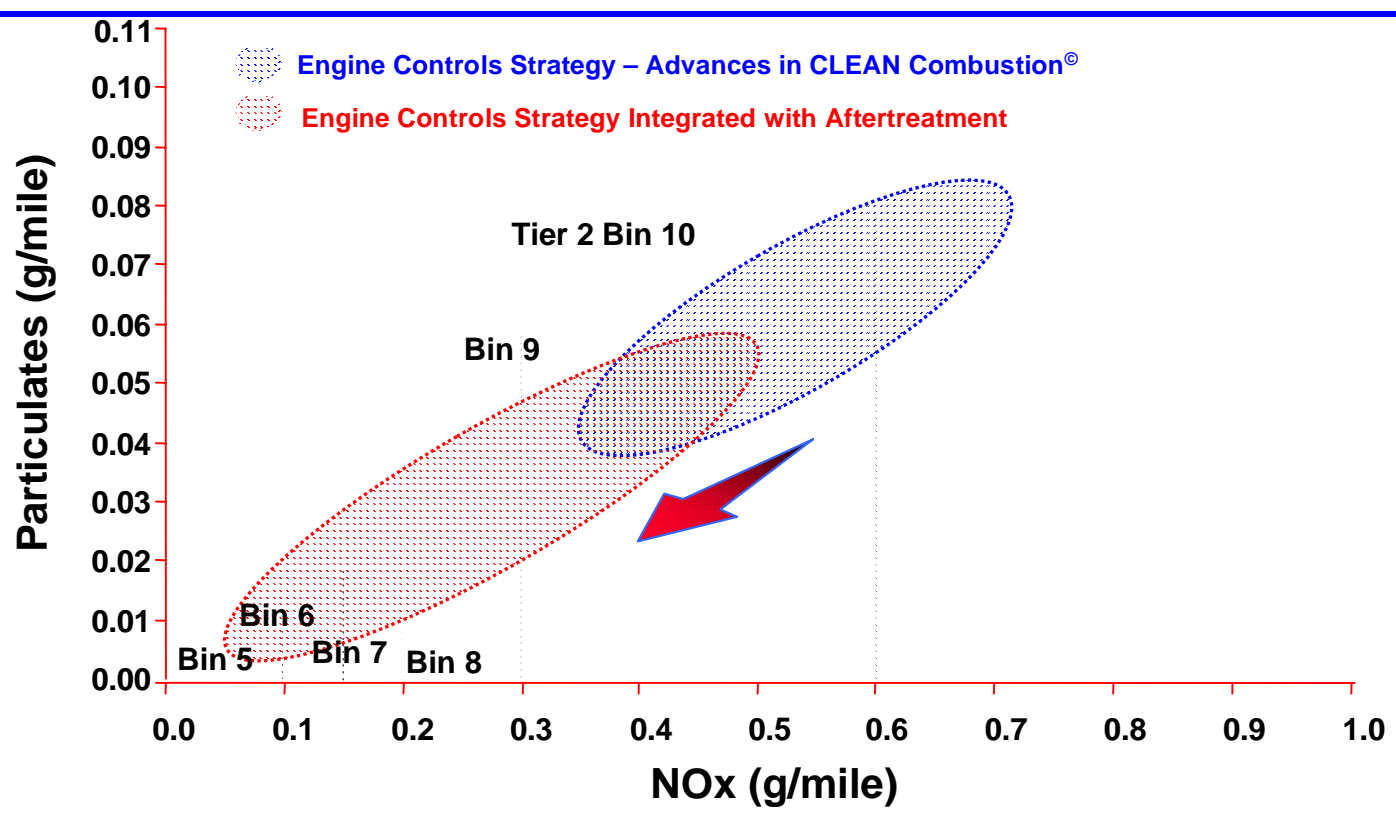

Figure 1.3 Integrated emission reduction roadmap

The most noticeable achievements in 2002 can be summarized as follows.

- FTP 75 Cycle

- Tier 2 Bin 6 emission levels achieved; $0.09 \mathrm{~g} / \mathrm{mile}$ NOx and $0.005 \mathrm{~g} / \mathrm{mile}$ PM

- $20 \mathrm{mpg}-45 \%$ advantage compared to gasoline baseline

- $0.04 \mathrm{~g} / \mathrm{mile} \mathrm{CO}, 0.02 \mathrm{~g} / \mathrm{mile}$ THC 
- HWYFE

- $28 \mathrm{mpg}-33 \%$ advantage over gasoline baseline

- Combined Fuel Economy

- $23 \mathrm{mpg}-41 \%$ advantage over gasoline baseline

Emissions reductions can be seen in Figure 1.4.

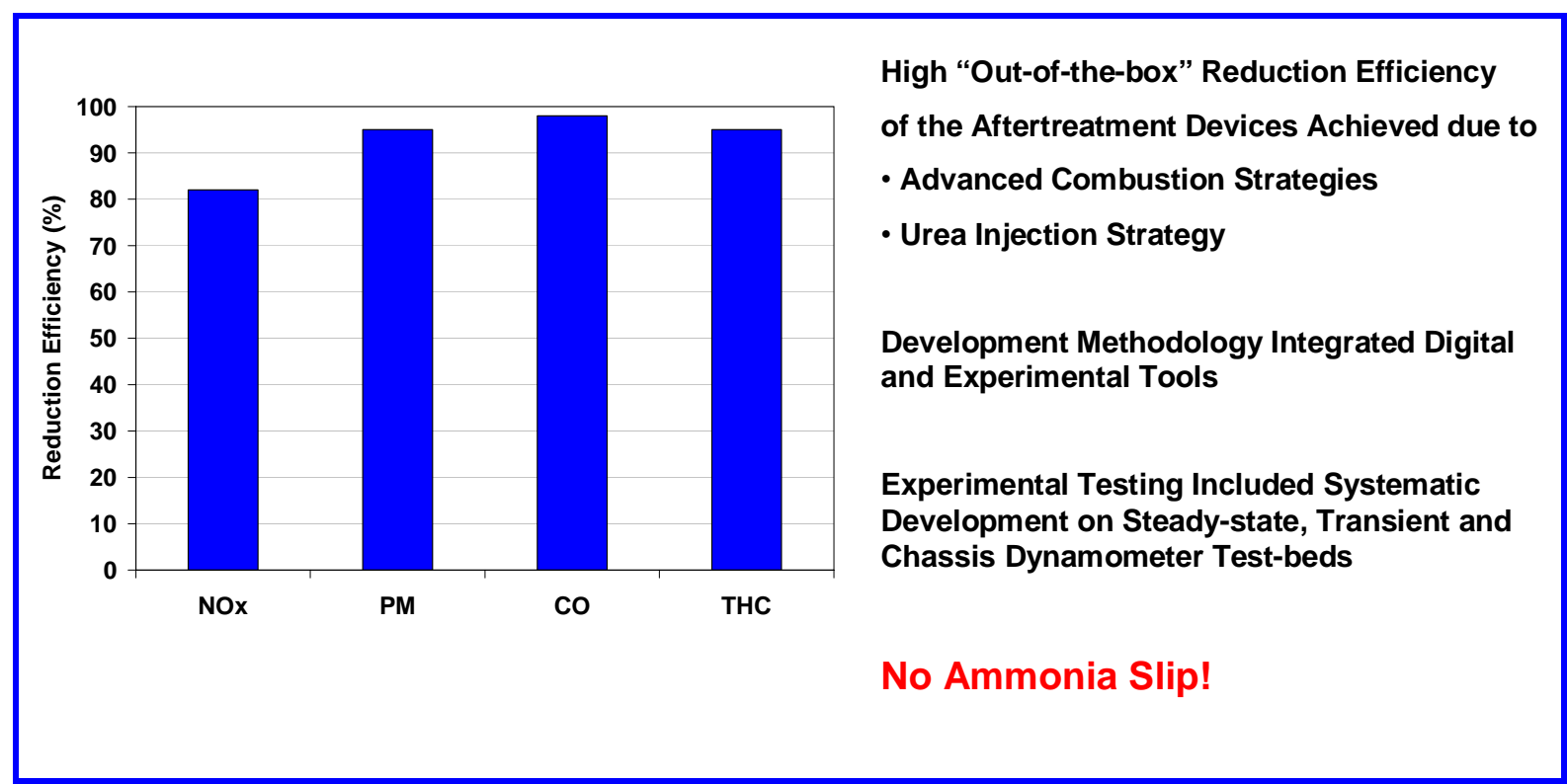

Figure 1.4 Emission reductions in vehicle chassis dynamometer

The technology building blocks to achieve such progress can be attributed to many factors, which are described in the following. 


\section{Component Designs Based on Simulation Results Improving:}

- Match of injector tip hardware to combustion chamber

- Understanding of the sensitivity to EGR

- Cooling of the EGR gas

- Quantity of air flow achievable under EGR application

- Distribution and mixing of EGR gas with intake air

- Level of injector-to-injector variation in injected fuel

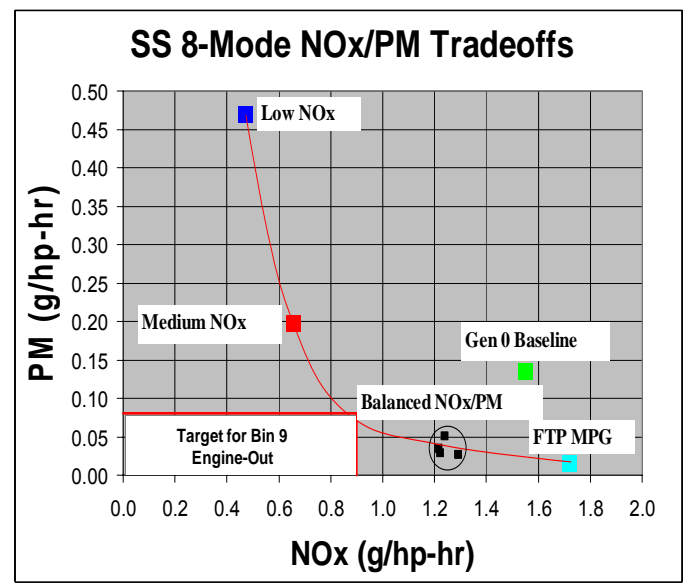

Overall potential: Tier 2 Bin 9 engine-out emissions with up to 55\% MPG advantage over gasoline engine

Figure 1.5 Forward engineering with virtual lab simulations

Successful forward engineering with virtual lab simulations was one of the keys shown in Figure 1.5. This is a key technology building block with all-around improvements to engine design using virtual lab tools.

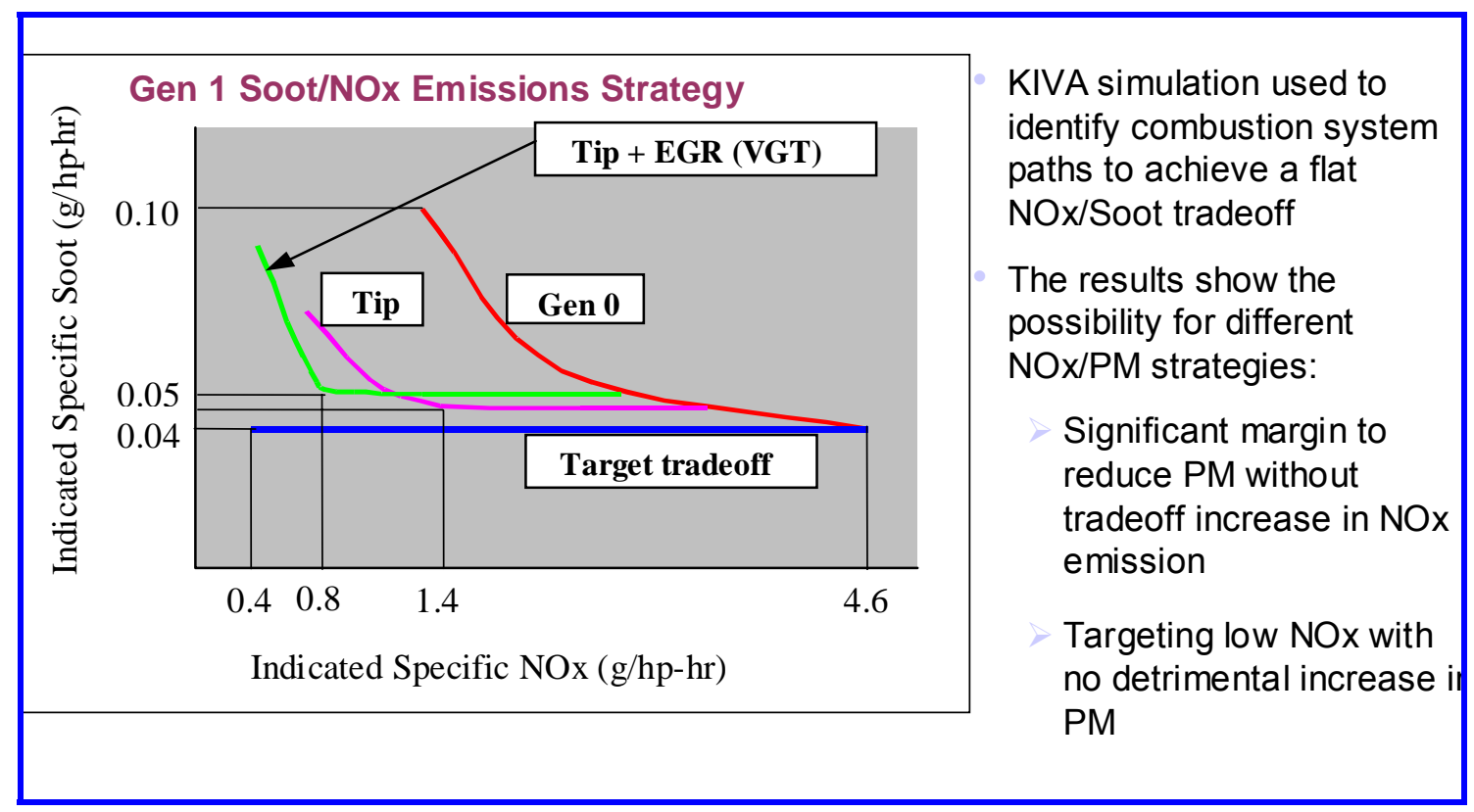

Figure 1.6 KIVA developed engine-out emissions strategy for DELTA combustion system

Figure 1.7 shows the integrated GT-Power/CFD simulations for improved EGR distribution and mixing, while Figure 1.8 shows the impact of more efficient EGR cooling. 


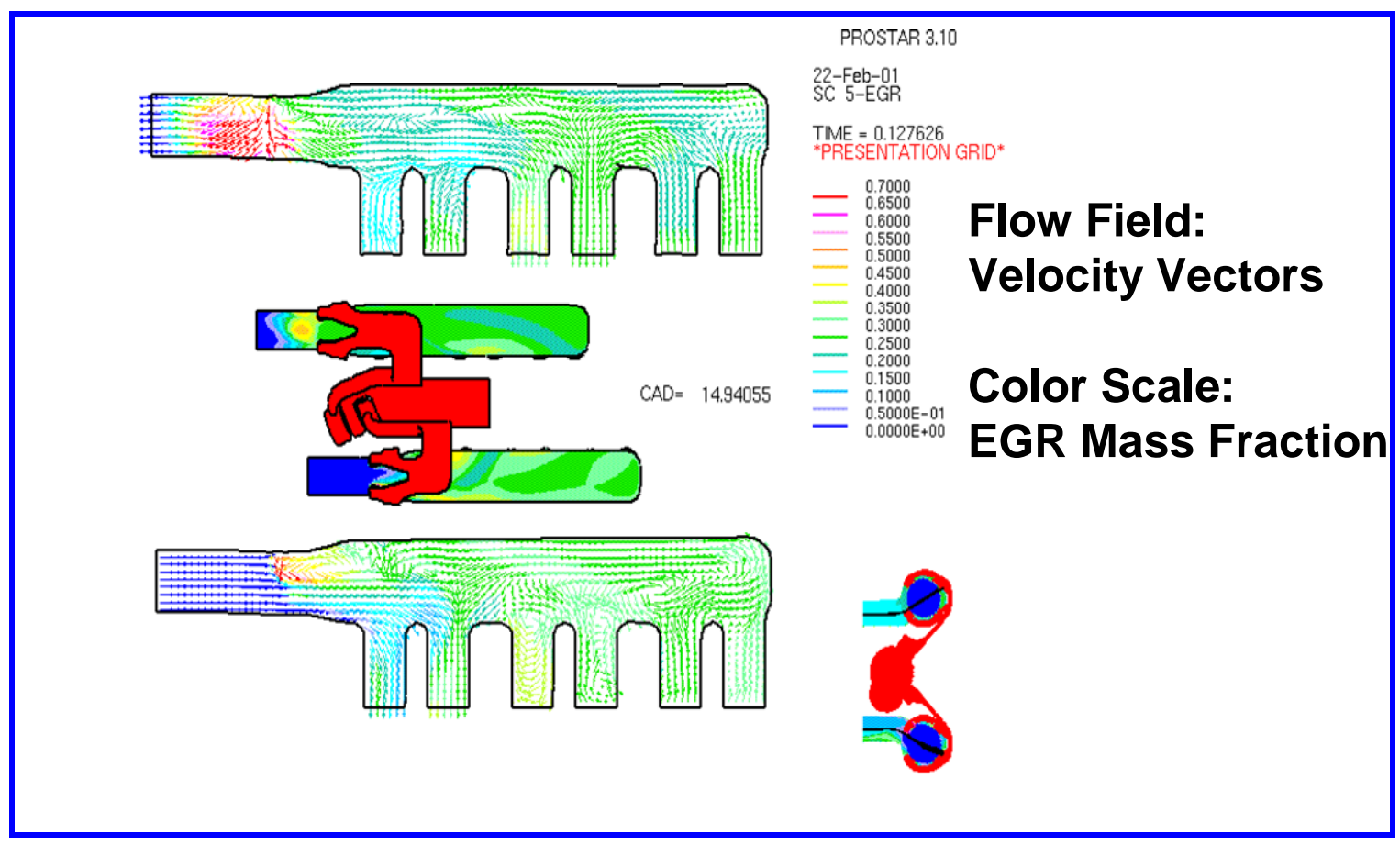

Figure 1.7 Integrated GT-Power/CFD simulations for improved EGR distribution and Mixing

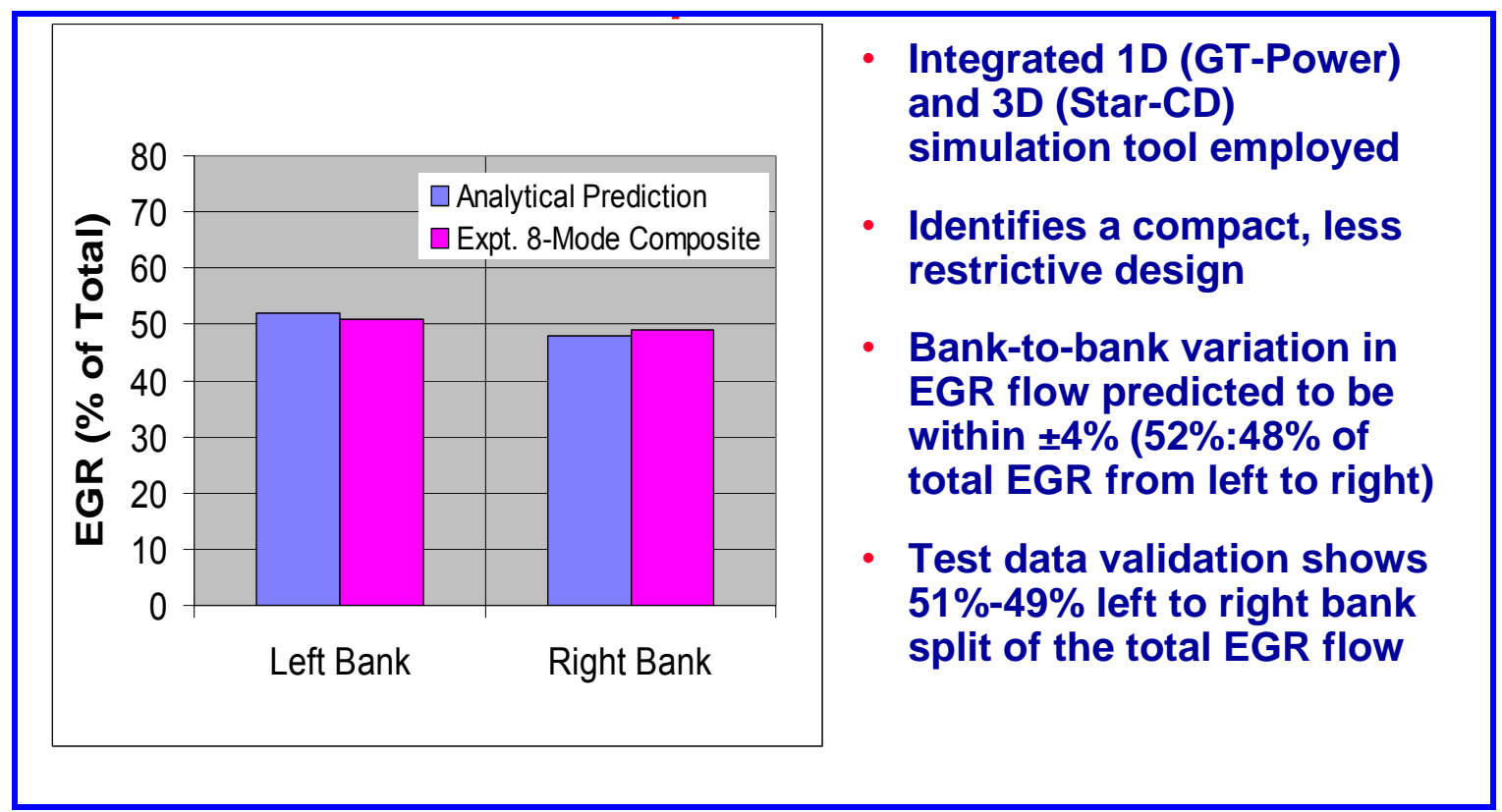

Figure 1.8 EGR flow path re-design \&validation

Figure 1.8 shows the EGR flow path redesign and validation of predicted improvement in EGR distribution. 


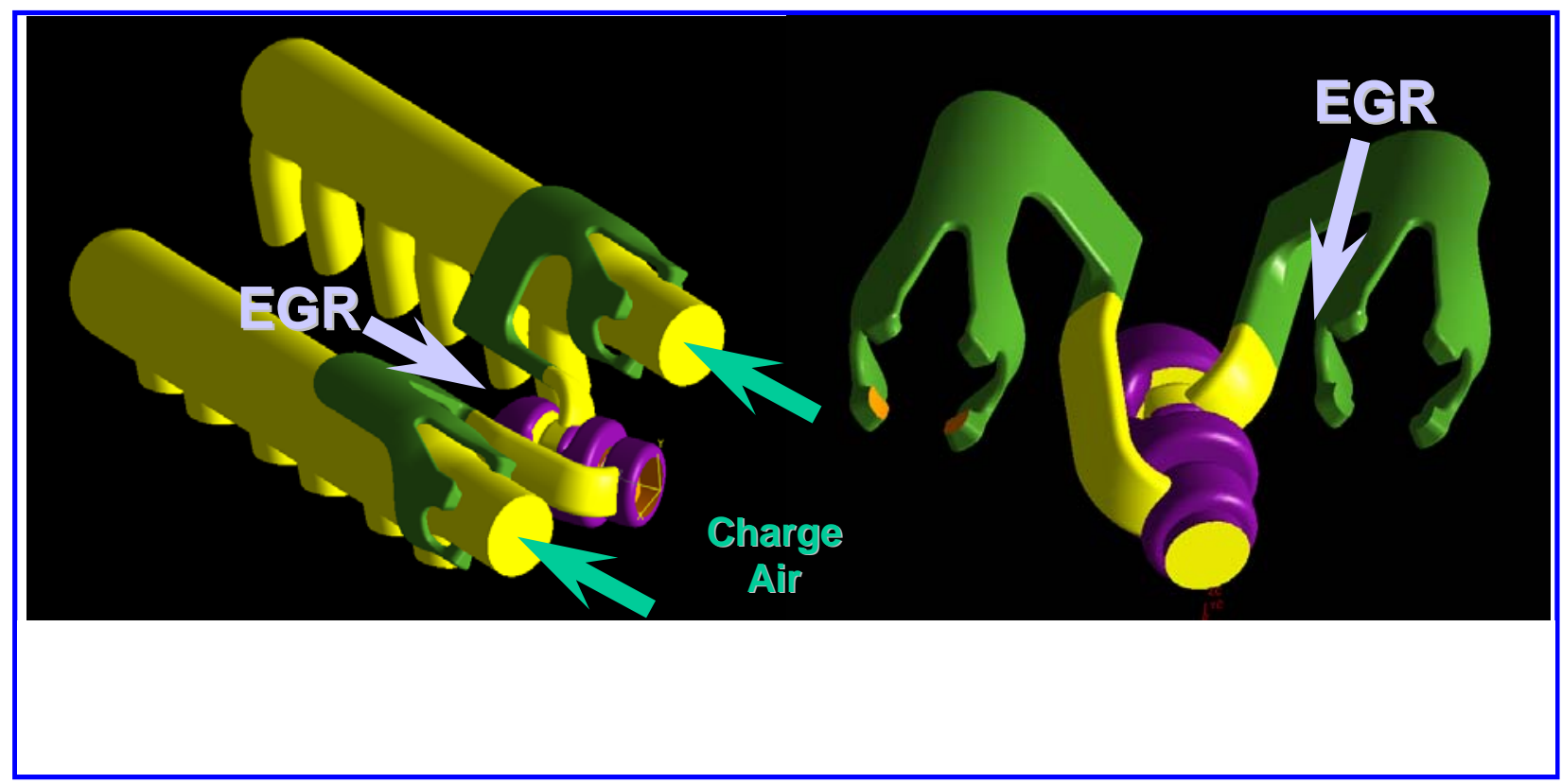

Figure 1.9 DELTA Gen 1 EGR system design

Figure 1.9 shows the DELTA GEN 1 EGR system re-design with the help of virtual lab applications. It shows:

- Design more complex than previous (Gen 0) but much more efficient

- Results in less than $\pm 4 \%$ variation in bank-to-bank EGR

- Transient CFD model used to evolve design with model incorporating EGR valve; mixing ports; intake manifold; \& port runners

- CFD Coupled to Full Engine Cycle Simulation

As indicated in Figure 1.10, improved distribution of the EGR flow has improved intake temperature distribution as well.

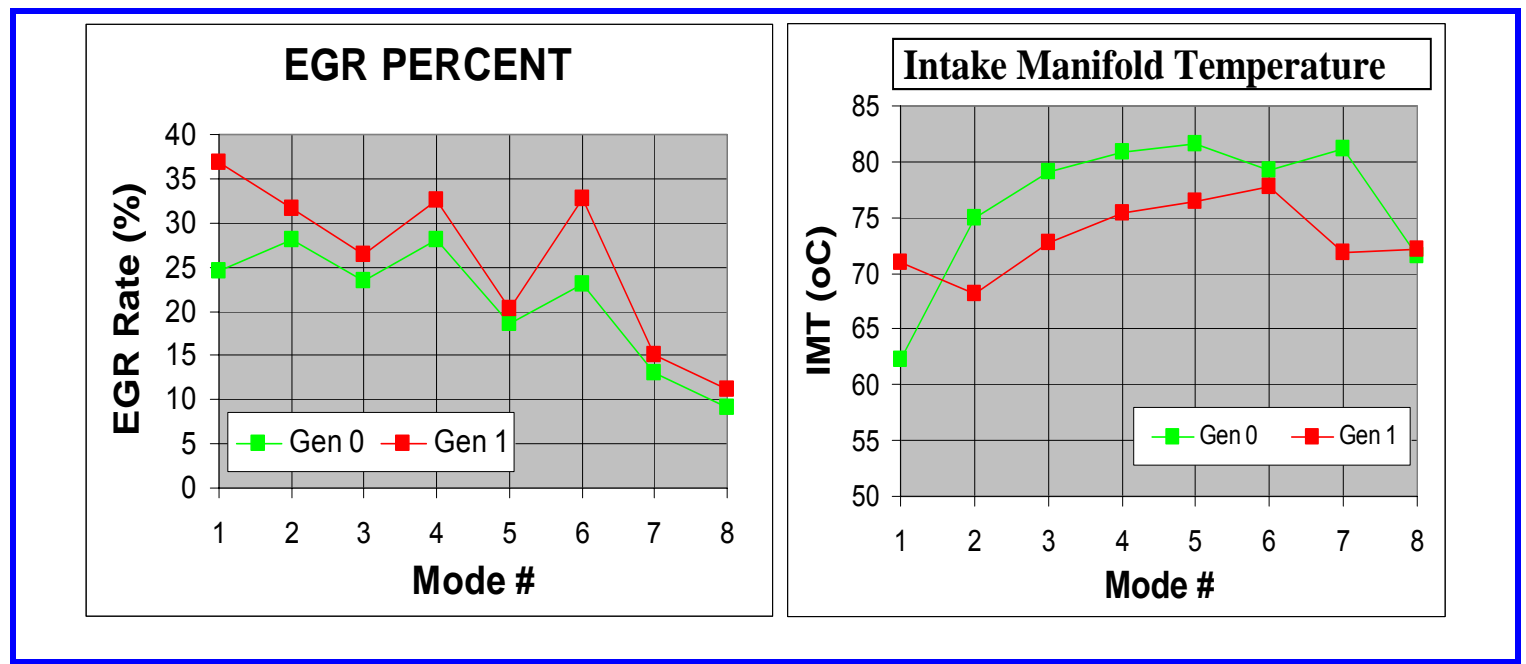

Figure 1.10 Impact of more efficient EGR Cooling 
Simulated transient modes using the steady state (SS) mode play a major role as well. Figures $1.11-1.12$ show the process of the selection SS modes based on transient vehicle operating points.

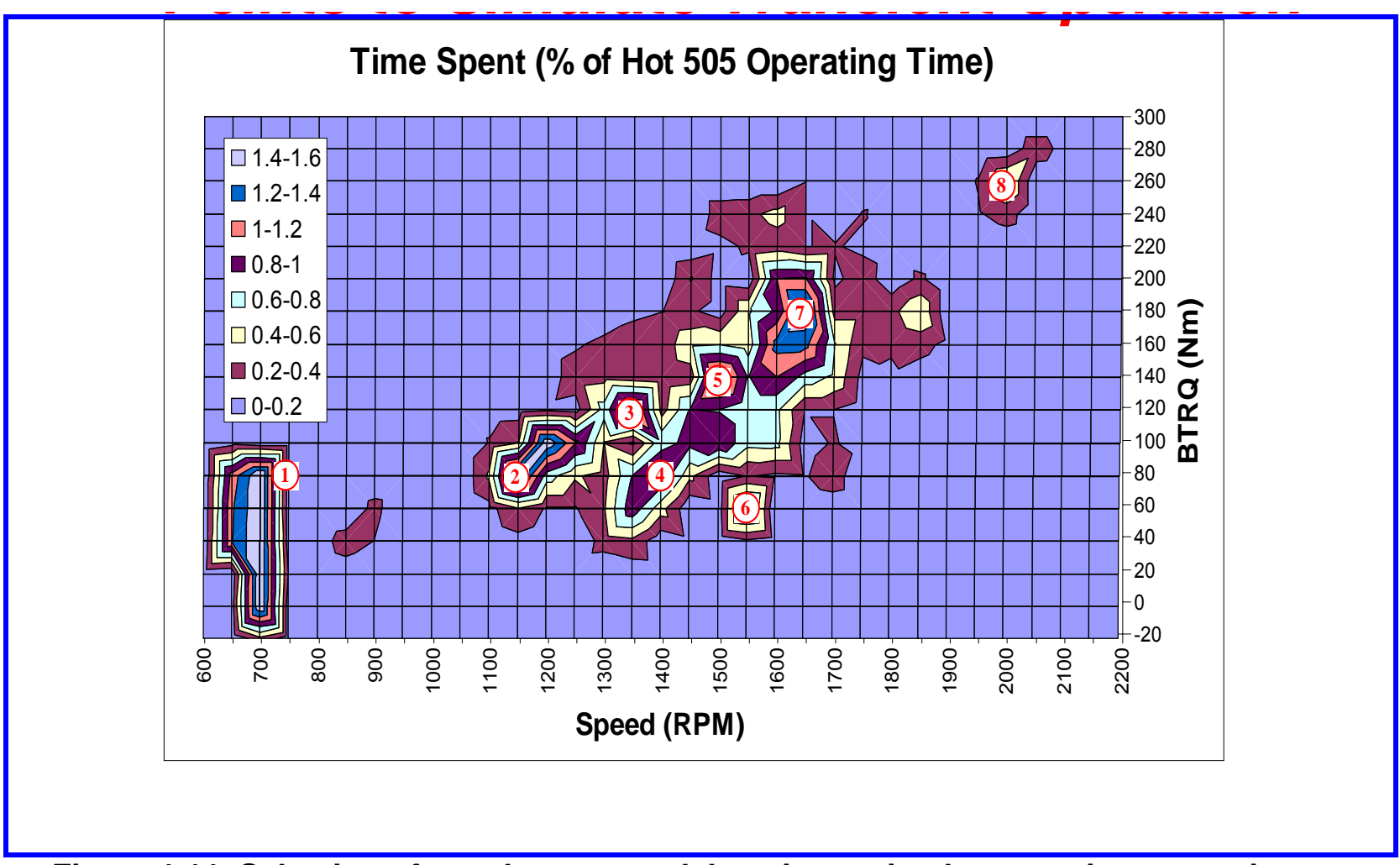

Figure 1.11 Selection of steady state modals point to simulate transient operations

Table 1.1 Modal points \& weighting factors.

\begin{tabular}{|c|c|c|c|c|c|}
\hline $\begin{array}{c}\text { Modal } \\
\text { Point }\end{array}$ & $\begin{array}{c}\text { Speed } \\
(\text { rpm })\end{array}$ & $\begin{array}{c}\text { BTRQ } \\
(\mathrm{Nm})\end{array}$ & $\begin{array}{c}\text { Weighting } \\
\text { Factor }\end{array}$ & $\begin{array}{c}\text { Load } \\
(\%)\end{array}$ & $\begin{array}{c}\text { BMEP } \\
(\text { Bar })\end{array}$ \\
\hline 1 & 750 & 80 & 0.20 & -- & 2.5 \\
\hline 2 & 1150 & 80 & 0.13 & 26 & 2.5 \\
\hline 3 & 1350 & 120 & 0.09 & 29 & 3.9 \\
\hline 4 & 1400 & 80 & 0.12 & 19 & 2.5 \\
\hline 5 & 1500 & 140 & 0.15 & 31 & 4.3 \\
\hline 6 & 1550 & 60 & 0.03 & 15 & 1.8 \\
\hline 7 & 1650 & 180 & 0.24 & 34 & 5.7 \\
\hline 8 & 2000 & 260 & 0.03 & 51 & 8.0 \\
\hline
\end{tabular}


Figure 1.12 is the result of NOx and PM trade-off, which is used to quantify the vehicle performance through careful selection of the steady state points based on the transient map (Figure 1.9)
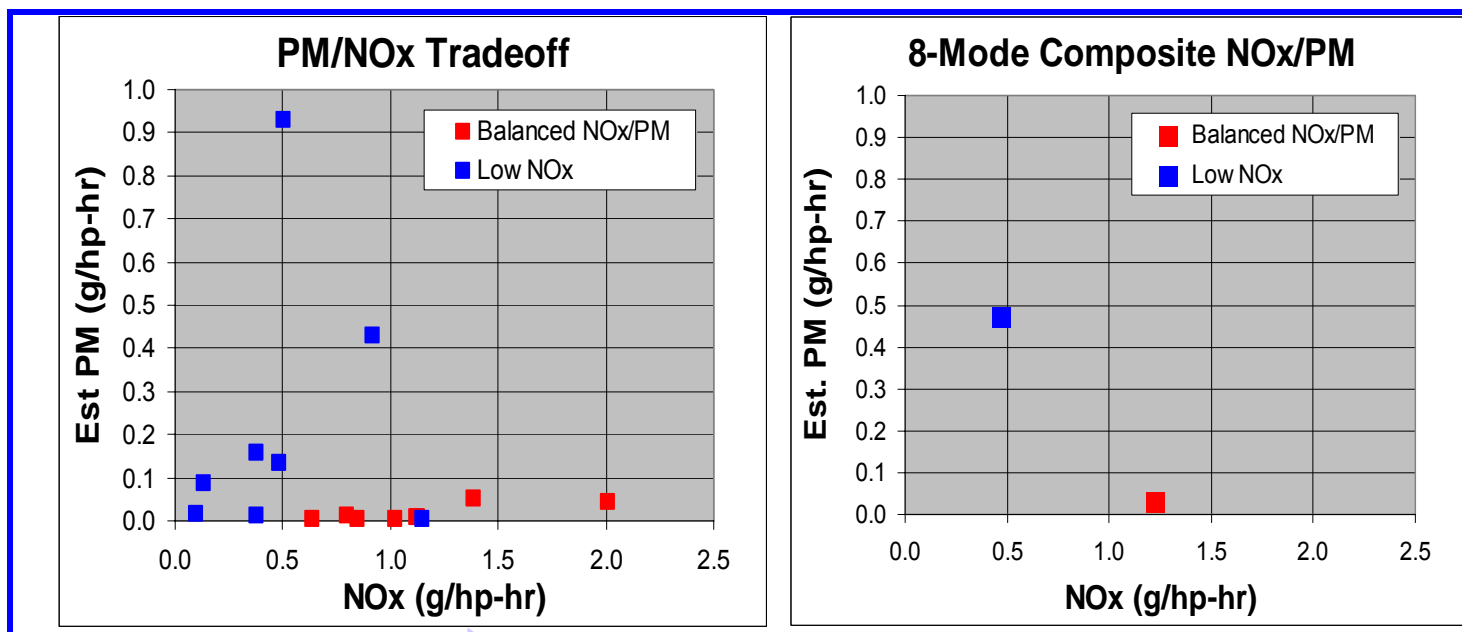

Figure 1.12 Steady state modal and 8-mode composite NOx and PM emission results

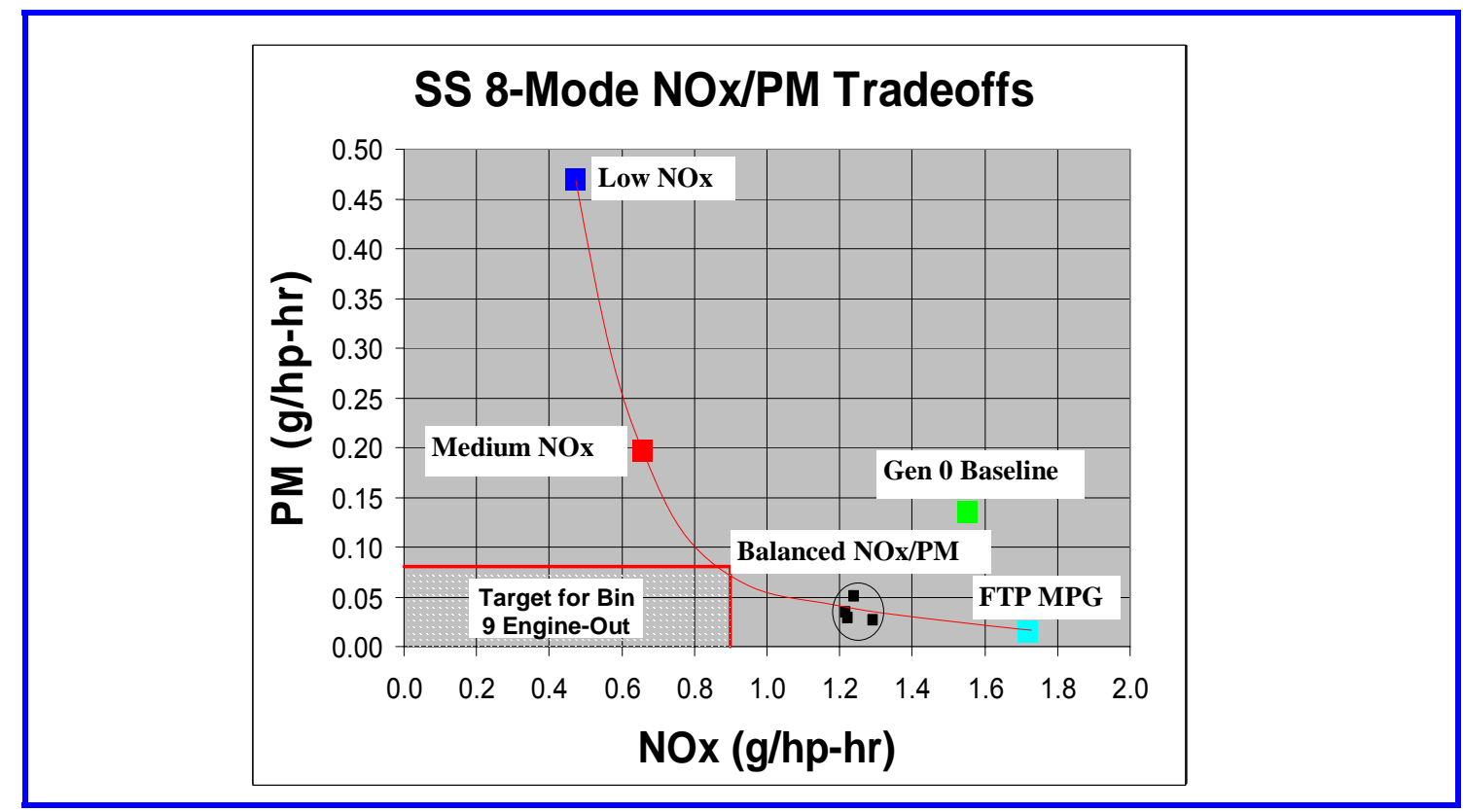

Figure 1.13 Summary of different potential strategies for Tier 2 FTP Emissions

In Figure 1.13, the legend "Gen 0 Baseline" is the early version of the DELTA engine. Figure 1.14 is the transient testing results of engine-out emissions. As can be seen, the transient emissions response successfully simulated steady state 8-mode. 


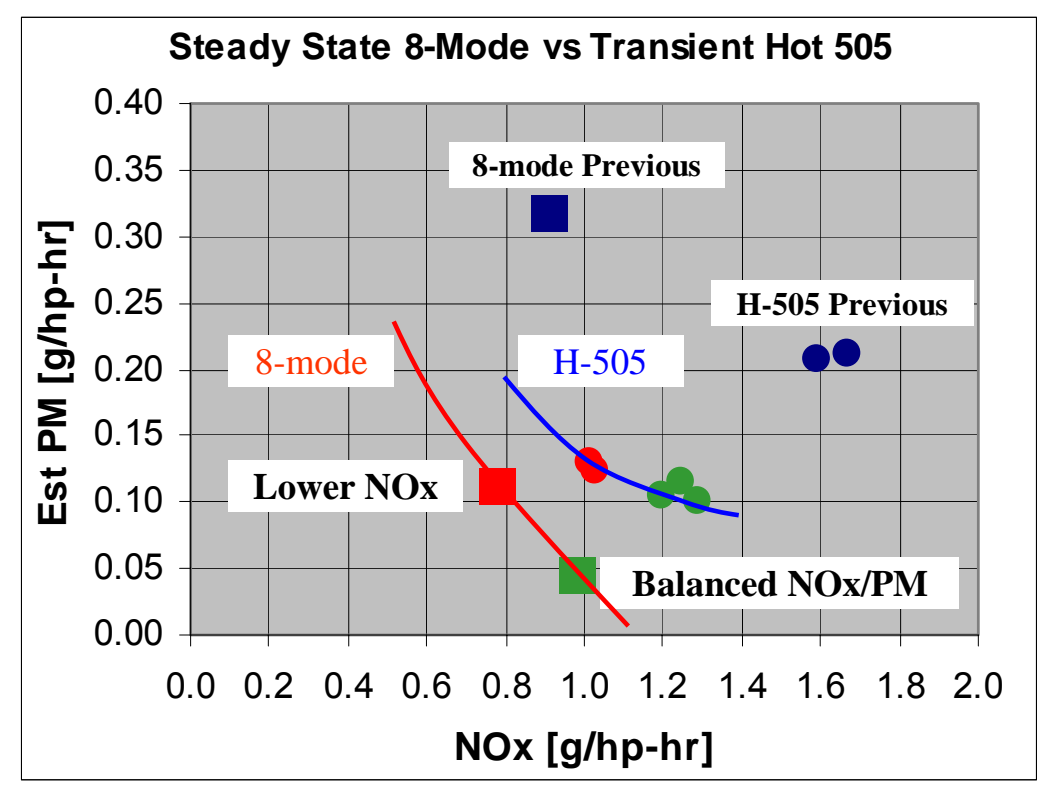

Figure 1.14 Transient testing results.

As opposed to Gen 0 baseline engine, keys to the achieved engine-out emission improvements with the Gen 1 engine are summarized as follows.

- Improved Engine Combustion System

- Better match of injector tip \& piston bowl

- Improved understanding of sensitivity to EGR

- Better Air/EGR System

- More efficient EGR cooling

- Increased air flow under EGR application

- More uniform distribution \& mixing of EGR with intake air

- Upgraded Fuel Injection System

- Reduced injector-to-injector variation

- Less fluctuation in high pressure rail

Detroit Diesel CLEAN ${ }^{\odot}$ combustion was another key building block technology in synergy with another DOE program- LEADER (Reference 6). Figure 1.15 shows the CLEAN $^{\odot}$ combustion region with green symbols. 


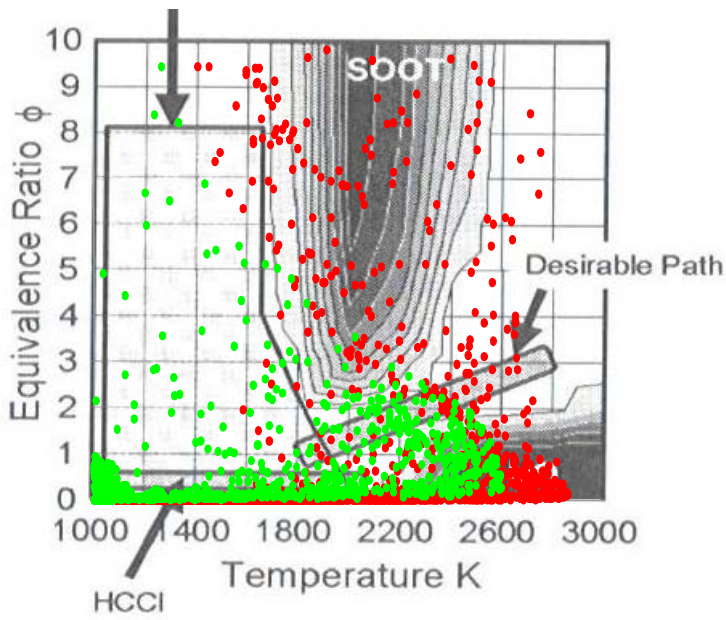

\section{CLEAN Combustion Region \\ - Emphasizes $\mathrm{HCCl}$ Zone \\ - Maintains Rich Regions at Low Temperature \\ - Emphasizes "Desirable Path" \\ - Limits NOx Formation and Almost Eliminates Soot Formation}

Engine Design Modifications Will Continue to Reduce Clean Combustion Penetration into "NOx Formation Zone"

\section{Figure 1.15 CLEAN $^{\odot}$ Combustion}

Some key features of $\mathrm{CLEAN}^{\oplus}$ combustion are also described in Figure 1.15.

The few key technical features of $\operatorname{CLEAN}^{\odot}$ combustion can be seen in Figures 1.16 and 1.17.

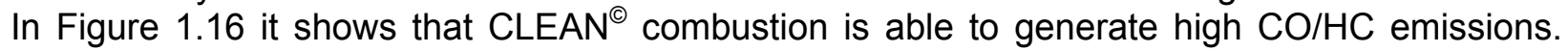
Each of the curves in this figure represents one engine calibration package.
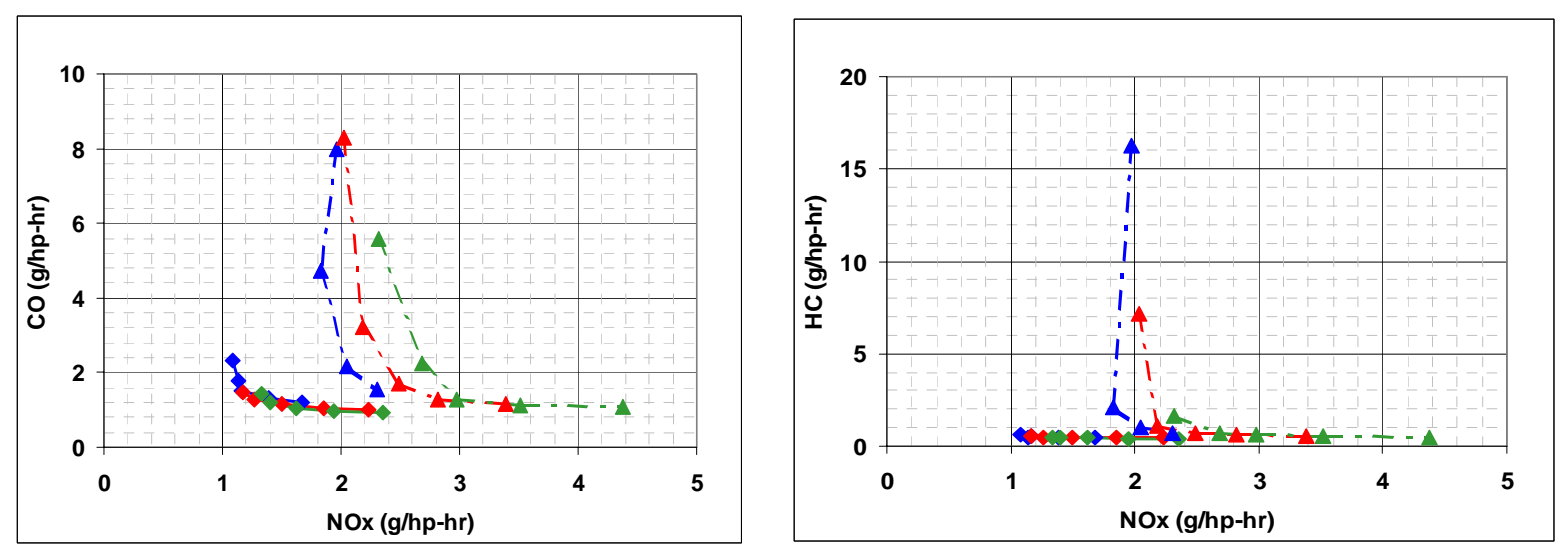

Figure 1.16 $\mathrm{CO}$ and $\mathrm{HC}$ emissions of $\mathrm{CLEAN}^{\odot}$ combustion 


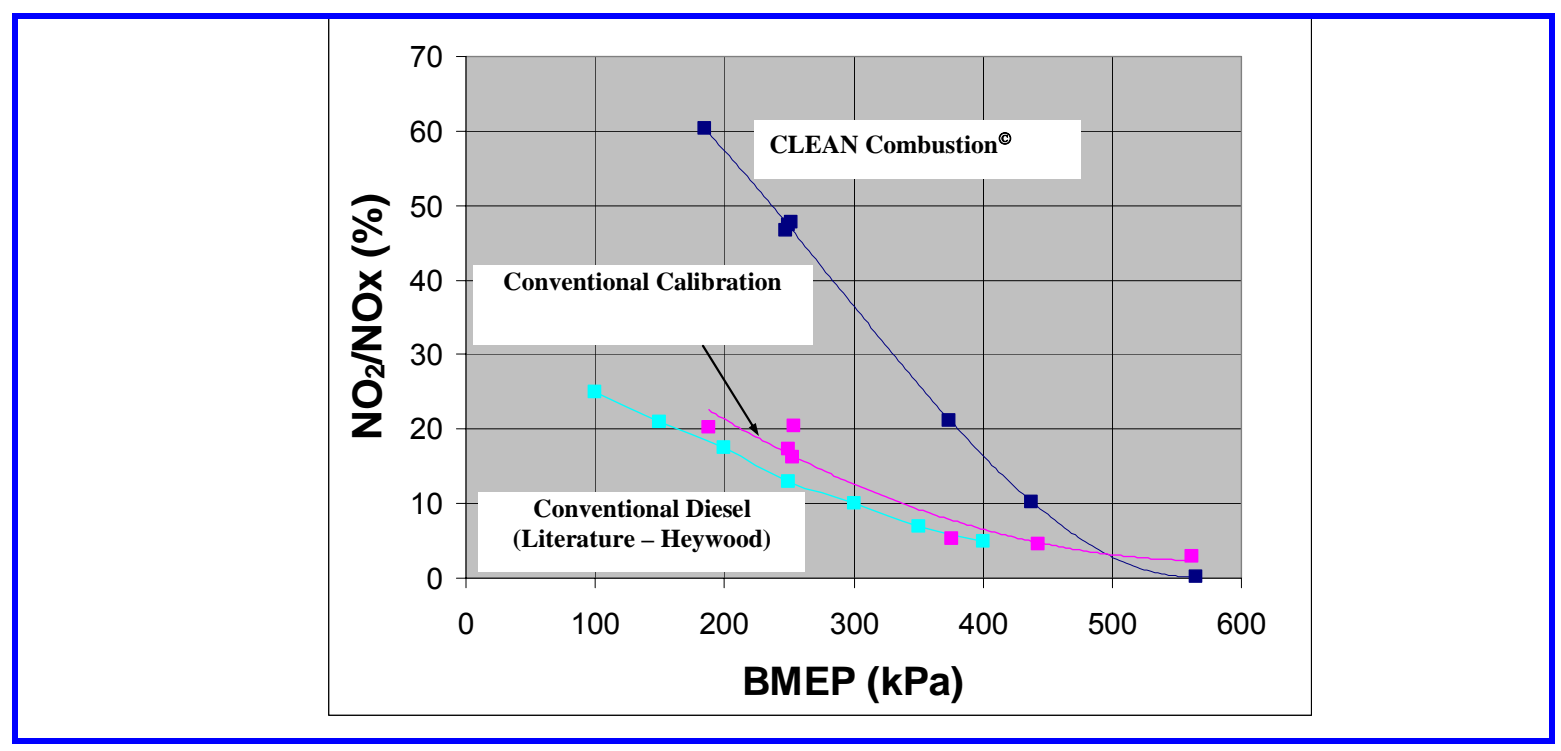

Figure 1.17 NO2/NOx emissions of CLEAN ${ }^{\odot}$ combustion.

Figure 1.17 shows that $\mathrm{CLEAN}^{\odot}$ combustion can also generate a high NO2/NOx ratio, which is critical for favorable aftertreatment system integration. 


\subsection{3}

The most significant achievement in 2003 was the demonstration of the Tier 2 Bin 3 emissions target over FTP75 on a light-duty truck equipped with a DELTA engine using a DPF + SCR system synergizing efforts with another DOE-DDC program (Reference 2). This aggressive reduction in emissions was obtained without ammonia slip with and a $41 \%$ fuel economy improvement, compared to the equivalent gasoline engine equipped vehicle. It demonstrated the Tier 2 emissions compliance over the US06 cycle. Figure 1.18 shows the integrated emissions reduction roadmap.

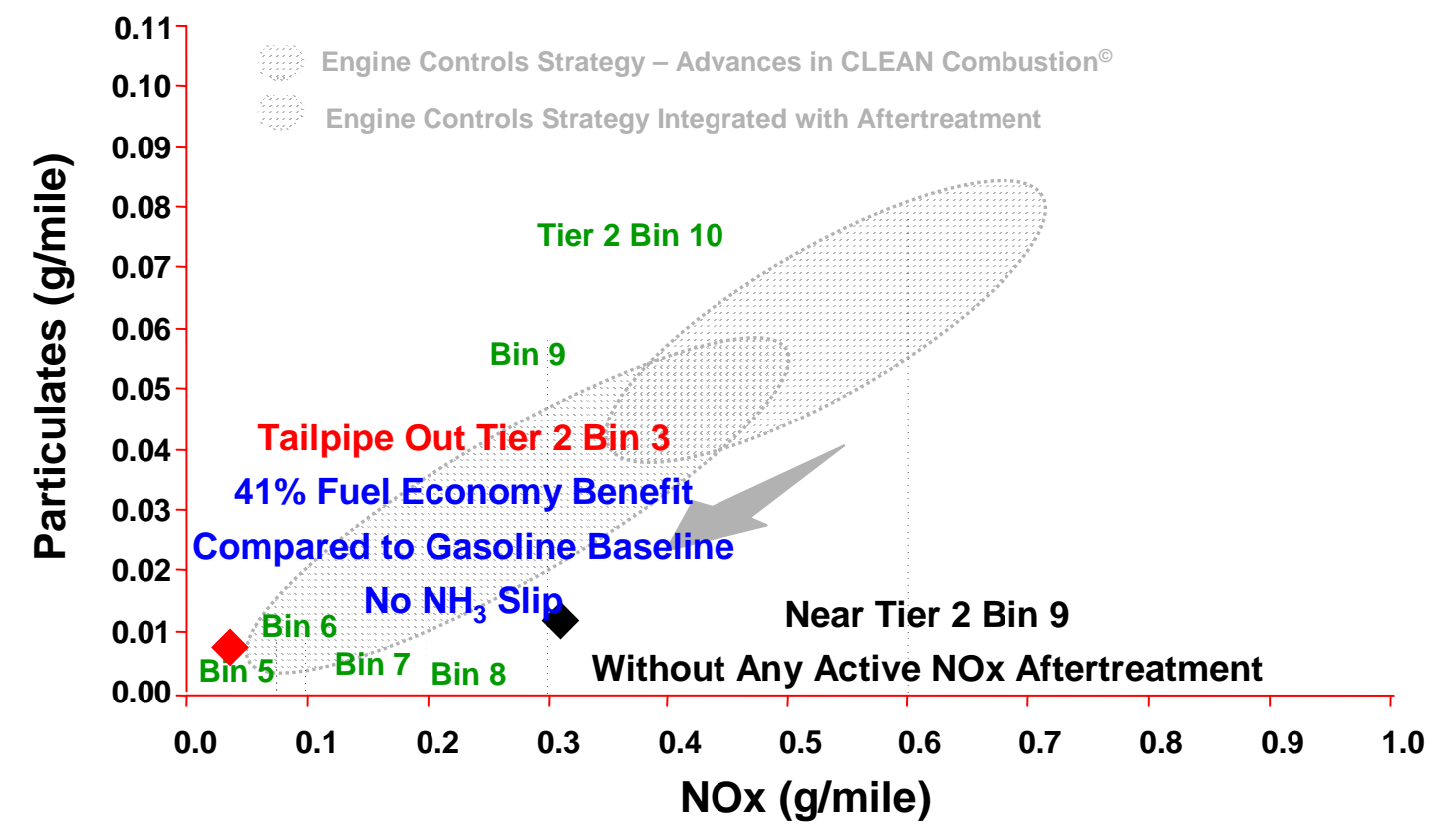

Figure 1.18 Integrated emission reduction roadmap in 2003

It should be pointed out that the achievement of Tier II Bin 3 emission can be mainly attributed to the technological building blocks described in the previous section when 2002 progress was presented, and it also took advantage of another DOE funded program - LEADER (Reference 6). Since then the technology building block has continued enhancing. One of the areas was the combustion optimization. The objective of combustion optimization is to achieve Tier-2 Bin 8 without active NOx aftertreatment. The approach included:

- Adopt new high-squish (HS) combustion system to extend the capabilities of $\mathrm{CLEAN}^{\odot}$ combustion

- Utilize existing closed loop controls to further extend $\mathrm{CLEAN}^{\odot}$ combustion application range and reduce FTP NOx

- Apply advanced KIVA submodels and methods such as genetic algorithm-based optimization to investigate additional potential

- In parallel, characterize advanced fuel injection technology that would enable multiple mode combustion approaches over the entire speed and load range 


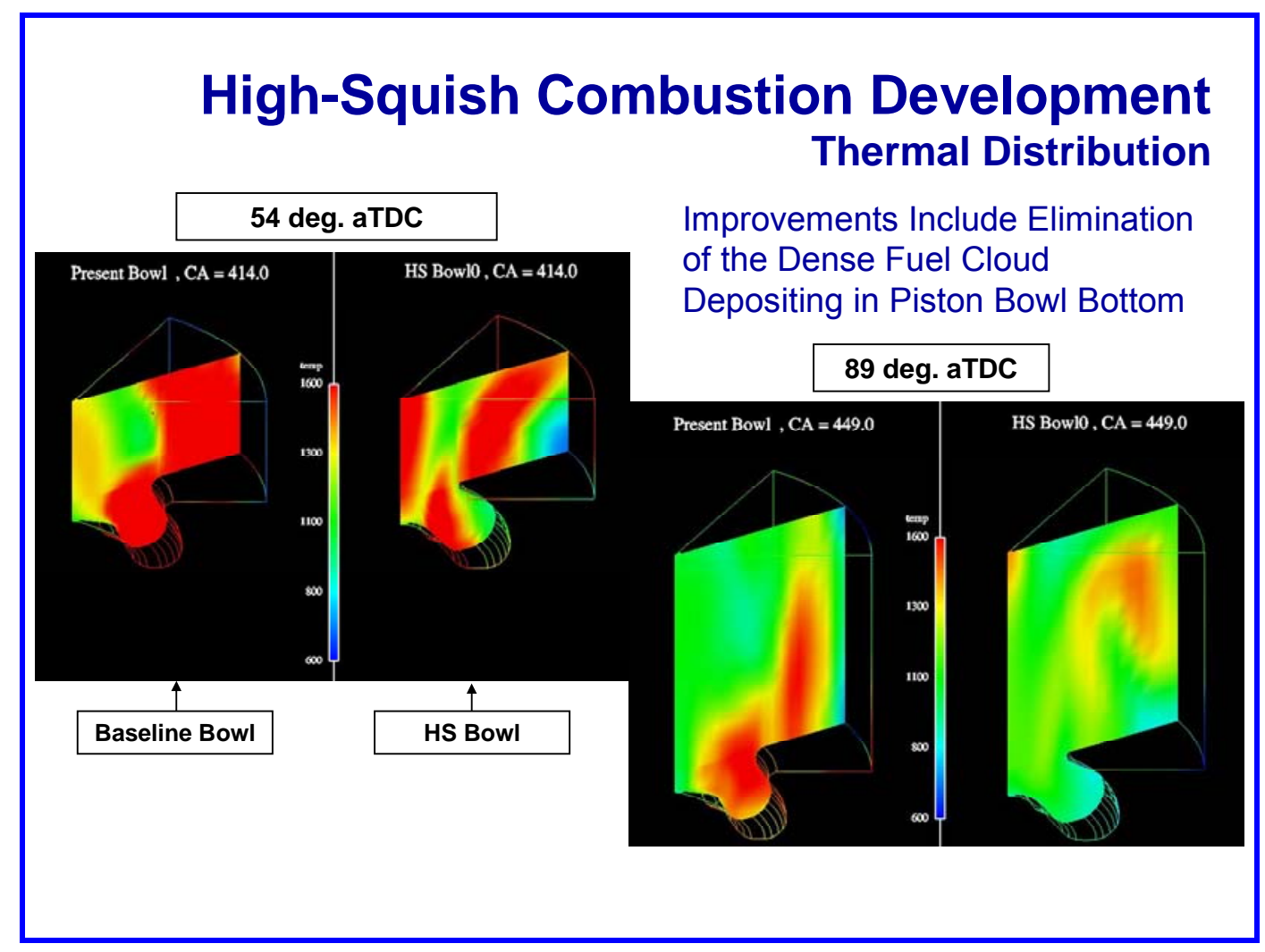

Figure 1.19 High-Squish Combustion Development

Displayed in Figure 1.19 is the combustion simulation using KIVA. It shows that high-squish combustion extends clean combustion regime and offers:

- Potential to improve DELTA engine out NOx and PM emissions \& performance

- $\quad$ Good match with CLEAN $^{\odot}$ combustion and potential to widen its application range

- Intensified turbulence and increased mixing rates

- Larger initial rate of heat release and earlier end of combustion

- Lower peak temperature (diminishing hot pocket)

- Requires only a new piston casting/machining to be realized (note: durability needs to be proved)

In addition to high-squish combustion development, wall wetting exploration due to post injection was also conducted using a 3D KIVA simulation tool. The main objective of this work was to investigate the feasibility of post injection to facilitate lean NOx trap regeneration if this path would move forward.

Figure 1.20 shows the wall wetting process with a post injection starting around 446 crank angle degrees, which is 86 degrees after the top dead center. Figure 1.21 shows the impact of post injection quantities on combustion, while Figure 1.22 displays the impact of the post injection timing on combustion. 


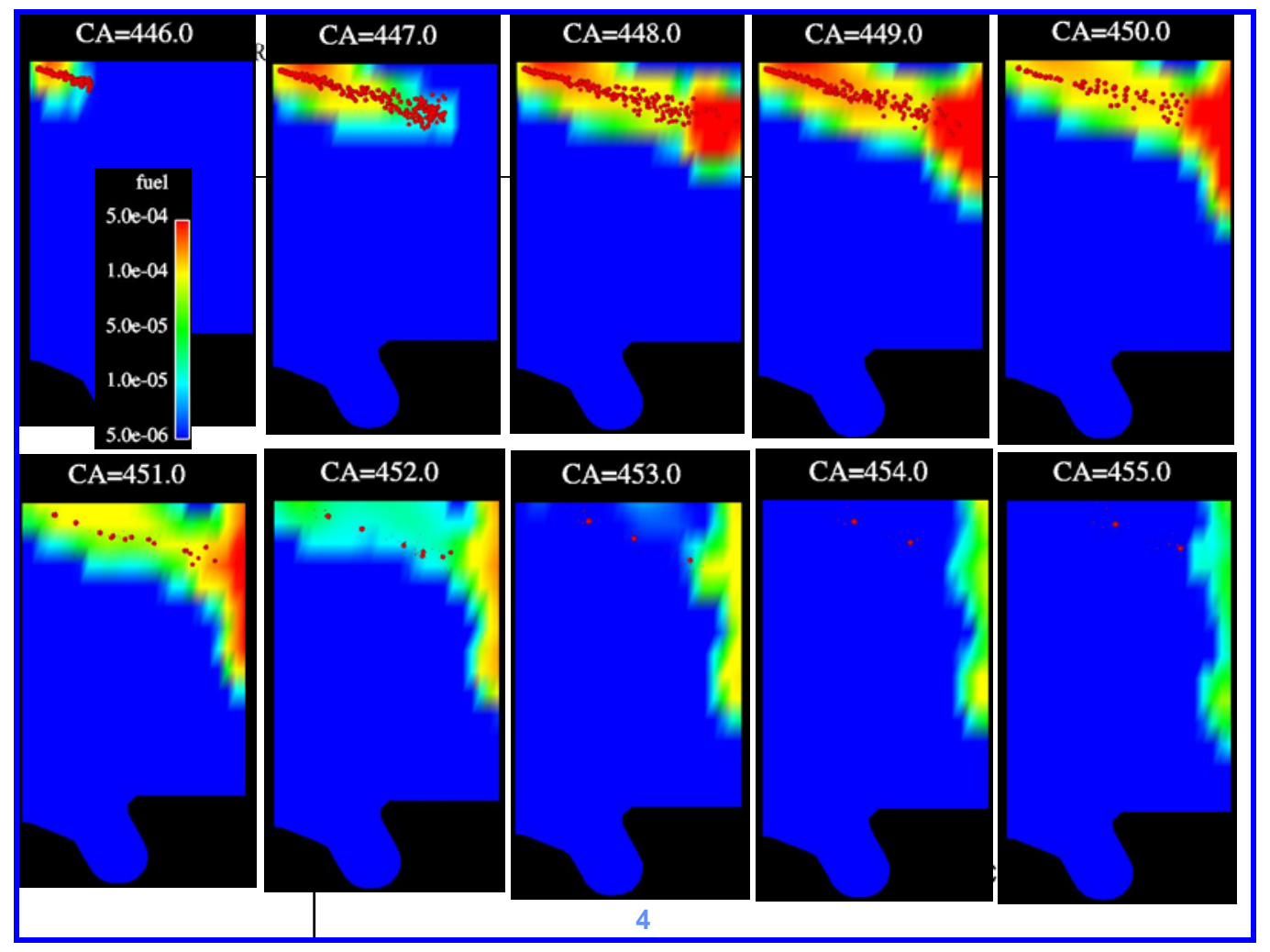

Figure 1.20 Post injection process on wetting the wall

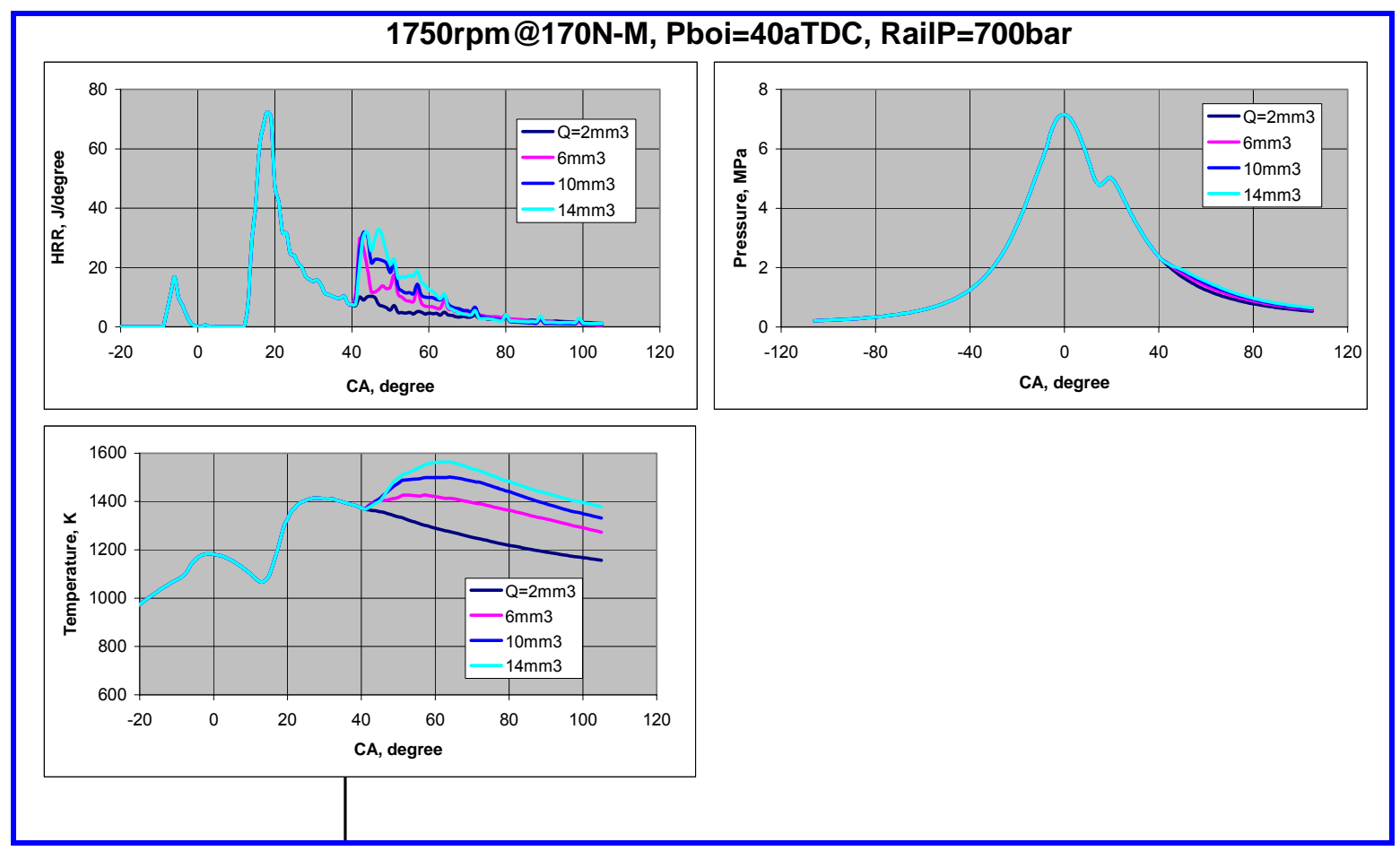

Figure 1.21 Impact of post injection quantity on combustion 


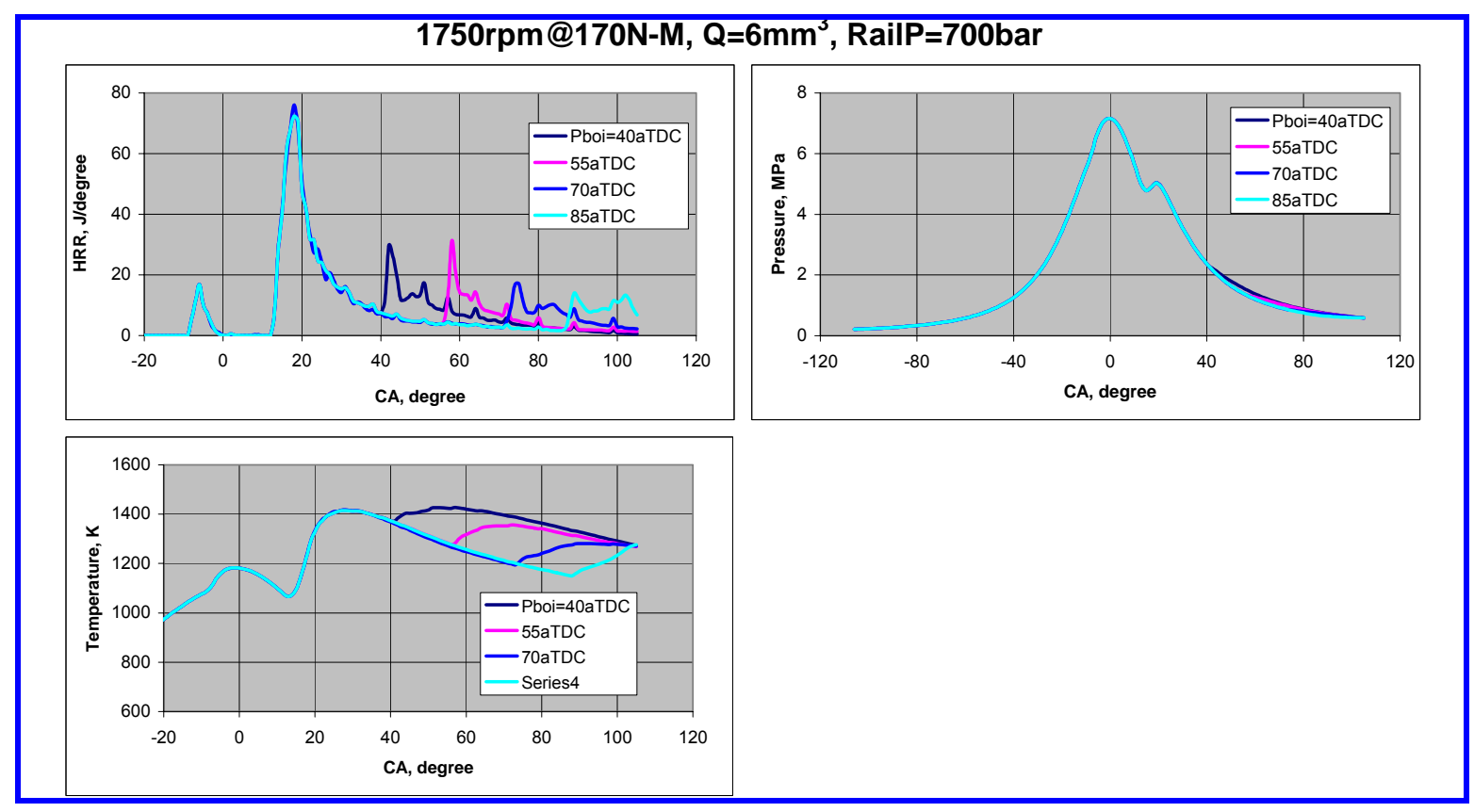

Figure 1.22 Impact of post injection timing on combustion

The studies showed no significant wall-wetting with post-injections operating at the following ranges:

- Rail Pressure: 700 1600 bar

- Post Injection Timing: 40 85 ATDC

- Post Injection Quantity: 2 22 mm3

However, obvious vapor spray/wall interactions were observed for large post injection quantity cases.

During this year, improvement of transient control was also achieved. This was done by improving variable geometry turbine performance with closed loop control. Figure 1.23 shows this result, indicating controller tuning is required to achieve boost and the required EGR rate. Figure 1.24 shows the transient response with the closed loop control. 

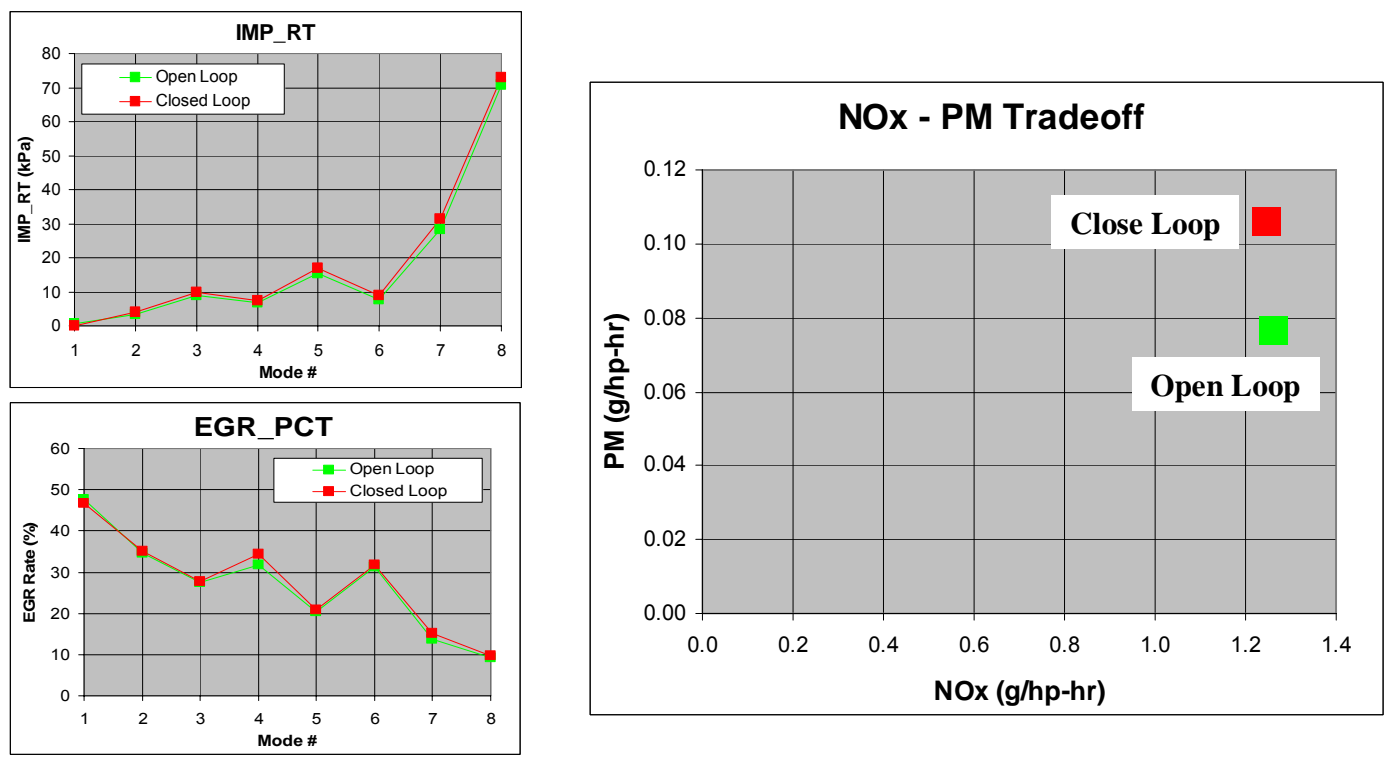

Figure 1.23 Closed loop control for variable geometry turbine

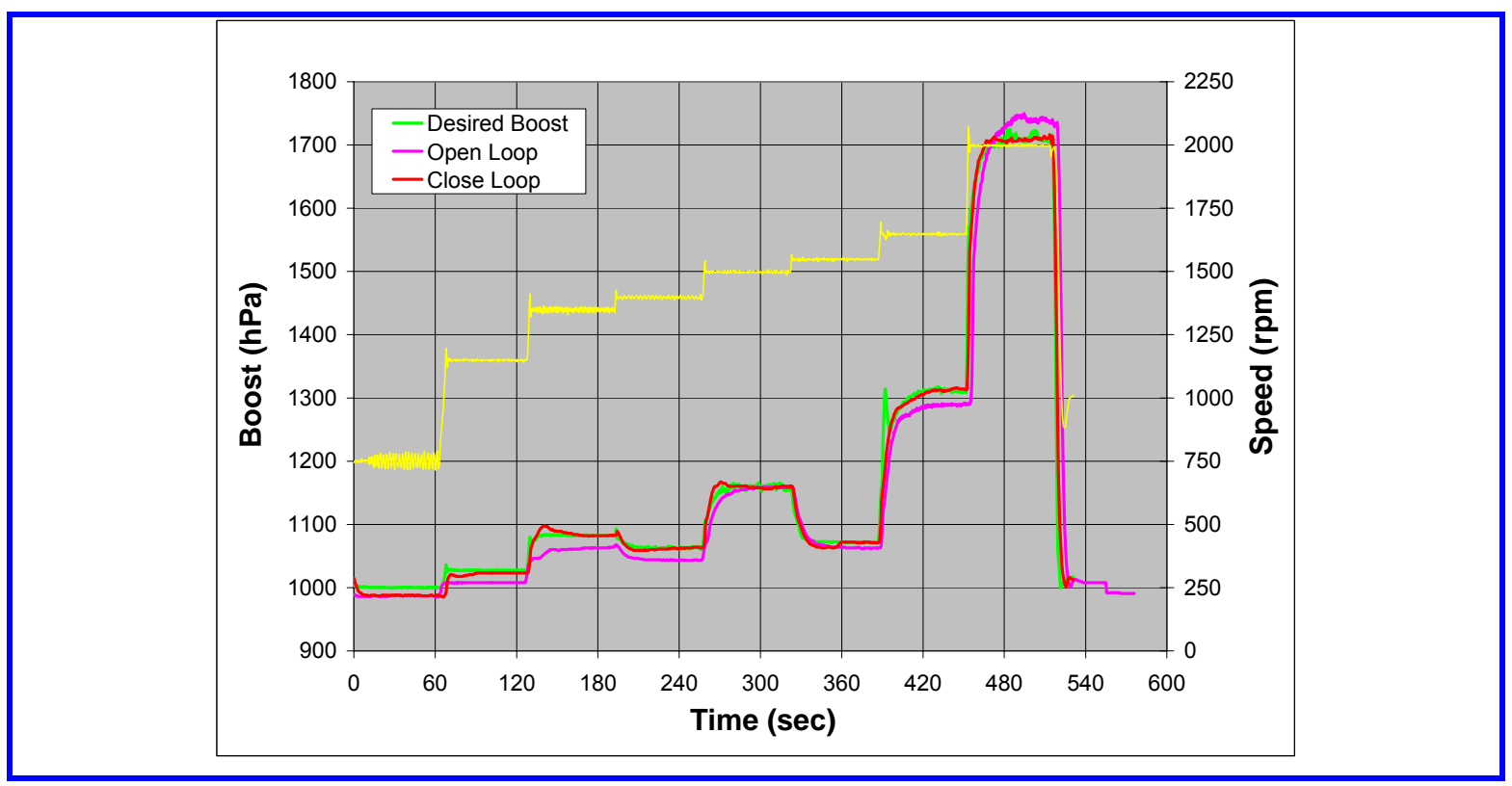

Figure 1.24 Transient boost response with closed loop control

DPF regeneration strategy was another area to work on in view of the low exhaust temperature profile for the light-duty truck engine, which would yield significant challenges for both passive and active regenerations. As indicated in Figure 1.25, low exhaust temperature makes passive regeneration virtually impossible over the FTP75 cycle. 


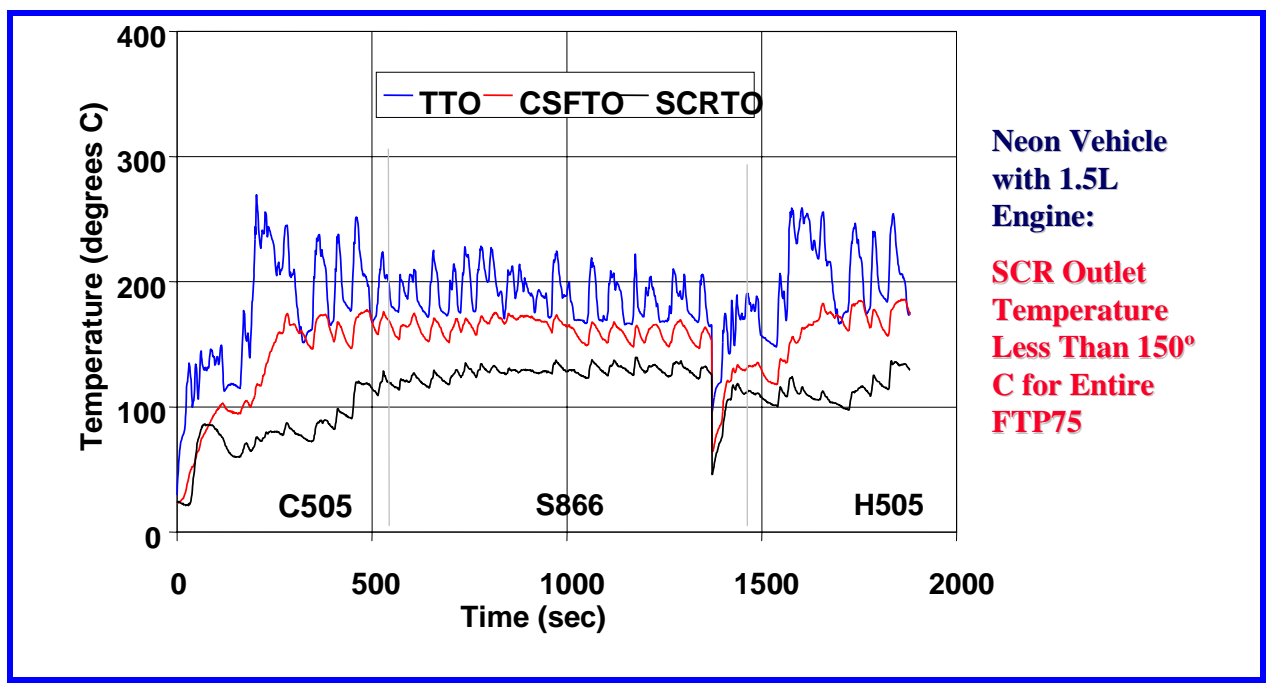

Figure 1.25 Exhaust temperature over a FTP75 cycle for a Neon vehicle with 1.5L engine

Different proposals were put forward during the course of the program. The following highlights the requirements of DPF regeneration.

- Passive regeneration requirements:

0 Exhaust temperature at the DPF inlet must be higher than $280^{\circ} \mathrm{C}$.

o NOx/PM ratio must be around 16 or higher

- Bin 9 engine out results in NOx/pm ratio of 4:1

- Active regeneration technology is required - how to minimize MPG impact?

- Active regeneration sub-system components

o Control

o System complications

o Fuel economy penalty

o Cost

o Packaging

Consequently, a comprehensive DPF regeneration work package was proposed.

Integrated passive and active regeneration strategy

1. Air management

a. Air by Pass

b. Intake and exhaust throttling

2. In-cylinder post injection

3. Fuel burner for wide range operation condition

The first two items were conducted via another DOE program - LEADER (Reference 6), thus providing maximum synergy between these two DOE programs, while the fuel burner work was conducted in this program. 
Figure 1.26 shows a concept of the fuel burner proposed in 2003, which ensured that it can cover the operation range for DPF or LNT regenerations for LD applications, where temperature must maintain $650-700^{\circ} \mathrm{C}$ at any operating conditions during regeneration.

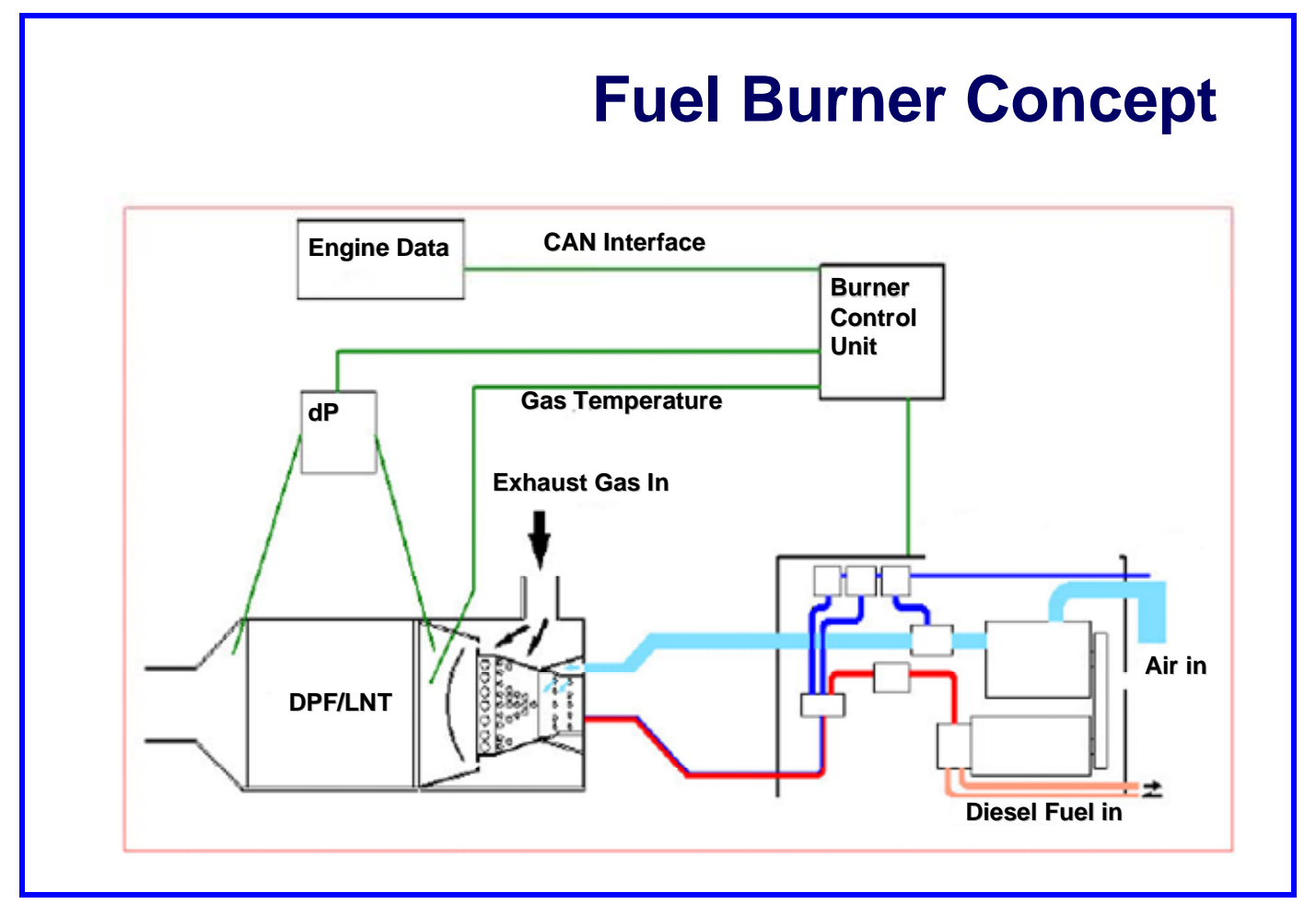

Figure 1.26 Fuel burner concept

The next section, which is the 2004 Progress Report, will give more detailed results.

Ash loading is one of the critical issues, which had significant impact on back pressure and soot loading characteristics. Figure 1.27 shows a few examples of ash loading in different filters. 


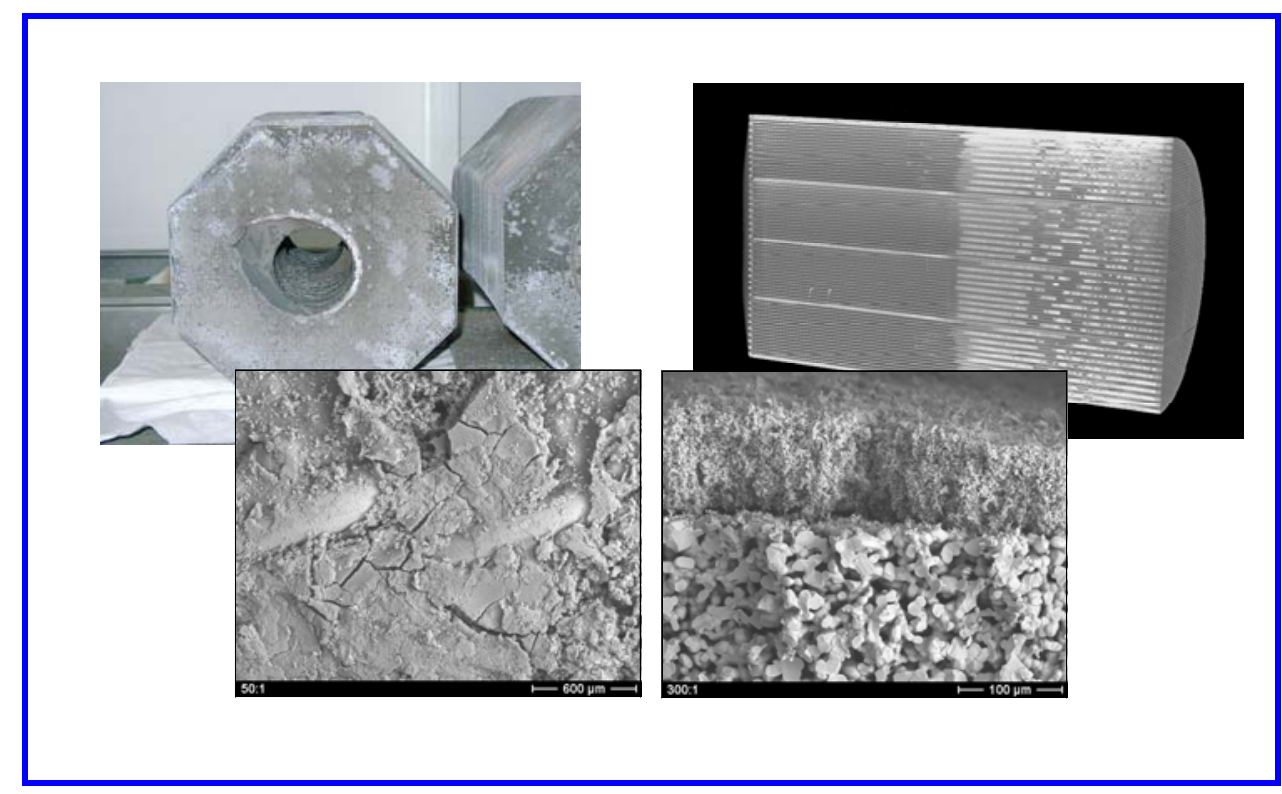

Figure 1.27 Ash loading in SMF (left side) and cordierite filter (right side)

In order to tackle this ash loading related challenge, the sintered metal filter (SMF) was under investigation, which offers a unique opportunity compared to more mature ceramic wall flow filters to achieve PM emission requirements with good packaging and without ash related servicing requirements. Figures 1.28 and 1.29 show the general features of SMF.

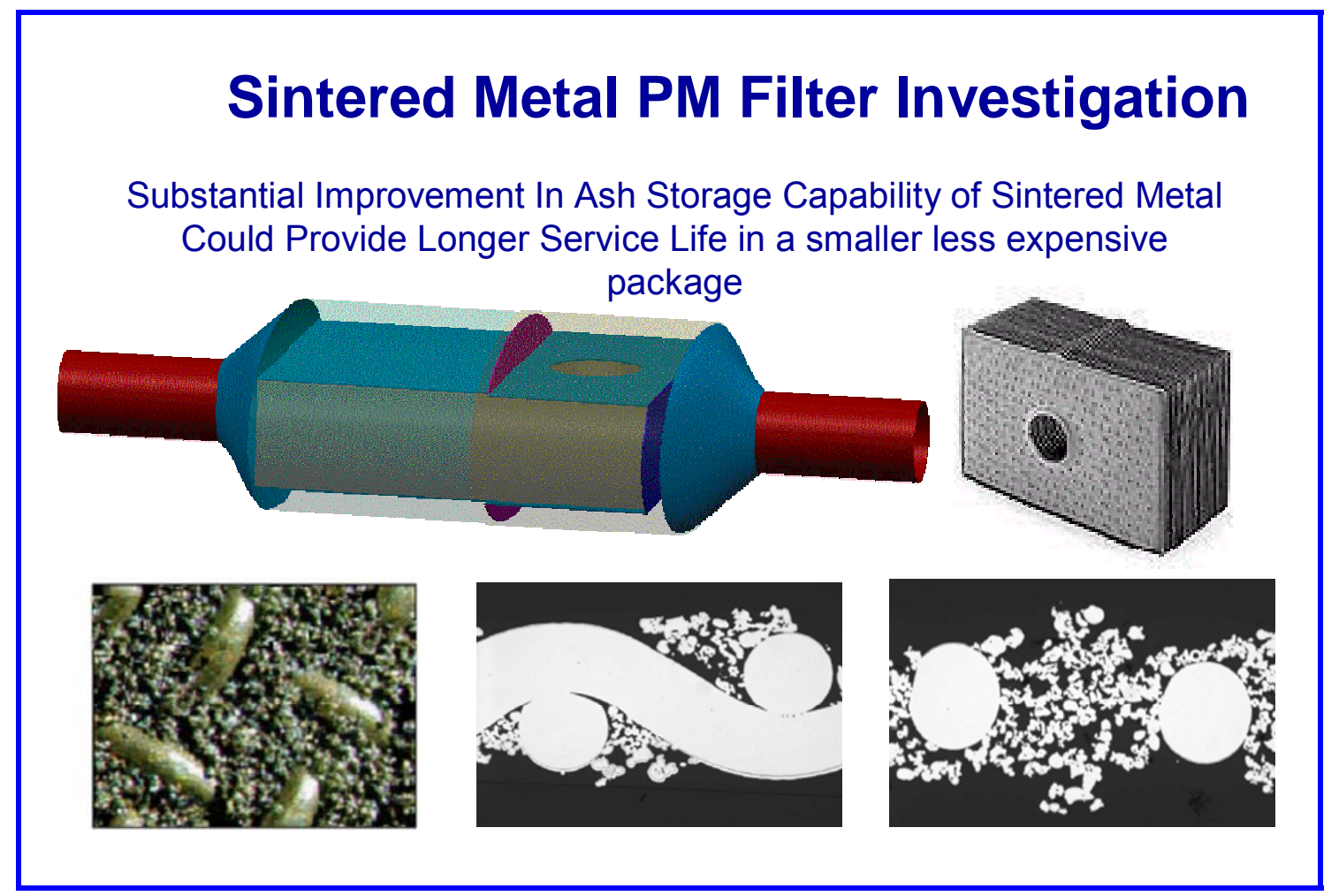

Figure 1.28 Sintered Metal PM Filter (1) 


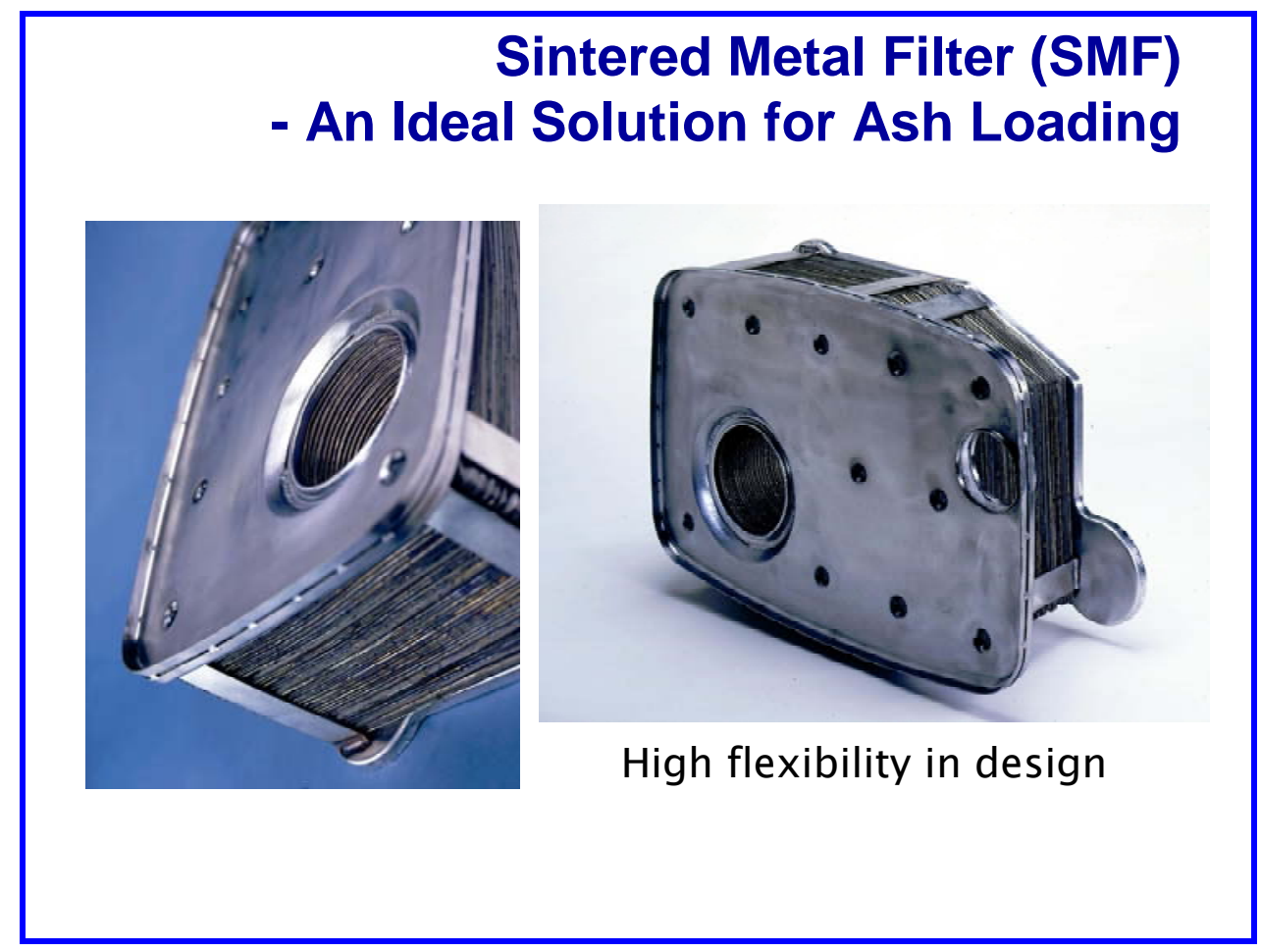

Figure 1.29 Sintered Metal PM Filter (2)

The technical characteristics of the type of filters can be seen in Figures 1.30 and 1.31. 


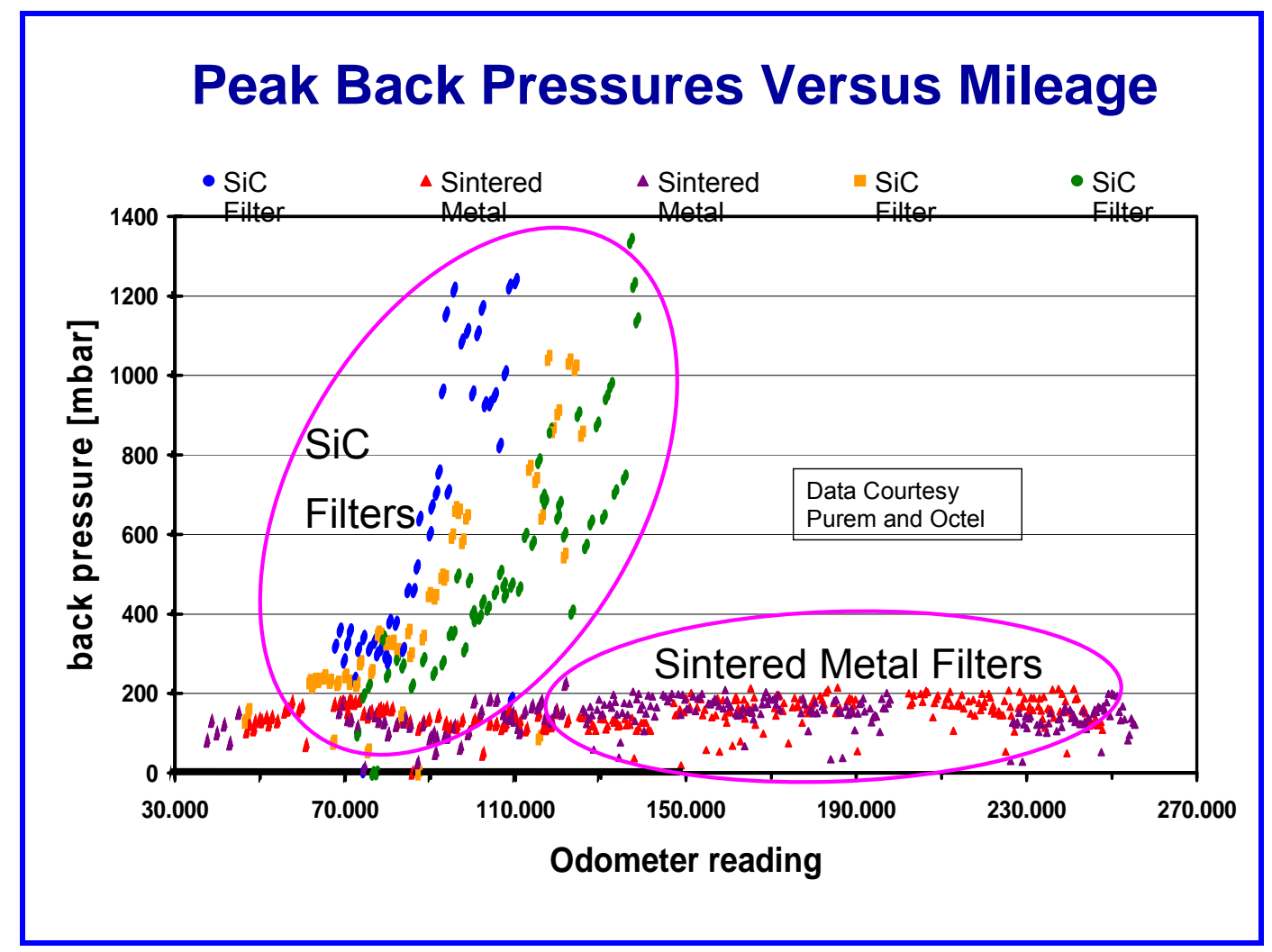

Figure 1.30 SMF back pressure characteristics

\section{0\% Ash loading SMF Advatange}

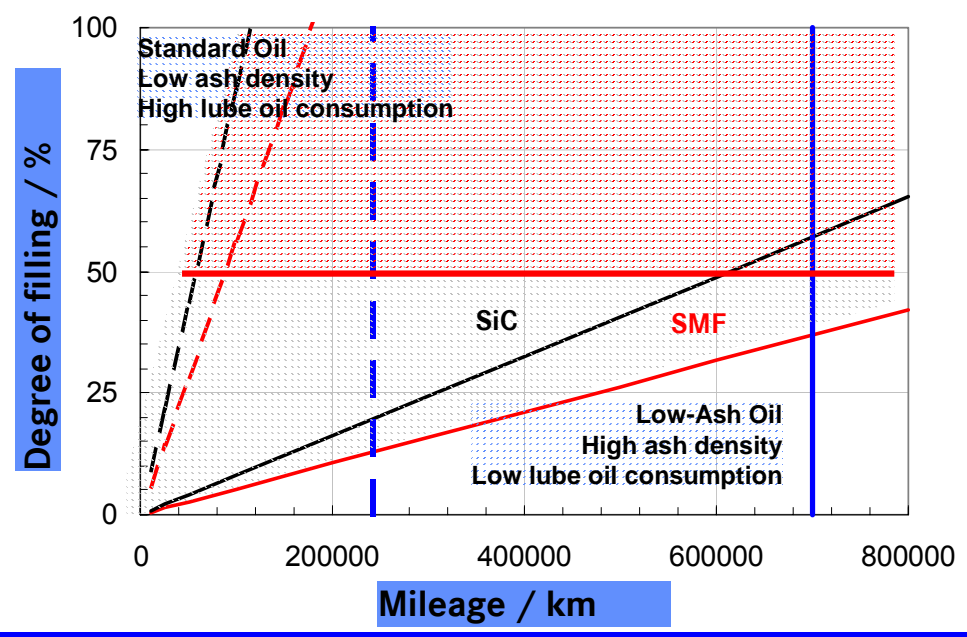

Figure 1.31 SMF ash loading characteristics 
In order to fully investigate the SMF characteristics, a work package was developed as shown in Figure 1.32, which was done at the BASF testing facility.

\section{Work Package for Ash Loading}

- Initiate an Ash Loading Project Using a Multiple Parallel Leg System to Address Durability Issues.

- Ash Patternation and Composition will be Analyzed in Details.

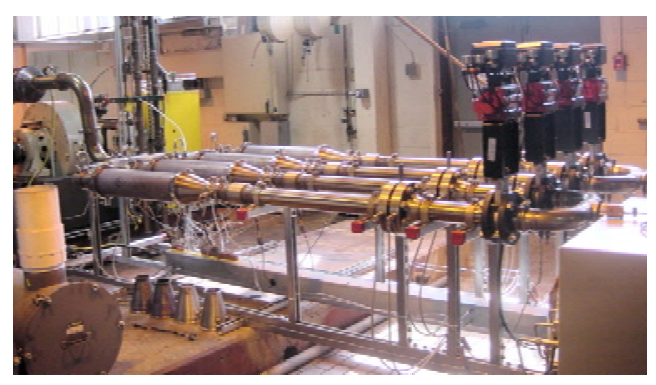

Figure 1.32 Ash loading working package.

The objective of this project was to evaluate ash loading in SMF. The highlight of this program is described as follows:

- $\quad$ BASF catalyzed soot filter technology

- Use parallel exhaust configuration to simultaneously age multiple DPFs

- Record DP and filter weight as a function of aging time

- Develop method for distinguishing ash from trapped soot

- Characterize ash deposition profile as a function of aging time

- Develop physical ash loading model to predict pressure drop and ash distributions

The next section, which is the 2004 Progress Report, will give more detailed results. 


\subsection{4}

Three major accomplishments were achieved in 2004.

(1) Ash loading characterization for SMF

(2) Fuel burner development for DPF regeneration

(3) DPF characterization using reactor bench

\subsubsection{Ash loading characterization for SMF}

Sintered Metal Filters (SMF) use a novel approach to filter soot from the exhaust and can have a reduced package size without a limitation in ash loading. It provides potential for low cost, volume and servicing requirements. However, technology is not mature and many questions remain. For this reason, the investigation was undertaken to answer some open questions specifically targeting ash loading.

All SMF under ash loading investigations were specifically designed for LD applications. A 2003 heavy-duty Series 60 engine was used for this program so that the aging rig with 4 parallel legs could be used to simulate LD operation in order to speed up the program as shown in Figure 1.32. Figure 1.33 shows how the filters were installed and how they were controlled.

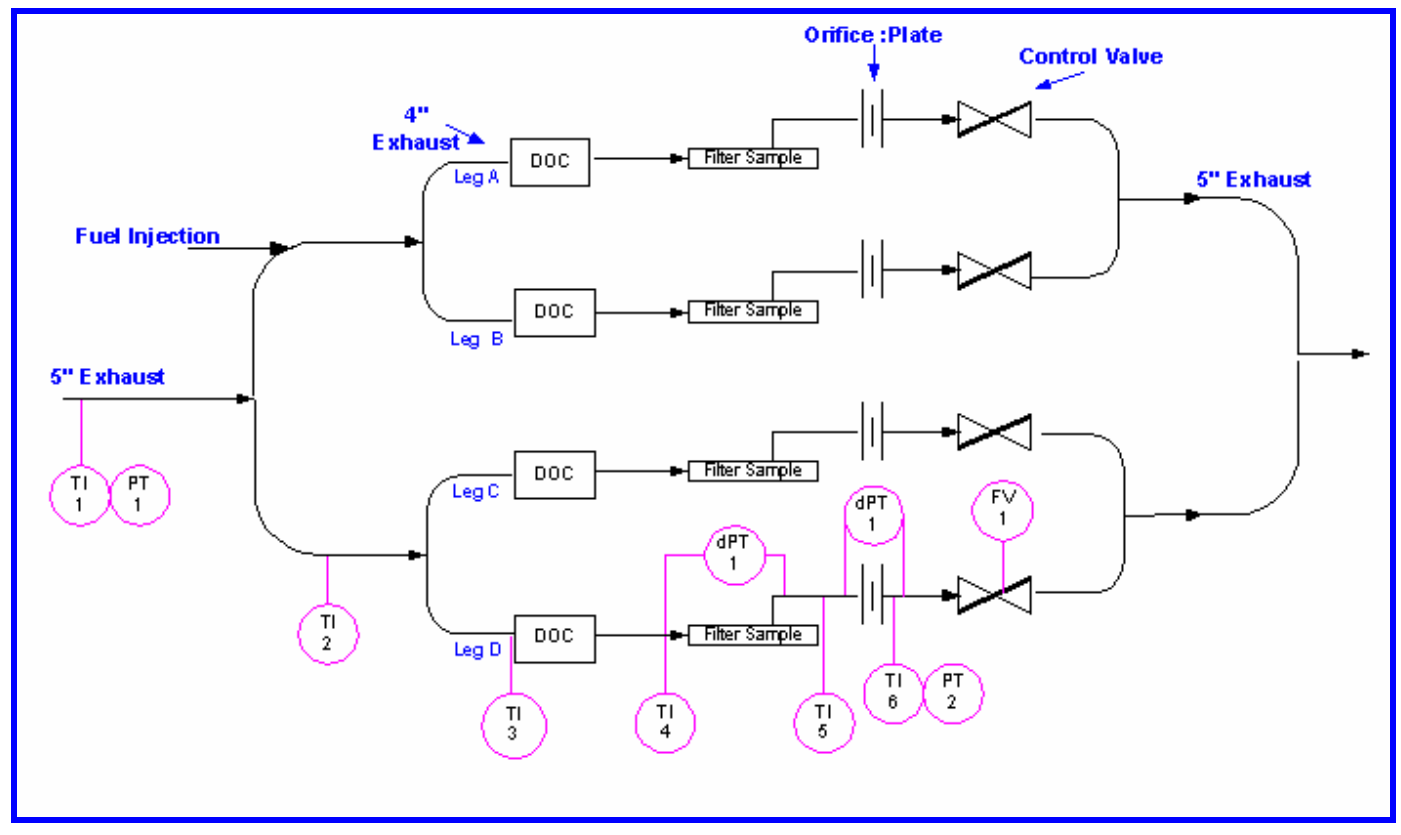

Figure 1.33 Flow diagram of aging rig with typical instrumentation shown 
Table 1.2 Instrumentation Referenced in Figure 1.33

\begin{tabular}{|c|c|c|c|}
\hline Instrument Tag & Instrument Type & Range & Measurement \\
\hline TI 1 & Thermocouple & Type K & Turbo Outlet Temperature \\
\hline PT 1 & Pressure Transducer & $0-300 \mathrm{kPa}$ & Engine Backpressure \\
\hline TI 2 & Thermocouple & Type K & Legs C/D Inlet Temperature \\
\hline TI 3 & Thermocouple & Type K & Leg D DOC Inlet Temperature \\
\hline TI 4 & Thermocouple & Type K & Leg D CSF Inlet Temperature \\
\hline dPT1 & Differential Pressure Transducer & $\pm 50 \mathrm{kPa}$ & Leg D Sample Pressure Drop \\
\hline TI 5 & Thermocouple & Type K & Leg D CSF Outlet Temperature \\
\hline $\mathrm{dPT} 2$ & Differential Pressure Transducer & $\pm 50 \mathrm{kPa}$ & Leg D Orifice Plate Differential Pressure \\
\hline TI 6 & Thermocouple & Type K & Leg D Orifice Plate Temperature \\
\hline PT 2 & Pressure Transducer & $75-110 \mathrm{kPa}$ absolute & Leg D Orifice Plate Pressure \\
\hline FV 1 & I/P Transducer & $0-100 \%$ & Leg D Flow Control Valve Control \\
\hline
\end{tabular}

Before conducting ash loading, the pressure drop was characterized. Figure 1.34 shows a typical SMF.

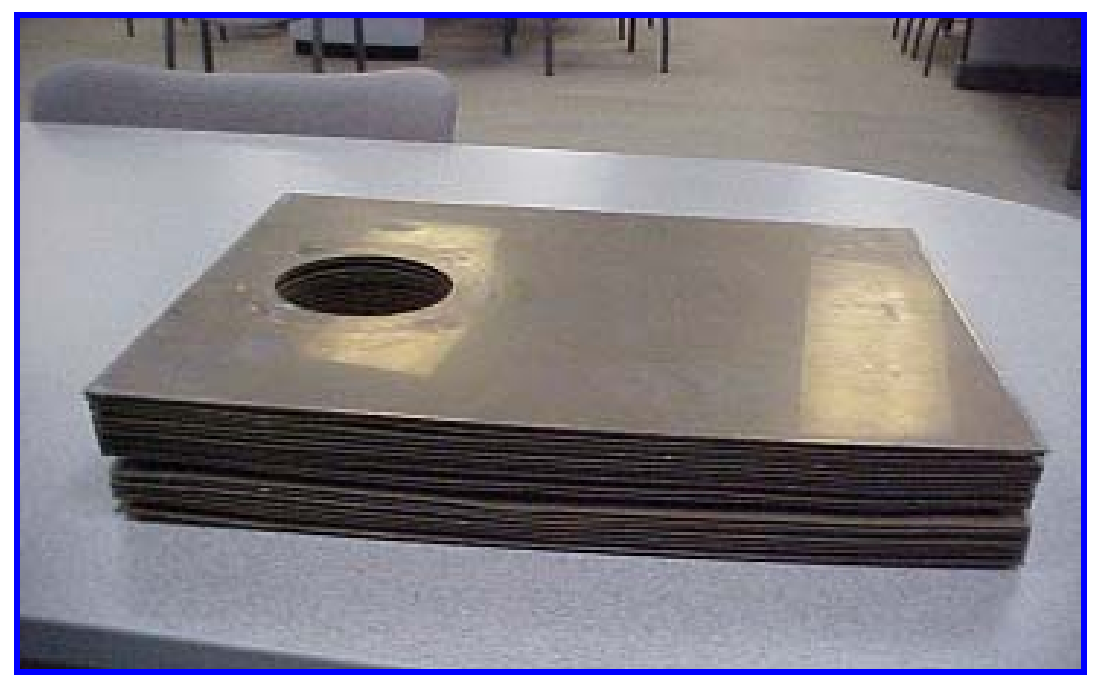

Figure 1.34 Sintered metal filter substrate (SMF)

Figure 1.35 shows the experimental setup to determine sample flowrate by increasing pressure drop. 


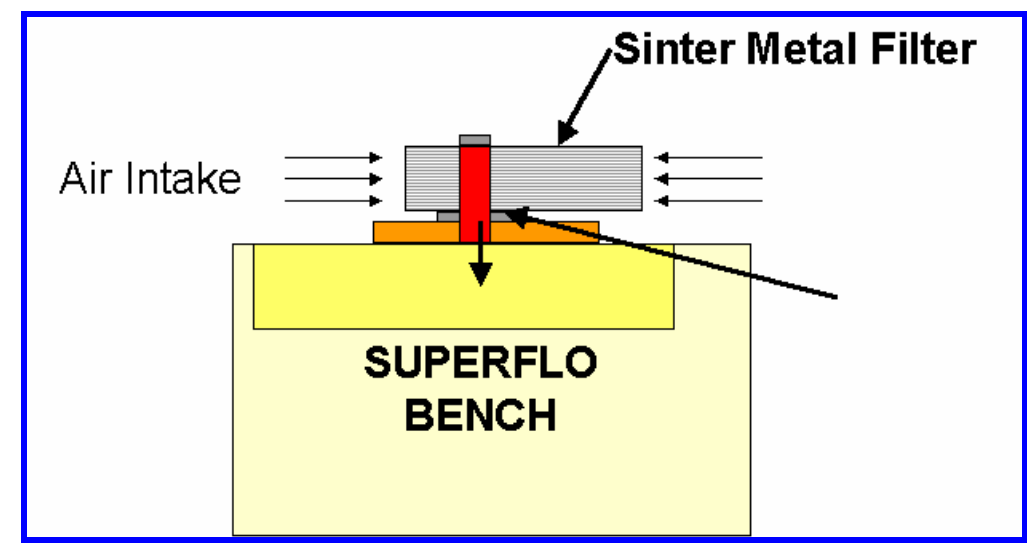

Figure 1.35 Experimental setup to determine sample flow rate by increasing pressure drop

The results of an evaluation of one sample over a pressure drop range of 2 " to 15" w.c. for both before and after coating are shown in Figure 1.36

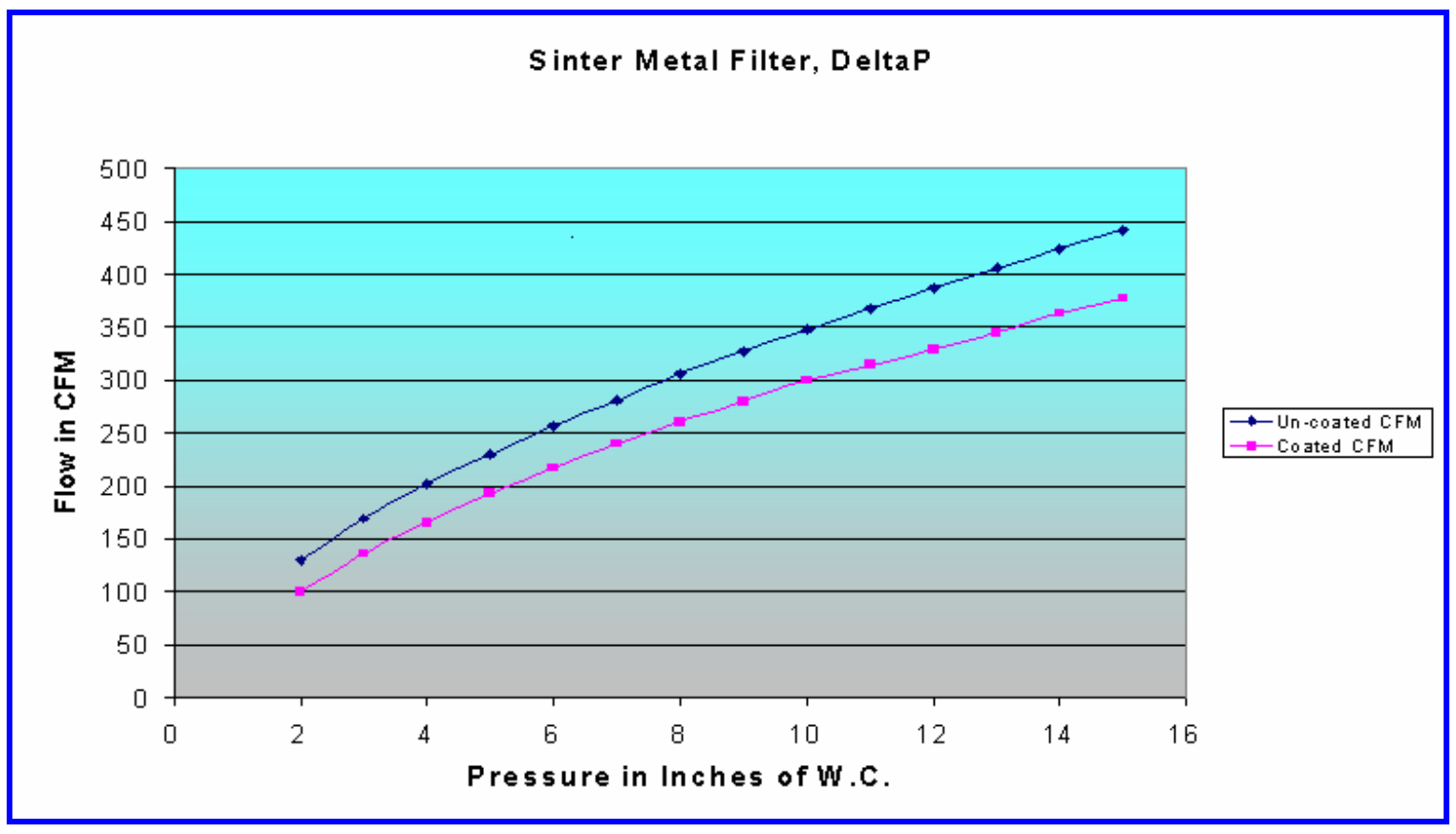

Figure 1.36 Experimental results for one sample, Coated and Uncoated

The cycle chosen for this ash loading program was a simple cycle consisting of a one hour soot loading step and a one hour regeneration step. The soot collection step was at the engine's $\mathrm{C} 25$ conditions and the regeneration step was at the A75 conditions. In Figure 1.37, the speed and torque measurements are shown for a series of soot collection and regeneration cycles. 


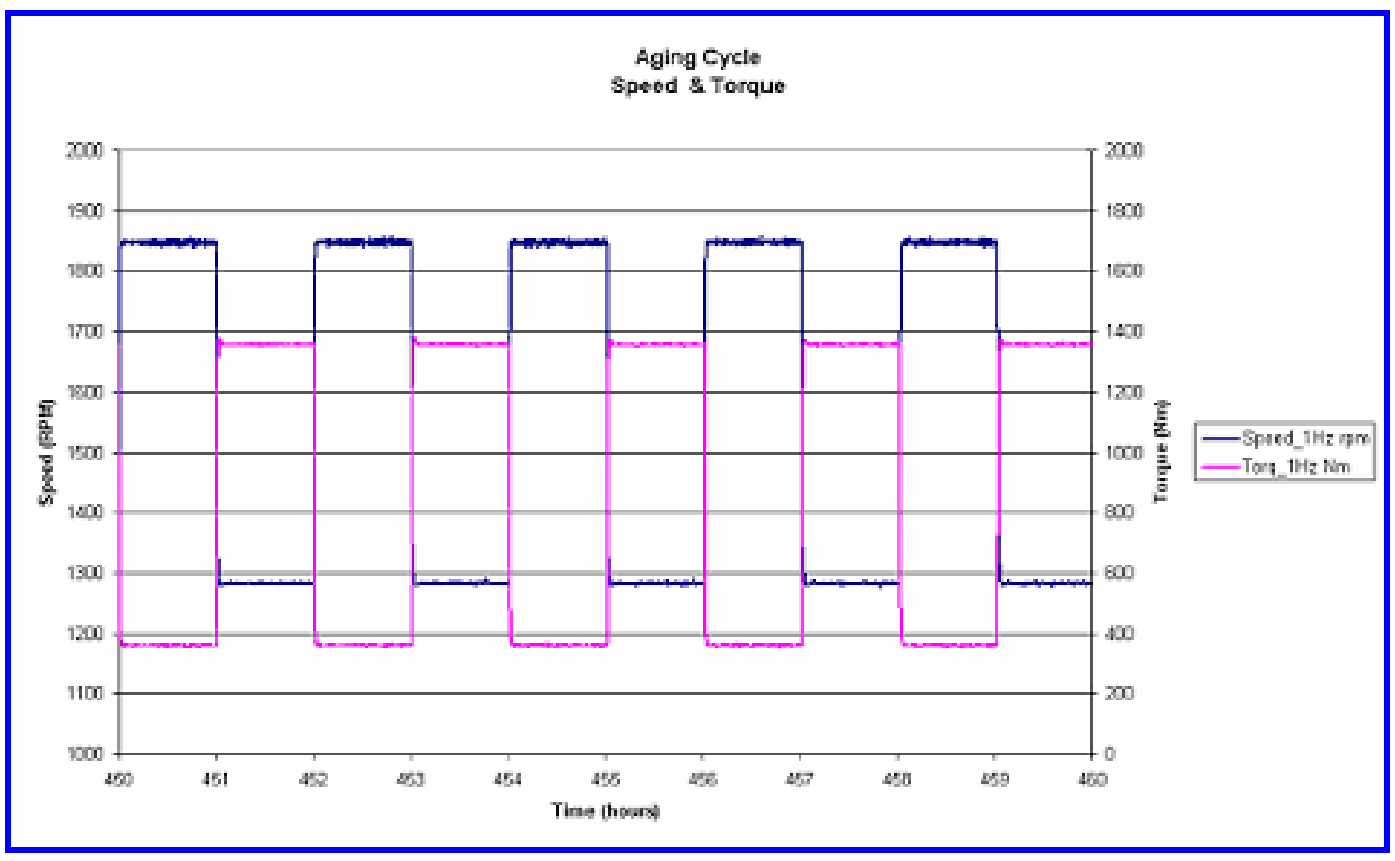

Figure 1.37 Aging Cycle, speed and torque

A typical temperature and pressure drop trace is shown for test leg $A$ in Figure 1.38. The red pressure drop trace increases during the lower temperature soot collection mode and then falls during the regeneration mode of the ash collection cycle.

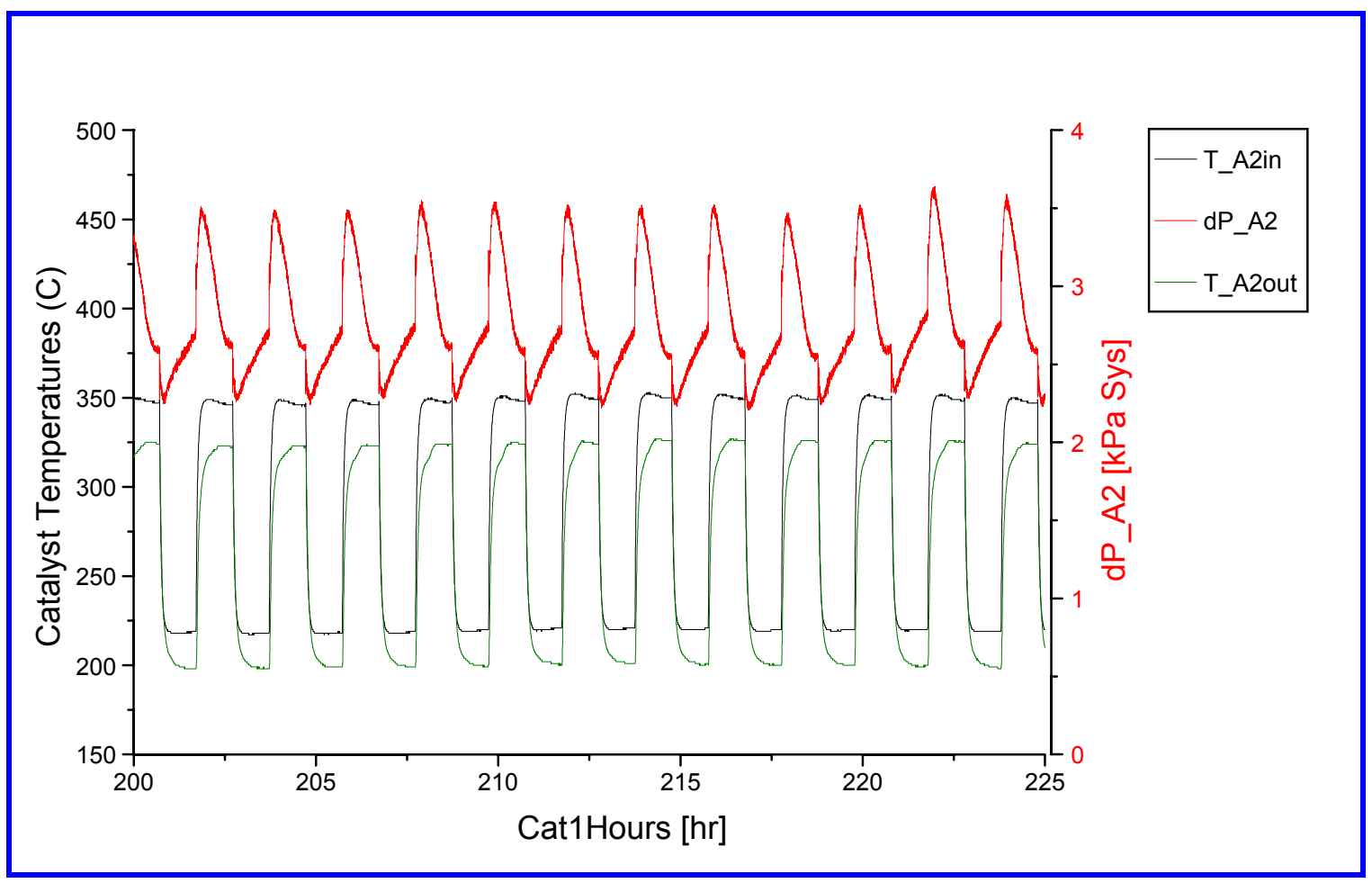

Figure 1.38 Typical Temperature Profile and Sample Pressure Drop 
The end-of-step DOC Inlet temperature for each parallel aging rig leg area is shown in Figure 1.39. This chart indicates consistent DOC inlet temperatures across all legs.

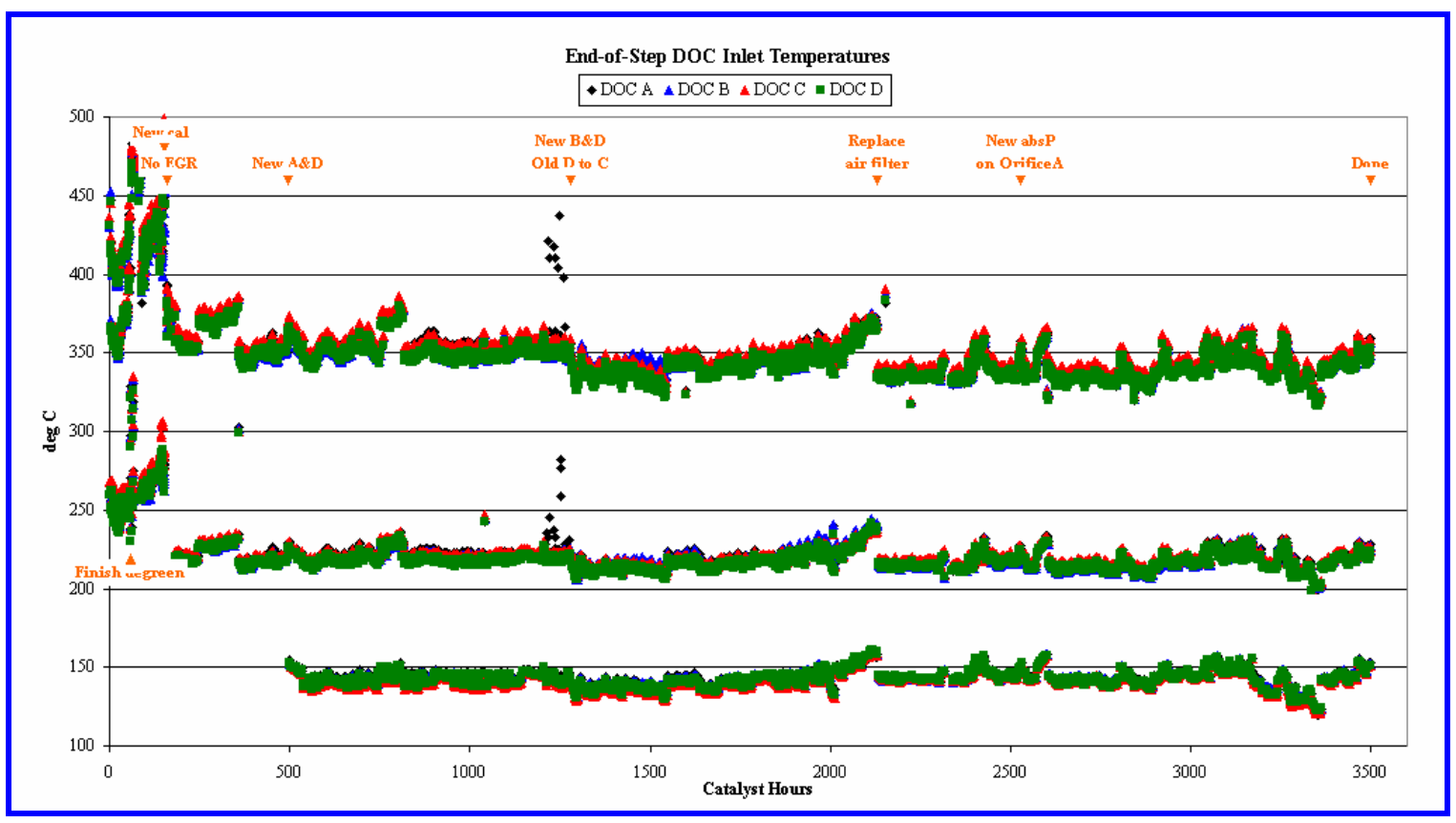

Figure 1.39 DOC Inlet Temperatures for all sample legs

In Figures 1.40 and 1.41, the end-of-step filter sample inlet temperatures are charted over the test, but in different ways. In Figure 1.38, the end-of-step temperatures are charted against catalyst hours. In Figure 1.40, a histogram is used to illustrate how much time the sample inlet temperature was at each $10^{\circ} \mathrm{C}$ interval over the aging. The histogram data is not generated from the end-of-state logs as in Figure 1.40. Instead, during runtime, the test cell control software monitors the sample inlet temperature at a $1 \mathrm{~Hz}$ sampling rate and calculates the number of occurrences for each $10^{\circ} \mathrm{C}$ interval. At the end of test, the accumulated totals can be plotted against the temperature interval to give an easy to understand visual of the temperature history at the location over the aging.

Figure 1.41 clearly shows the bi-modal aging cycle and the temperature ranges of the sample inlet during those modes, and that the temperatures were consistent across the legs of the rig. During the soot collection mode (C25), the sample inlet temperature was in the range of $210^{\circ} \mathrm{C}$ $230^{\circ} \mathrm{C}$, while during the regeneration, the sample inlet temperature was $330^{\circ} \mathrm{C}-360^{\circ} \mathrm{C}$. 


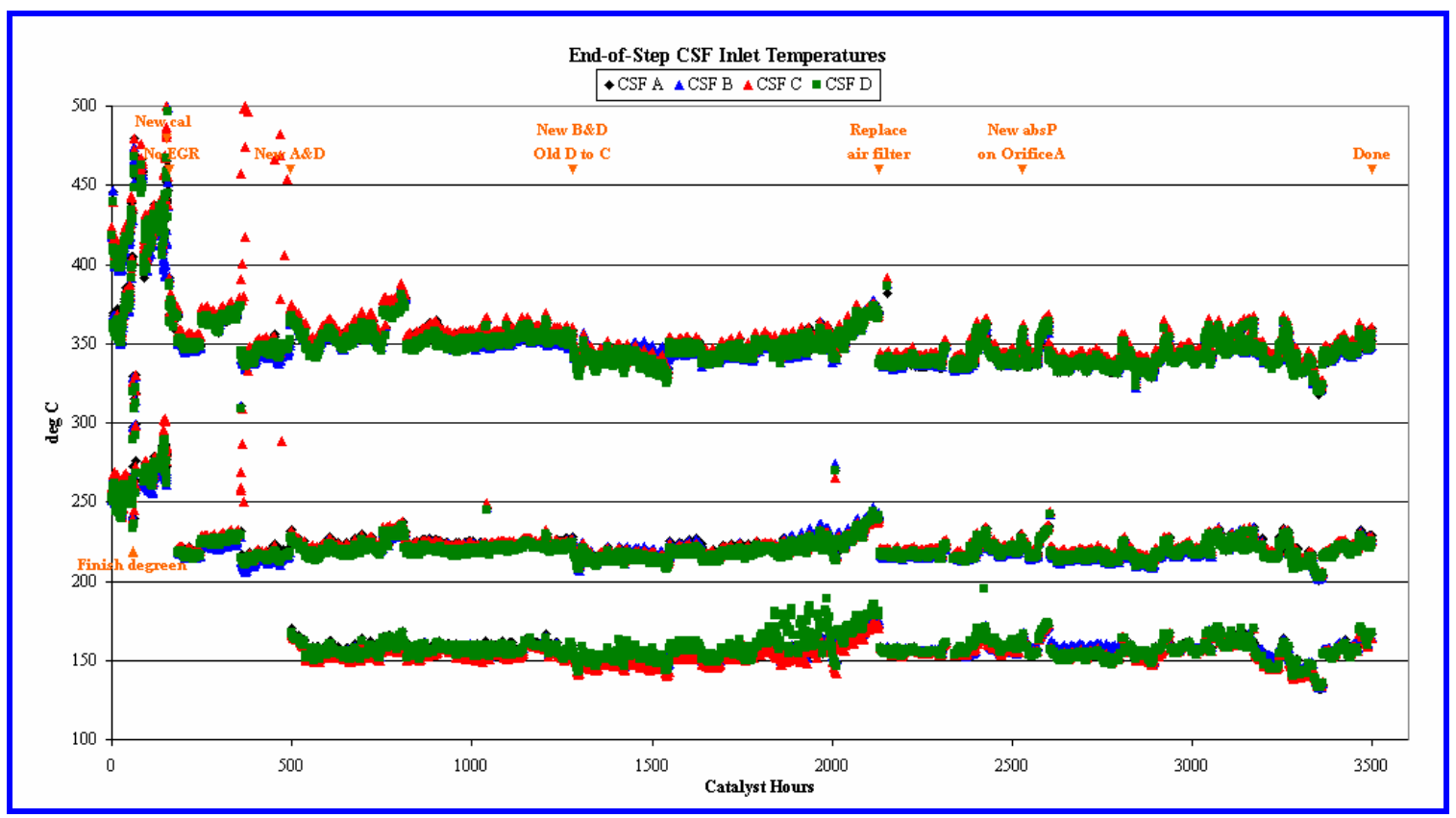

Figure 1.40 CSF Inlet Temperatures for all sample legs

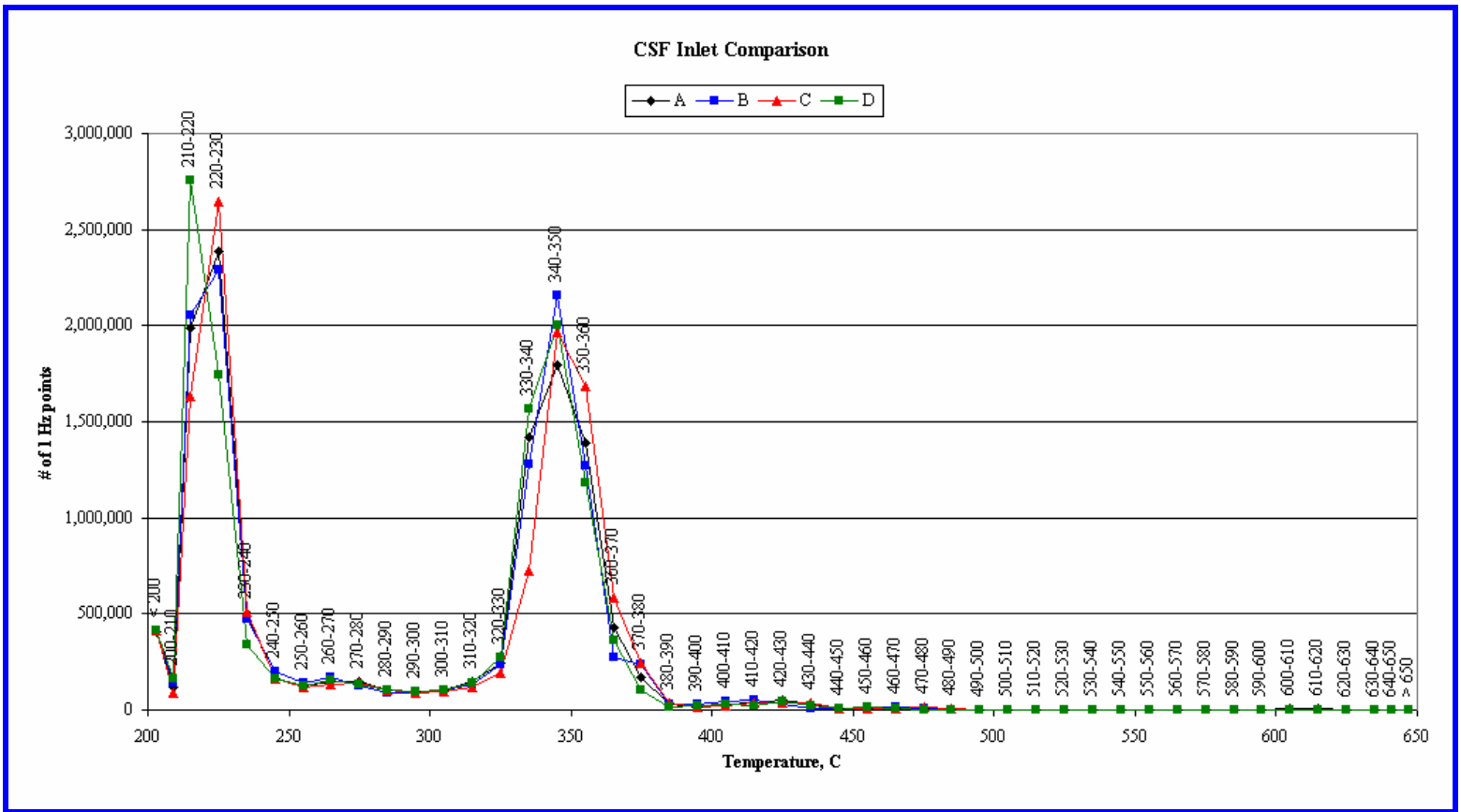

Figure 1.41 Histogram of CSF Inlet Temperatures for all sample

The chart of end-of-step sample differential pressure measurements for each leg over the entire ash accumulation shows two samples with higher than normal pressure drops measurements. As can be seen in Figure 1.42, from the beginning of the aging, the samples in both legs $B$ and $D$ had higher Delta $P$ measurements and did not return to normal until each sample was replaced with fresh samples, at 500 hours for leg D and 1250 hours for leg B. 


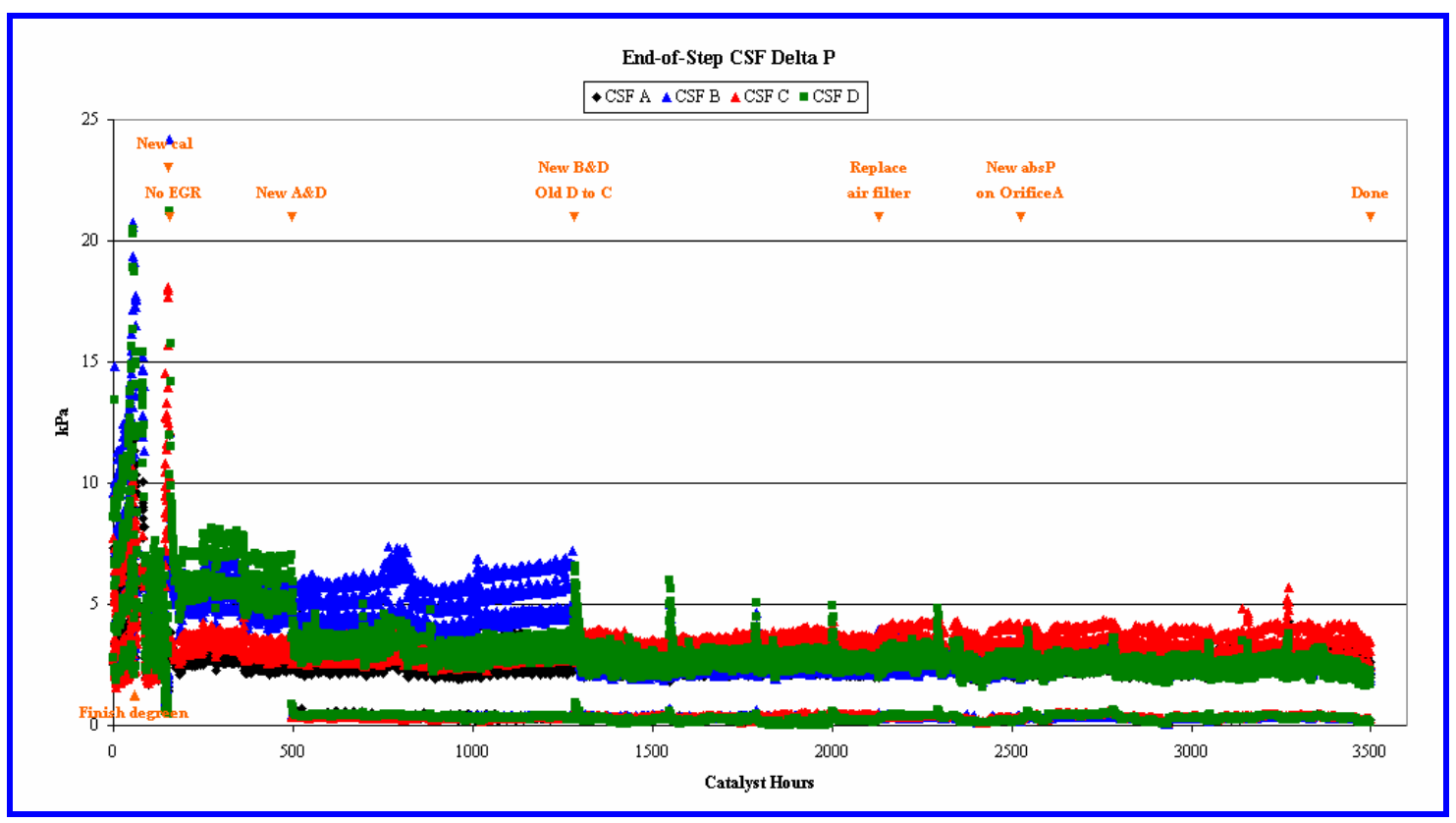

Figure 1.42 CSF Pressure Drops for all sample

Throughout the long-term ash accumulation study, the parallel rig was shut down for engine maintenance and for sample weights to be taken. Initially, the samples were weighed every 500 hours, but the weighing interval was shortened to 250 hours after the first 500 hour weighing of the 3000 hour samples. Weighing data for the 2250 and 3000 hour samples are shown in Figure 1.43. In this figure, legends with a number after DF is the unique identification of the filter, and active and passive mean that the filters have been through passive and active regenerations only.

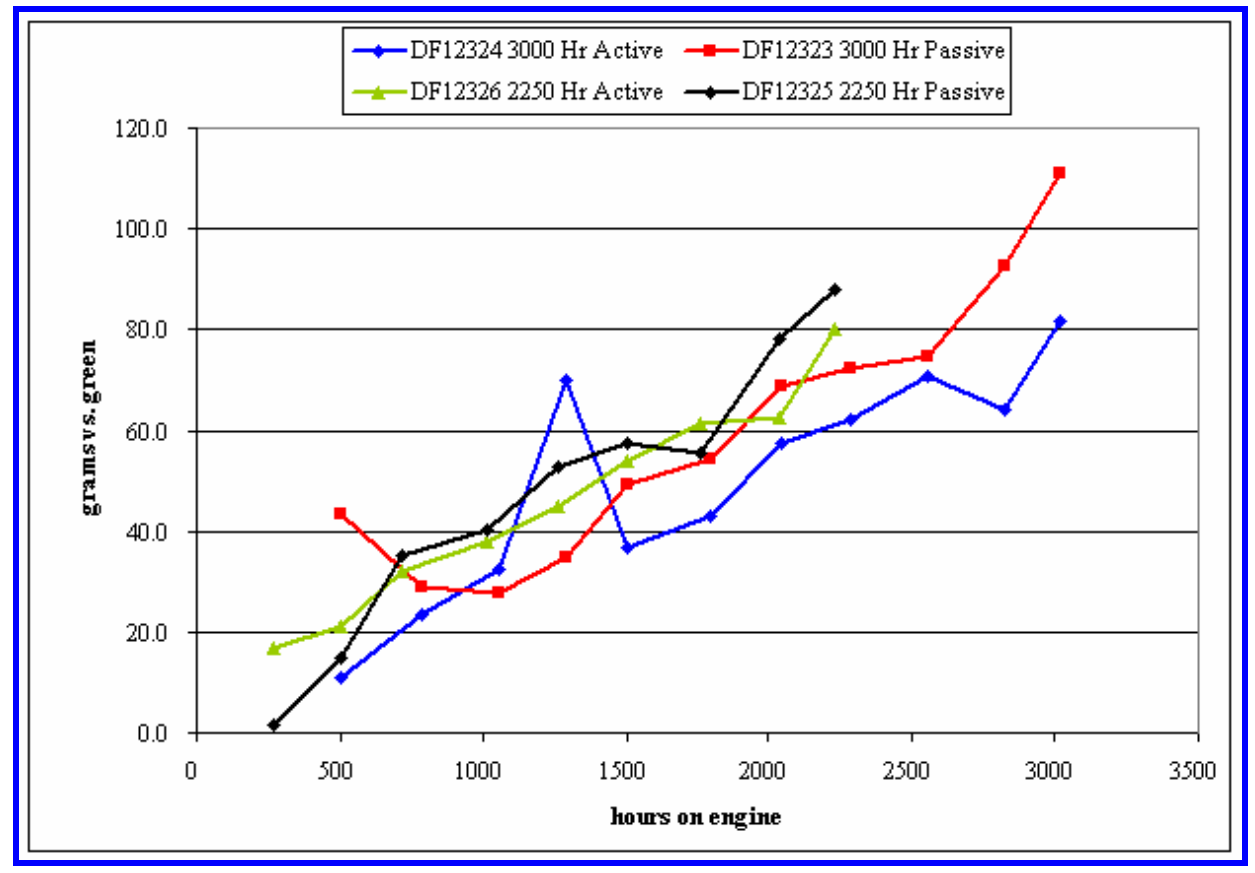

Figure 1.43 Increase in sample weights over ash accumulation 


\section{SMF Ash Material Analysis}

Ash that was collected from the cans as well as the loose ash collected from the filters was analyzed with X-ray fluorescence spectroscopy for elemental analysis. The powders were ground and pressed into pellets. XRF analysis of the gasket material was also performed to be able to distinguish ash elements from contamination coming from the gasket.

Table 1.3 below shows the XRF results for the ash tapped off of the filter for the 2250 and 3000 $\mathrm{hr}$ filters. Also included is the XRF of the gasket material. The major elemental constituents of the ash are $\mathrm{Ca}, \mathrm{S}, \mathrm{Zn}$, and $\mathrm{P}$ which is consistent with other data published on ash compositions. The gasket material contains primarily $\mathrm{Si}, \mathrm{Mg}, \mathrm{Al}$, and $\mathrm{Fe}$ (as the oxides) and, while the gasket does seem to contain at least some $\mathrm{Ca}$ and $\mathrm{S}$, both $\mathrm{Zn}$ and $\mathrm{P}$ are at very low levels. Thus, the major elemental constituent of the gasket and the ash do not overlap much, if at all. XRF elemental analysis of the rest of the ash samples from the cans and the other filters indicates mostly mixtures of ash and gasket materials as well as oxidation from the can walls. The data indicates that there is no real difference between active and passive samples nor any obvious difference between 2250 and $3000 \mathrm{hr}$ samples.

Table 1.3 XRF elemental analysis of collected ash samples.

\begin{tabular}{|c|c|c|c|c|c|}
\hline $\begin{array}{l}\text { Element } \\
\text { (as oxide) }\end{array}$ & Gasket & $\begin{array}{l}\text { wt } \% \\
\text { DF12325 } \\
2250 \text { passive }\end{array}$ & $\begin{array}{l}\text { DF12326 } \\
2250 \text { active }\end{array}$ & $\begin{array}{l}\text { DF12323 } \\
3000 \text { passive }\end{array}$ & $\begin{array}{l}\text { DF12324 } \\
3000 \text { active }\end{array}$ \\
\hline $\mathrm{SO} 3$ & 0.199 & 25.59 & 24.68 & 26.53 & 25.76 \\
\hline $\mathrm{CaO}$ & 2.16 & 23.38 & 22.36 & 24.00 & 23.91 \\
\hline P2O5 & 0.131 & 13.75 & 15.11 & 14.94 & 15.69 \\
\hline $\mathrm{ZnO}$ & 0.0295 & 9.91 & 10.29 & 10.78 & 11.39 \\
\hline $\mathrm{MgO}$ & 21.68 & 6.41 & 5.99 & 5.98 & 5.42 \\
\hline $\mathrm{Fe} 2 \mathrm{O} 3$ & 11.05 & 6.58 & 6.62 & 5.41 & 4.64 \\
\hline $\mathrm{SiO} 2$ & 41.4 & 5.16 & 4.89 & 3.86 & 4.36 \\
\hline $\mathrm{Al} 2 \mathrm{O} 3$ & 14.86 & 3.63 & 4.16 & 2.68 & 3.97 \\
\hline $\mathrm{Na} 2 \mathrm{O}$ & $n / d$ & 0.945 & 1.08 & 1.27 & 1.25 \\
\hline $\mathrm{CuO}$ & 0.0162 & 0.866 & 0.924 & 0.952 & 1.00 \\
\hline $\mathrm{PbO}$ & $n / d$ & 0.823 & 0.856 & 0.961 & 1.08 \\
\hline $\mathrm{NiO}$ & 0.0565 & 0.515 & 0.537 & 0.910 & 0.315 \\
\hline $\mathrm{Cr} 2 \mathrm{O} 3$ & 0.197 & 1.12 & 1.19 & 0.565 & 0.302 \\
\hline K2O & 5.45 & 0.477 & 0.47 & 0.352 & 0.275 \\
\hline $\mathrm{MnO}$ & 0.0951 & 0.281 & 0.208 & 0.223 & 0.148 \\
\hline TiO2 & 2.11 & 0.214 & 0.249 & 0.185 & 0.115 \\
\hline $\mathrm{CeO} 2$ & $n / d$ & 0.13 & 0.106 & 0.125 & 0.150 \\
\hline
\end{tabular}

The initial visual observations were in line with the general testing results. Only one of the filters showed any obvious failure and the rest were consistent in the manner that ash was collected and stored in the filter. The most valuable data is from the 2250 and $3000 \mathrm{hr}$ sample sets because they had the most consistent testing and because they allow the furthest extrapolation. Ash appears to build up a layer on the inlet face of the filter starting first closest to the outlet of the filter and then building up farther away from the outlet area. 
The filter weights taken during the aging show a generally linear increase in weight with time (Figure 1.43). Sample DF12324 had an unexplained weight increase at approximately 1250 hrs, possibly due to a data transposition error. There is also an unexplained decrease in weight for that same sample at approximately $2800 \mathrm{hrs}$. It does not appear that this is associated with a breach in the filter since the weigh continues to increase at the final weighing. Furthermore, no filter breach was apparent from further visual inspection. Because of the difficulties in measuring small increases in weight of a heavy object, deviations from the general trend are likely within the experimental error of the weighing method.

\section{$\underline{\text { SMF material analysis conclusion }}$}

Materials analysis of a set of aged sintered metal filters was performed in order to understand the impact of ash accumulation on backpressure and see what, if any, impact the regeneration method had on ash properties. What was discovered was:

1. Ash accumulates in the filters by growth of a porous layer on the filter inlet faces.

2. Only a small percentage of the ash actually accumulates in the can in the test orientation and under test conditions.

3. While some ash presumably could be removed by in-service vibration, at least $50 \%$ of the ash is likely to remain on the filter face.

4. Even with vibratory removal of ash, back pressure increases with aging presumably due to the remaining ash on the filter

5. Ash does not appear to penetrate the wall, rather building up on the inlet side of the filter face.

6. The ash composition does not seem to be affected by differences in passive and active regeneration or by aging time. The ash is largely $\mathrm{Ca}, \mathrm{S}, \mathrm{Zn}$, and $\mathrm{P}$ with other elemental constituents from gasket material, engine wear, oil, and fuel contaminants. 


\subsubsection{Fuel burner development for DPF regeneration}

The objective of this task was to develop a commercially viable fuel burner for the thermal regeneration of diesel particulate filters. Many options of fuel burners were evaluated, which included

- Plasma Assisted Burner

- Thermal Regenerator

- Diesel Vaporizer

- Duct Burner

- Axial Duct Burner

The final selection was axial duct burner due to its more mature technologies and better chance for LD commercialization. Figure 1.44 shows a sketch of the axial duct burner concept.

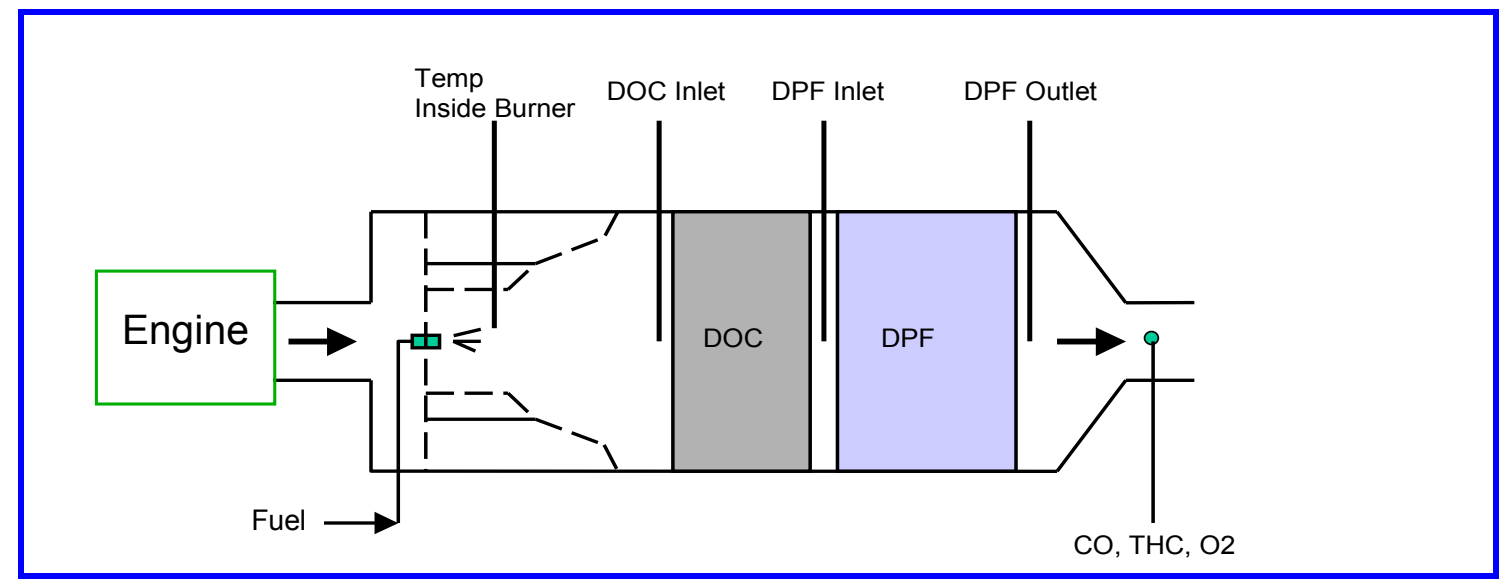

Figure 1.44 Axial duct burner system configuration

The key component of this axial duct burner consists of the following parts.

- Dual fuel/air pump which outputs fuel and air alternatively

- A Hago M2 nozzle located inside the burner

- A pair of electrodes and driver board

- Four thermocouples

- A fuel injector

- A controller

- DPF

Figures 1.45 and 1.46 are the photos of the fuel burner. 


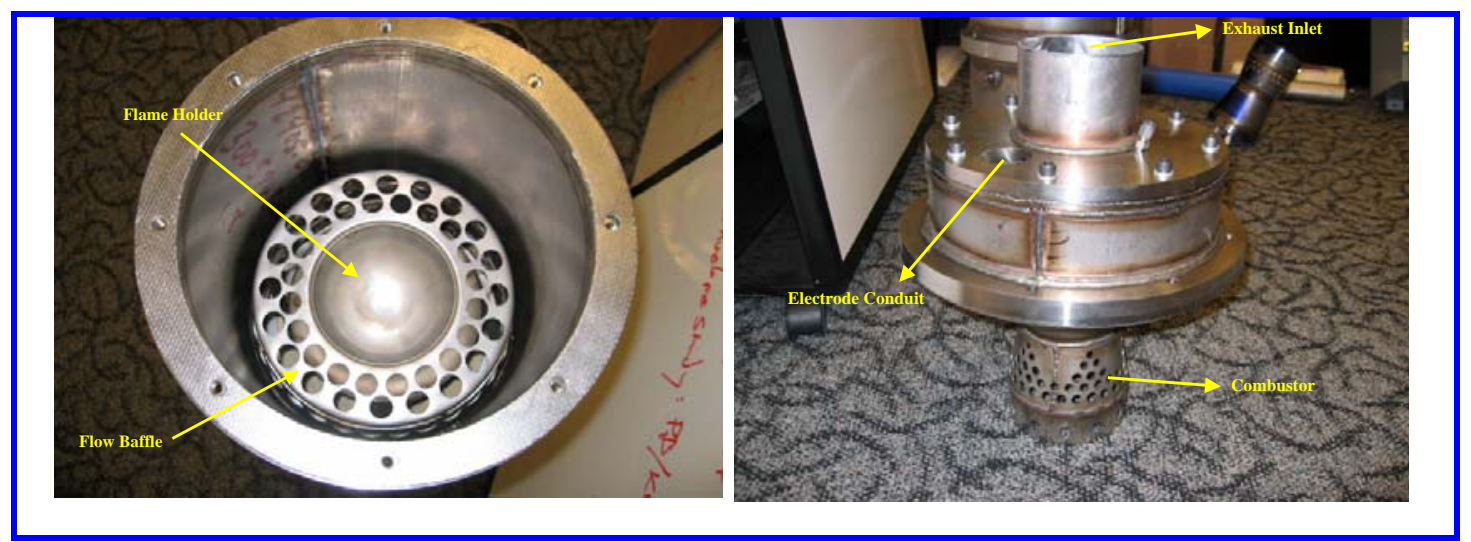

Figure 1.45 Fuel burner (1)

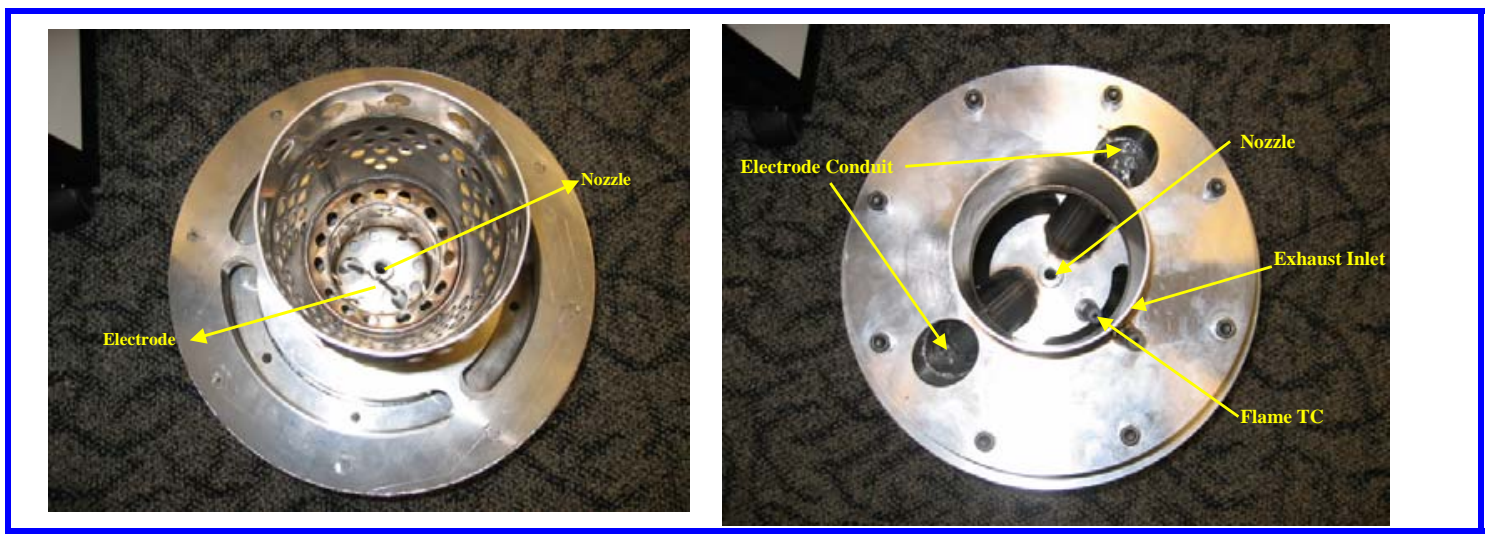

Figure 1.46 Fuel burner (2)

Full system test of axial burner was conducted in a $15 \mathrm{~L}$ diesel engine with cooled-EGR. A smaller diesel engine with the displacement volume of about $4.2 \mathrm{~L}$ would be the ideal engine. However, this $15 \mathrm{~L}$ was the only available engine at the time when the test was prepared. However, the values out of these testing results were still applicable to LD application as long as the flow rate and exhaust temperature were properly controlled to simulate LD application. In all the tests below, the fuel flow is controlled with 100psi constantly. The test results are shown in Figures 1.47 and 1.49 


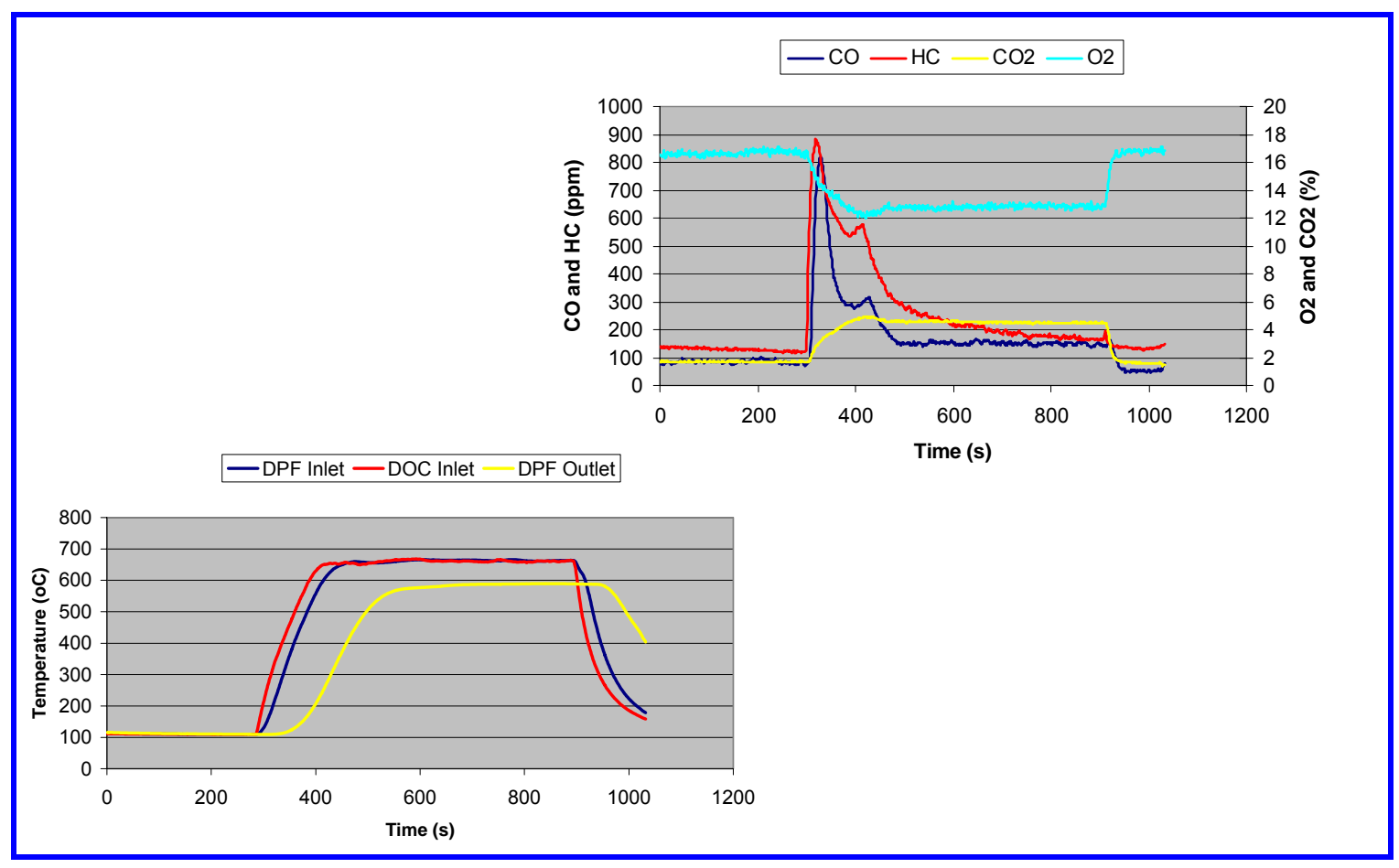

Figure 1.47 Burner performance at idle speed

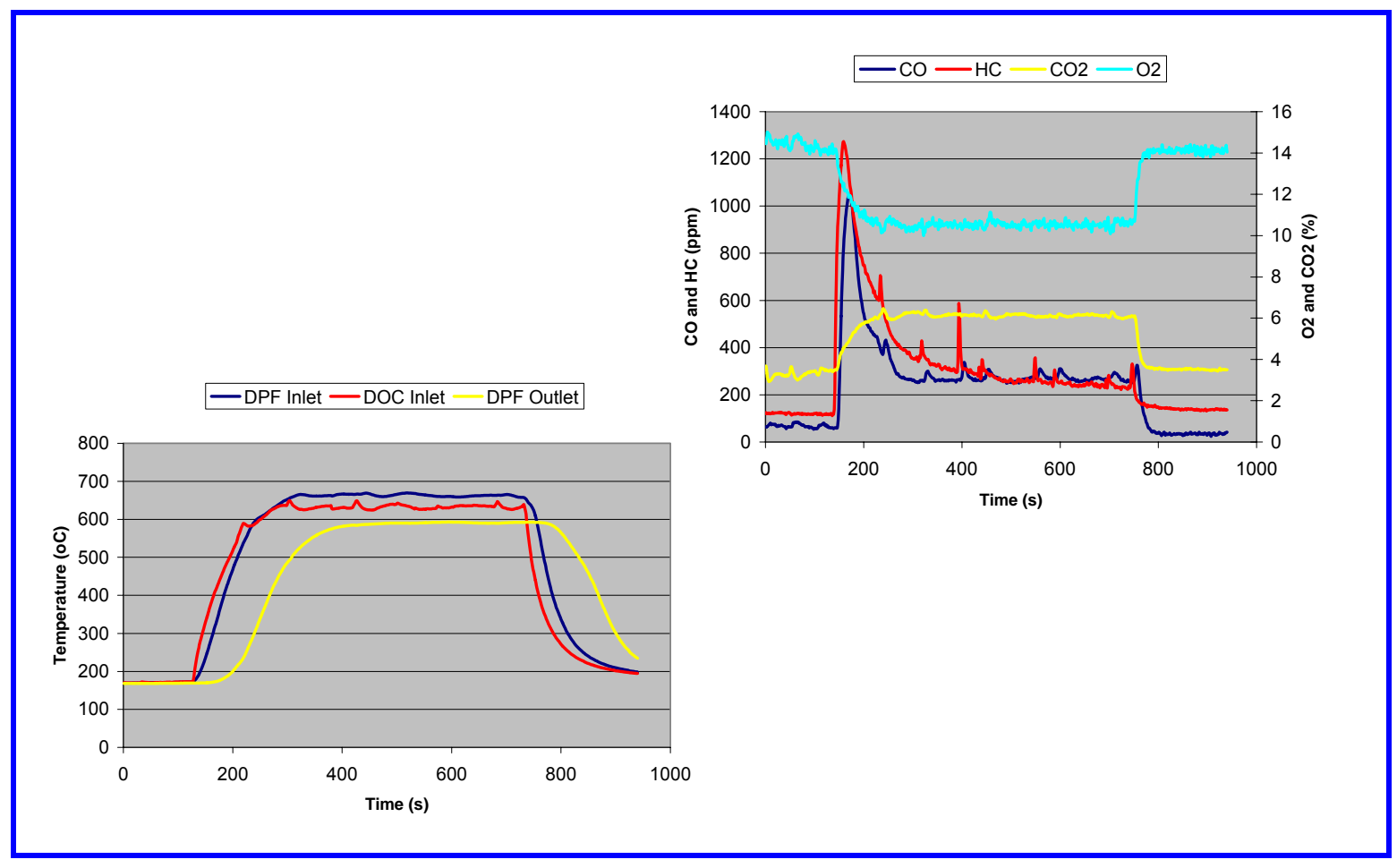

Figure 1.48 Burner performance at 700rpm and 200ft-lb 


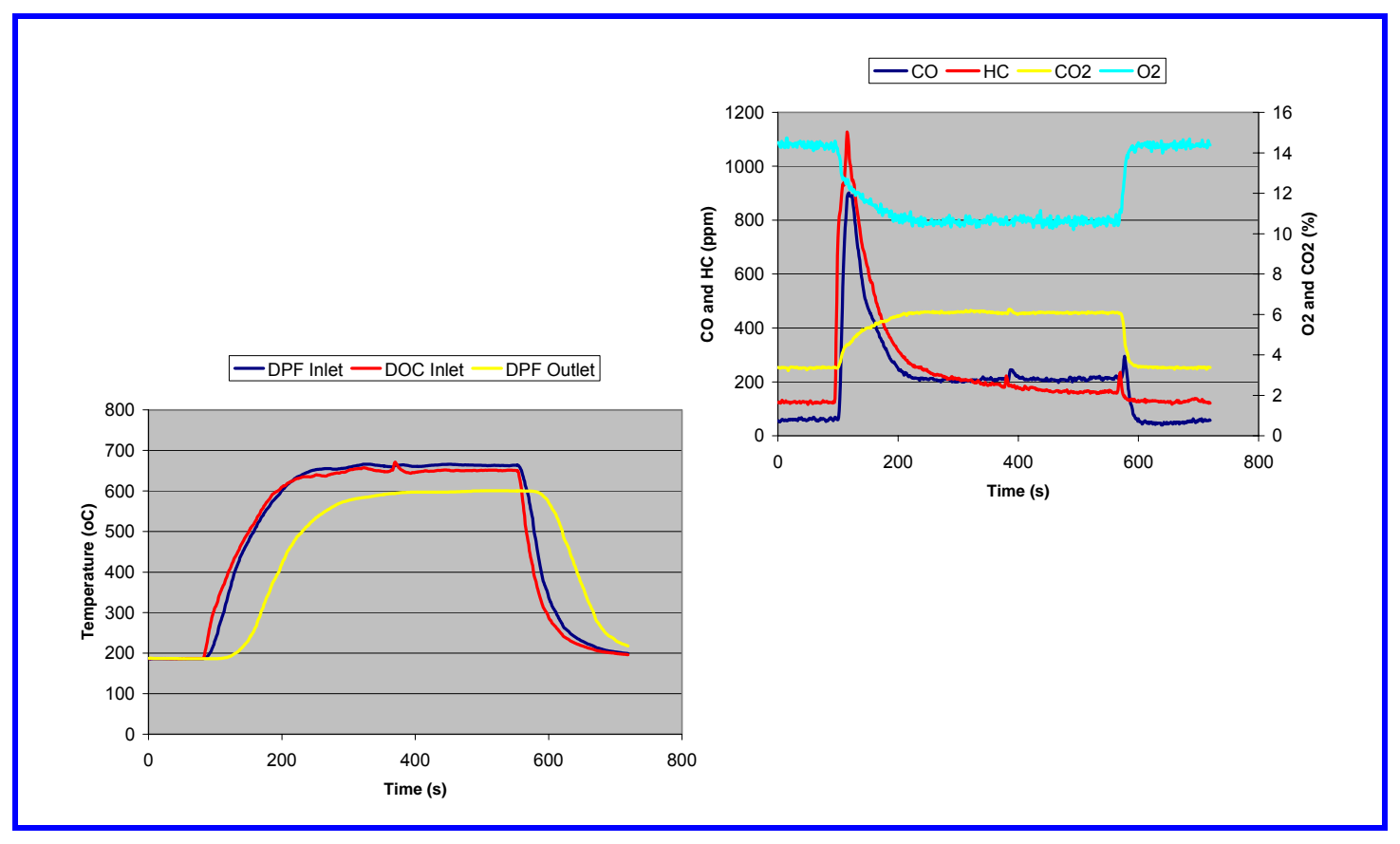

Figure 1.49 Burner performance at 800rpm and 200ft-lb

As can be seen in all the three testing conditions, the temperature at the DPF inlet can reach $600^{\circ} \mathrm{C}$, which is the requirement of the DPF regeneration temperature. 


\subsubsection{DPF characterization using reactor bench}

The objective of this work was twofold. The first was to provide a better understanding of the different types of filter characteristics and their performance under different operating conditions. The second was to provide DPF kinetic data for use in DPF modeling. Figure 1.50 is the reactor bench set up.

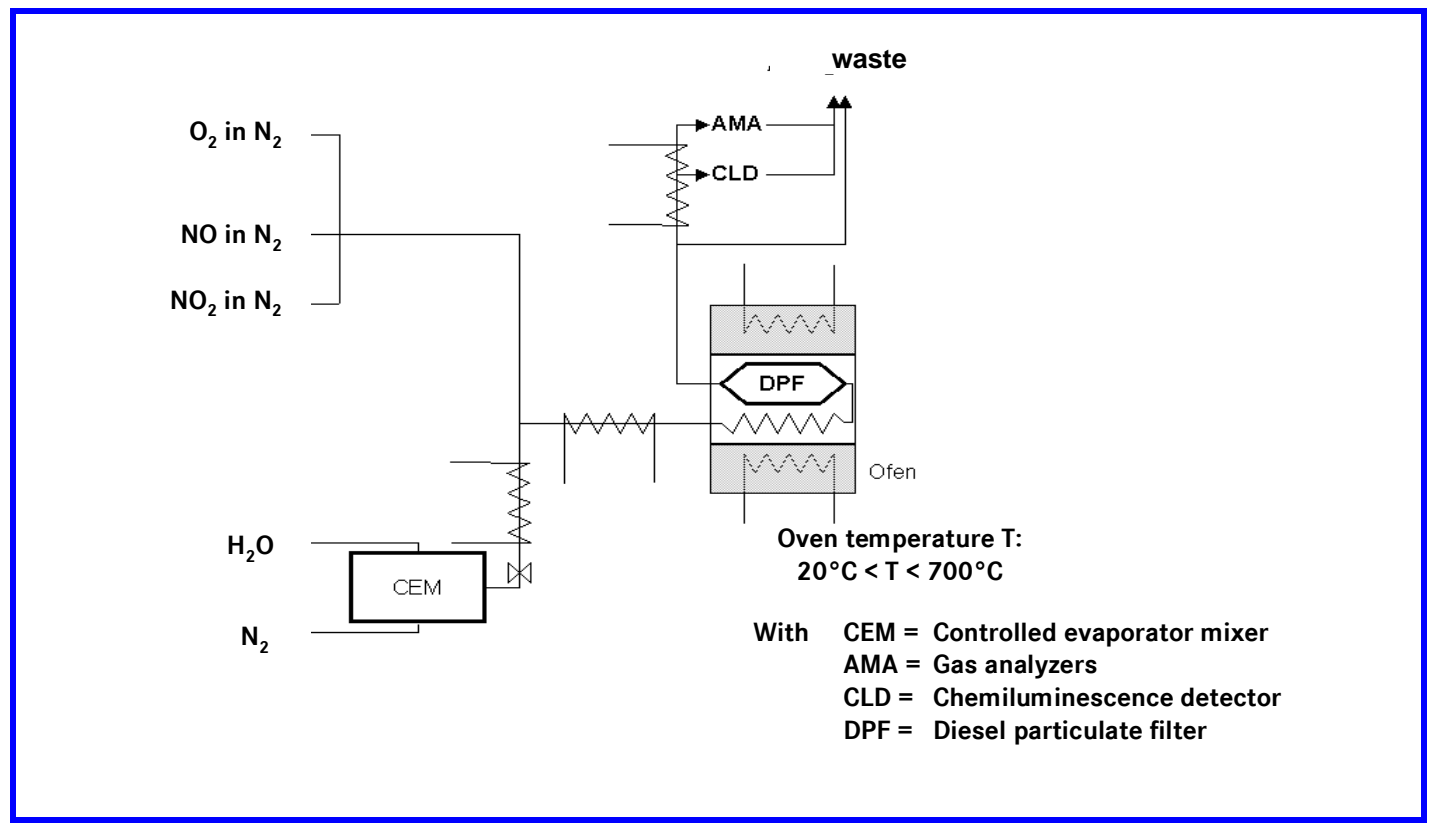

Figure 1.50 DPF Characterization Using Reactor Bench Laboratory setup

Table 1.4 is the test matrix specifically developed for this project, which covers a wide range of operating conditions.

Table 1.4 DPF characterization using reactor bench test matrix

- Total of 6 DPF Samples Were Investigated

- Two Types of Coated Material

- Two Types of Substrates

\begin{tabular}{|cccccccccc|}
\hline $\begin{array}{c}\text { DPF } \\
\text { Test Point }\end{array}$ & $\begin{array}{c}\text { SV } \\
\text { 1/h }\end{array}$ & $\begin{array}{c}\text { Temp } \\
\text { Deg C }\end{array}$ & $\begin{array}{c}\text { NO } \\
\text { ppm }\end{array}$ & $\begin{array}{c}\text { NO2 } \\
\text { ppm }\end{array}$ & $\begin{array}{c}\text { HC } \\
\text { ppm }\end{array}$ & $\begin{array}{c}\text { CO } \\
\text { ppm }\end{array}$ & $\begin{array}{c}\text { H2O } \\
\text { \% }\end{array}$ & $\begin{array}{c}\text { O2 } \\
\text { \% }\end{array}$ & $\begin{array}{c}\text { Soot loading } \\
\text { g/l }\end{array}$ \\
\hline TP1 & 12570 & 600 & 192 & 394 & 15 & 265 & 4 & 5 & $4 / 6$ \\
TP2 & 12570 & 600 & 192 & 394 & 15 & 265 & 4 & 10 & $4 / 6$ \\
TP3 & 12570 & 600 & 192 & 394 & 15 & 265 & 4 & 5 & $5.3 / 8$ \\
TP4 & 12570 & 600 & 192 & 394 & 15 & 265 & 4 & 10 & $5.3 / 8$ \\
TP5 & 52000 & 250 & 648 & 181 & 0 & 0 & 4 & 10 & $4 / 6$ \\
TP6 & 52000 & 350 & 51 & 86 & 0 & 0 & 4 & 10 & $4 / 6$ \\
TP7 & 52000 & 350 & 398 & 429 & 0 & 0 & 4 & 10 & $4 / 6$ \\
TP8 & 52000 & 450 & 82 & 50 & 0 & 0 & 4 & 10 & $4 / 6$ \\
TP9 & 52000 & 600 & 70 & 70 & 15 & 265 & 4 & 8.45 & $4 / 6$ \\
\hline
\end{tabular}


The DPF characterization test procedure is described as follows:

- DPF is first loaded with soot using a single cylinder engine

- Loaded filter is then moved to the reactor bench and is characterized in a controlled environment using a range of temperatures, space velocities, and emission species concentrations

- Comprehensive data-set is acquired, including soot consumption, and provides information for DPF model calibration and for better understanding on DPF performance

Figure 1.51 shows the standard laboratory test procedure at high temperature $\left(600^{\circ} \mathrm{C}\right)$ for active regeneration, which can be described as follows.

- Heating up under nitrogen until conditions are stable (isothermal)

- Exothermal reaction of soot with controlled feed gas compounds at $600^{\circ} \mathrm{C}$

- Determination of maximum soot consumption rate, overall soot consumption rate (from $90 \%$ to $10 \%$ soot loading) and CO-/HC-slip

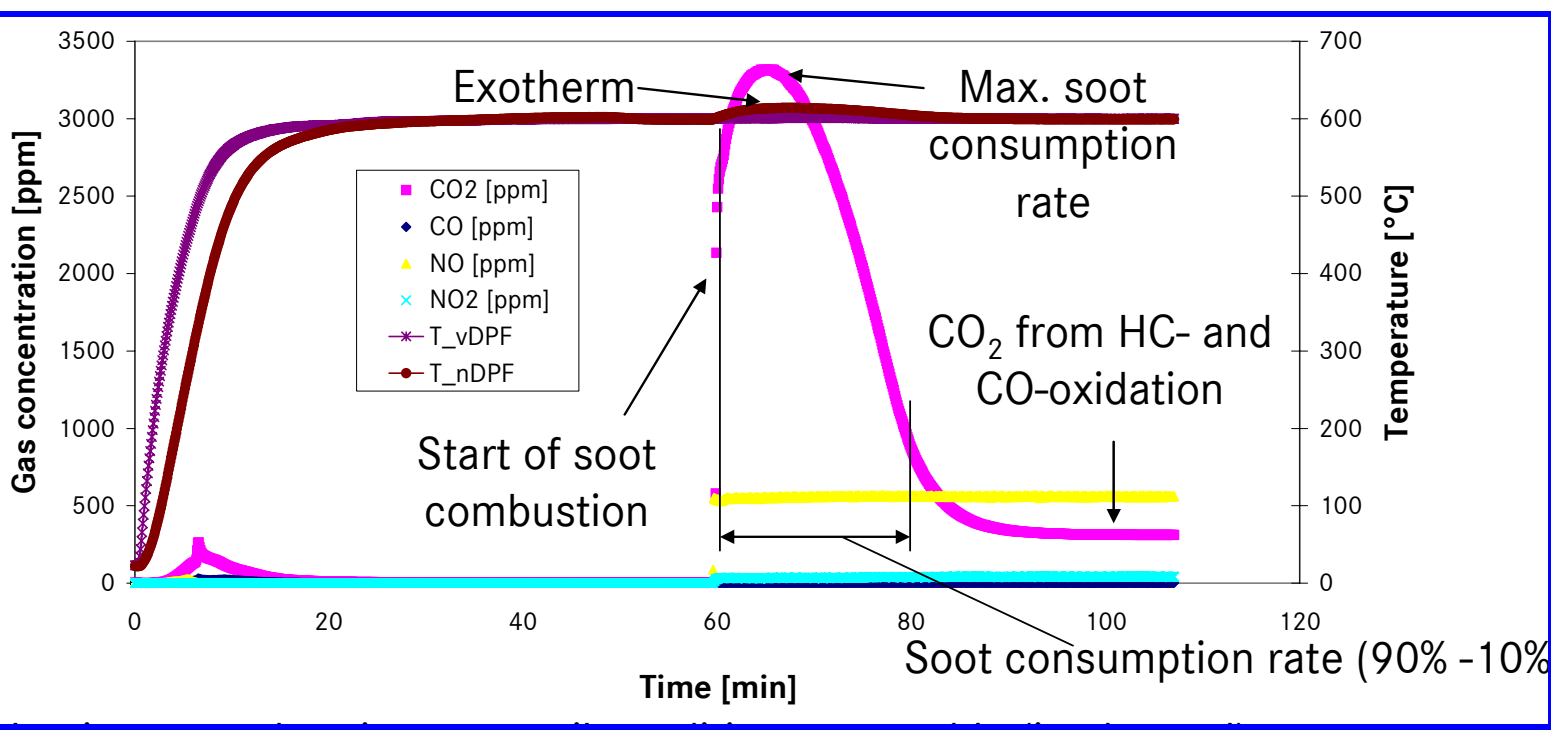

Figure 1.51 Standard tests for active regeneration

Figure 1.52 shows the soot consumption at different operating conditions. As indicated, the highest soot consumption rate at high oxygen concentration is on filters with coating 2 . Figure 1.53 shows the $\mathrm{HC}$ conversion rate. High $\mathrm{HC}$ conversions for all test points are seen with substrate 1 samples coated by both coatings and substrate 2 with coating 2 regardless of oxygen concentration, SV and soot loading. In both figures, the legend "uc" stands for uncoated, while "c" is for coated. 


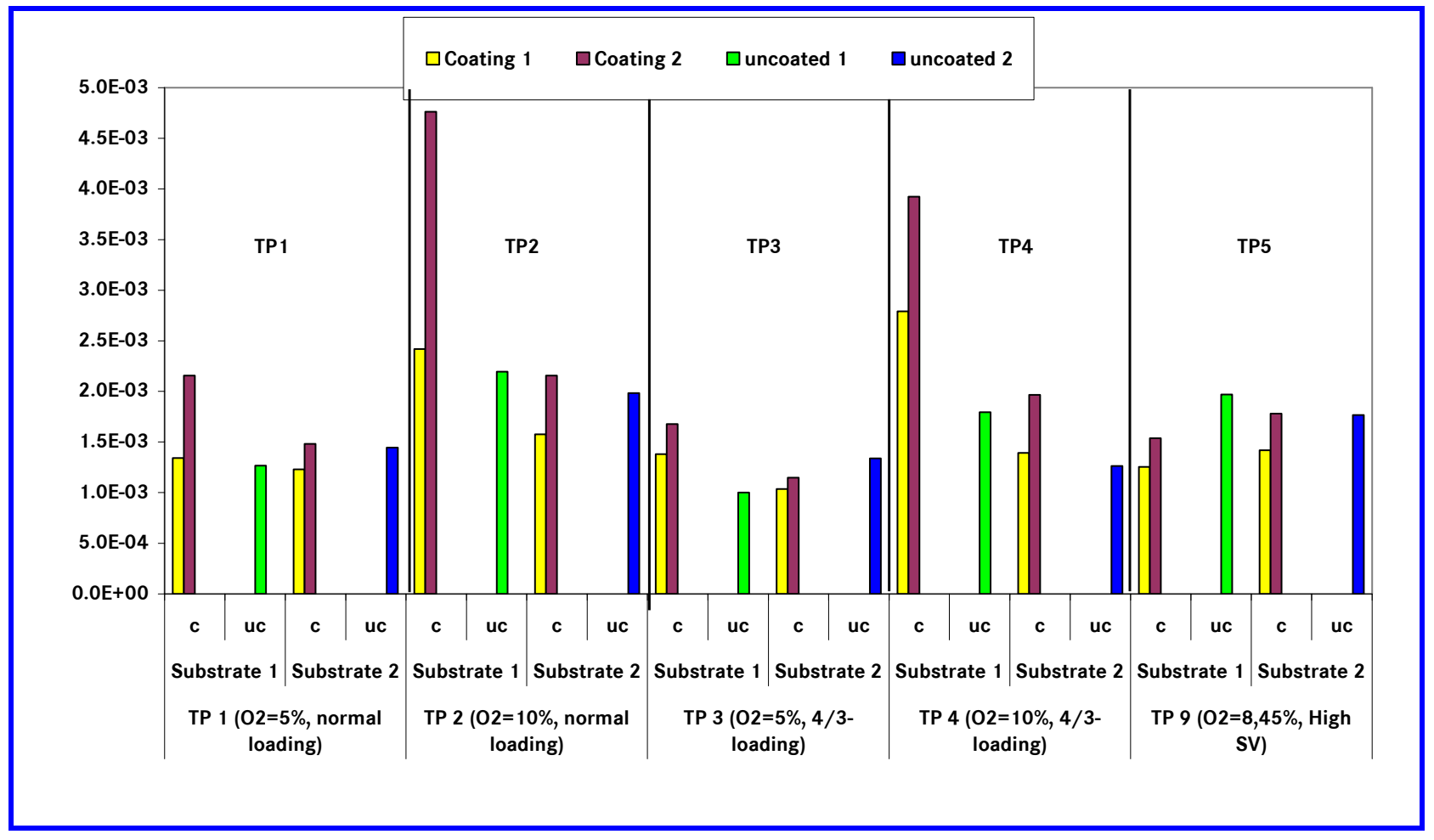

Figure 1.52 Soot consumption rate (1/s) at different operating conditions

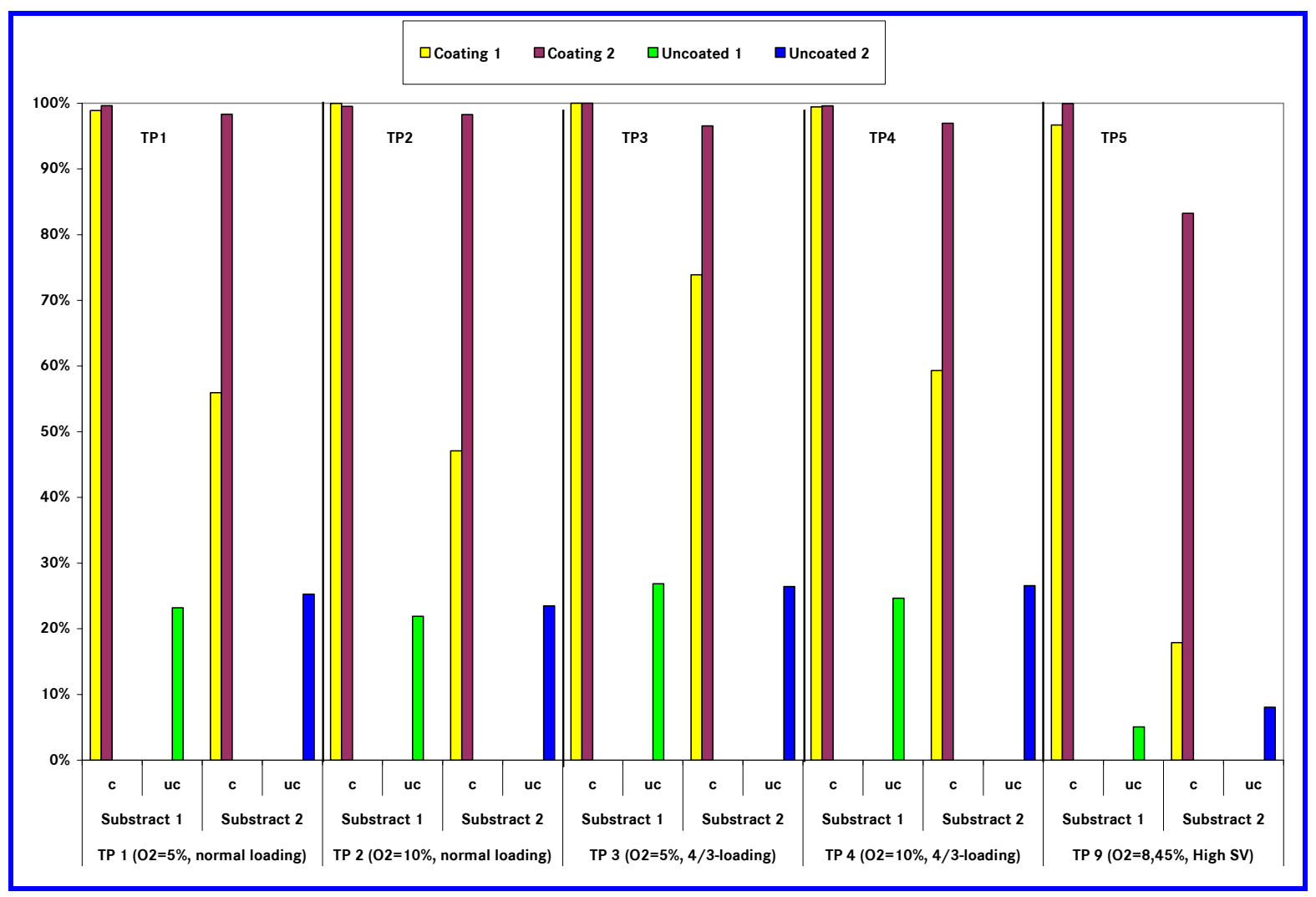

Figure 1.53 HC conversion rate 
The results from the measurements that targeted active regeneration at high temperature show:

- The maximum soot consumption rates increase with oxygen concentration for all sample types with the coating material 2 , yielding the highest rates

- No influence of substrate type, soot loading and space velocity could be observed

- The soot consumption rates (from $90 \%$ to $10 \%$ soot loading) also increase with the oxygen content and are slightly higher for substrate 1 based filters

- A benefit of the filter coatings is significant with coating 2 leading to higher consumption rates than coating 1

- The $\mathrm{HC}$ conversion is decreasing with space velocity for the substrate 2 samples 


\subsection{DPF Soot Layer Characterization and Substrate Material Assessment}

\section{Program Objectives of Soot Layer and Ash Distribution}

The program objective was aimed at advancing general understanding of wall flow type of DPF operation and behavior. More specifically, it was desired to know how soot and ash deposit in the DPF, both in cake layers and in the pore structure. Parameters that need better estimation include permeability of cake layers, change in the DPF system permeability as soot and ash deposit (and react with NO2) into pores, and spatial distribution of soot and ash. This was complicated by the high difficulty in measuring such properties, the wide variety of exhaust conditions possible, and the difficulty of understanding regeneration phenomena. Improving understanding of the structure and properties of the DPF itself was found to be an important part of the effort.

\subsection{DPF soot-loading exhaust leg/sampling system for miniature DPFs}

A pre-prototype 2007 Series 60 engine was installed at ORNL as shown in Figure 2.1. The full sized soot filter is mounted on a cart as shown on the right. A thermostatically controlled valve was added to the engine cooling system to eliminate undesired coolant temperature swings observed during engine operation. This eliminated potential for thermal shock problems and enhanced consistent operation. The propylene glycol water mixture which circulates through the engine is cooled by a liquid-liquid tower type heat exchanger using processed water for cooling. The automatic control valve gives fine control over the water flow process, so the propylene-glycol coolant entering the engine remains within tight temperature specifications (88 $\left.\pm 2{ }^{\circ} \mathrm{C}\right)$.
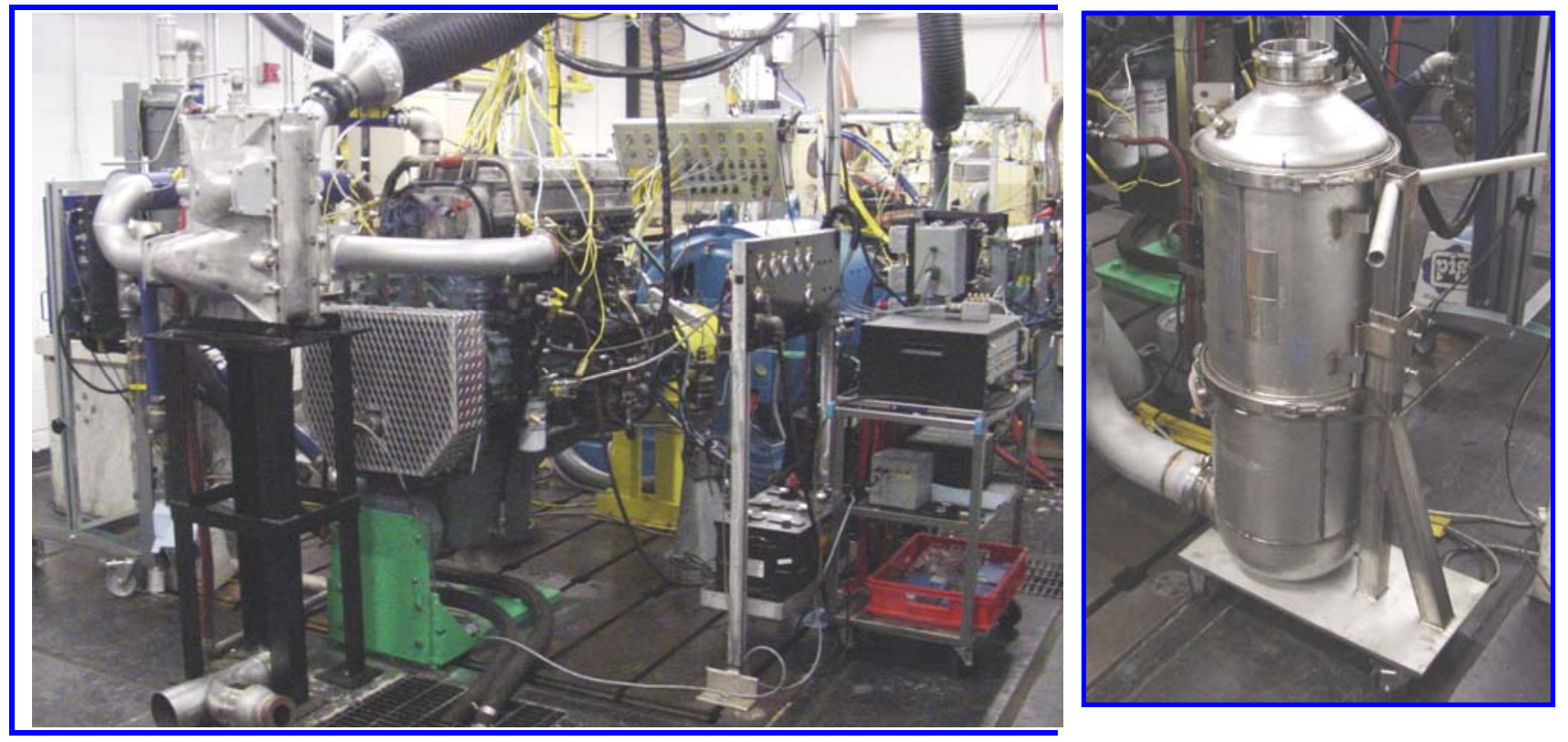

Figure 2.1 The pre-prototype 2007 engine installation

The small exhaust leg flow system is shown schematically (with the large DPF and exhaust) in Figure 2.2, and in the photographs in Figures 2.3 and 2.4. A speed-controlled positive displacement pump (blower) is the prime mover used to pull flow through the exhaust leg. 
Exhaust pulled through the small DOC and DPF is then cooled by a heat exchanger to protect the blower system and downstream components. The heat exchanger also is equipped to remove a significant amount of water by employing a peristaltic pump to remove condensate.

The total flow through the positive displacement pump can come from two sources, the exhaust leg and a mass-flow controlled dry air stream (if desired). Before the blower inlet, the exhaust can be diluted by the dry air stream with the purpose of preventing water condensation reaching the blower (which could damage the blower and skew the laminar flow element readings) and to allow higher turndown of the exhaust flow. The lower flow rates desired for the small exhaust leg might require the blower to run at excessively low speeds (which are hard on the drive motor) if no dilution gas is added. The calibrated flow rate of dilution air is subtracted from the measured total flow (measured by a laminar flow element) through the blower to obtain the exhaust flow. In the course of this work, the blower was run at very low speeds without any failures, so turndown was no longer an issue.

Note that the unused full-sized DPF was removed from the exhaust system to be preserved for possible later use. However, the large DOC was left in place and the result is the "short can" seen in Figure 2.3.

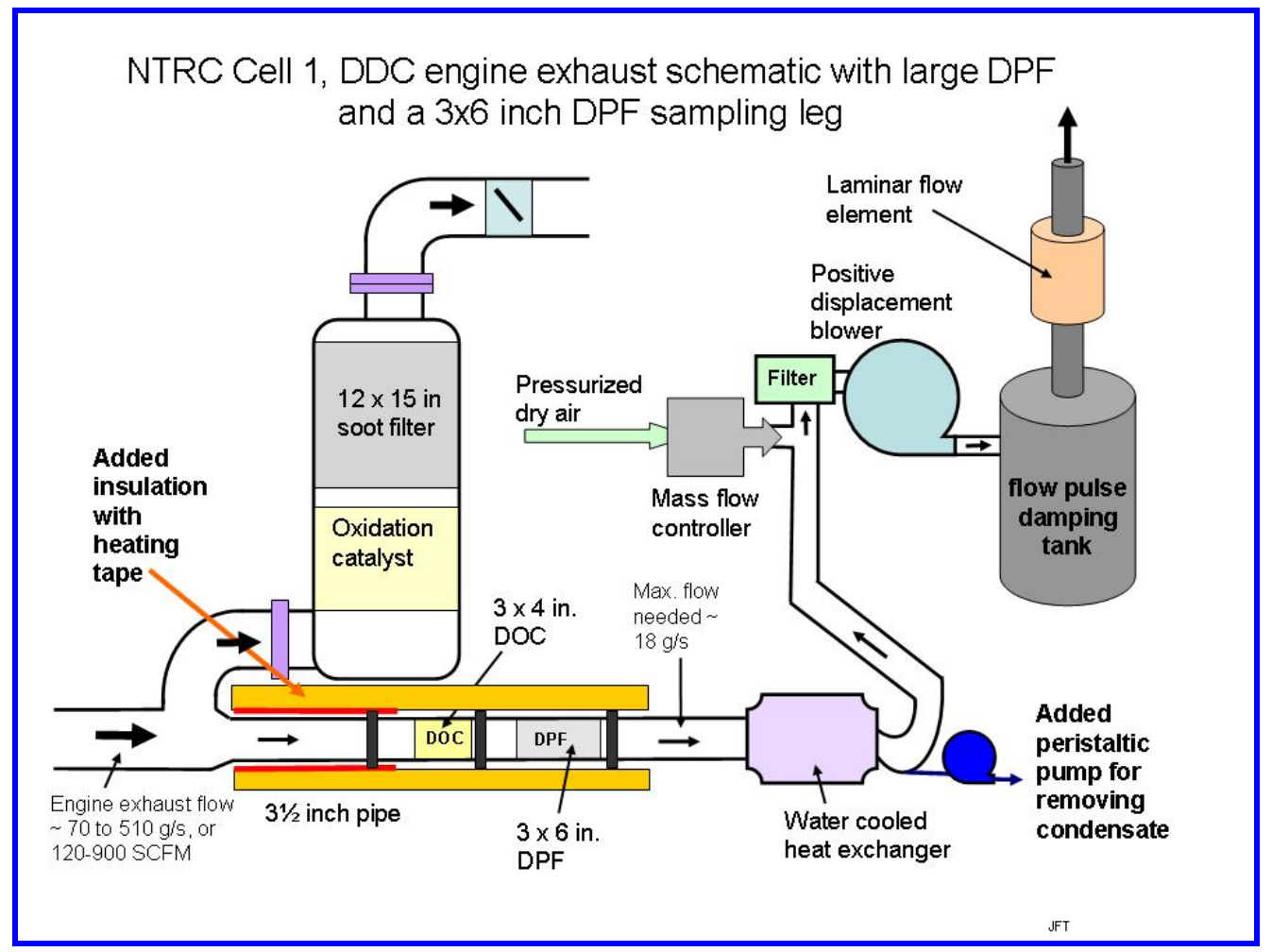

Figure 2.2 Schematic diagram of exhaust system set up with the pre-prototype 2007 DDC engine.

The system is capable of loading both full size and miniature soot filters. 


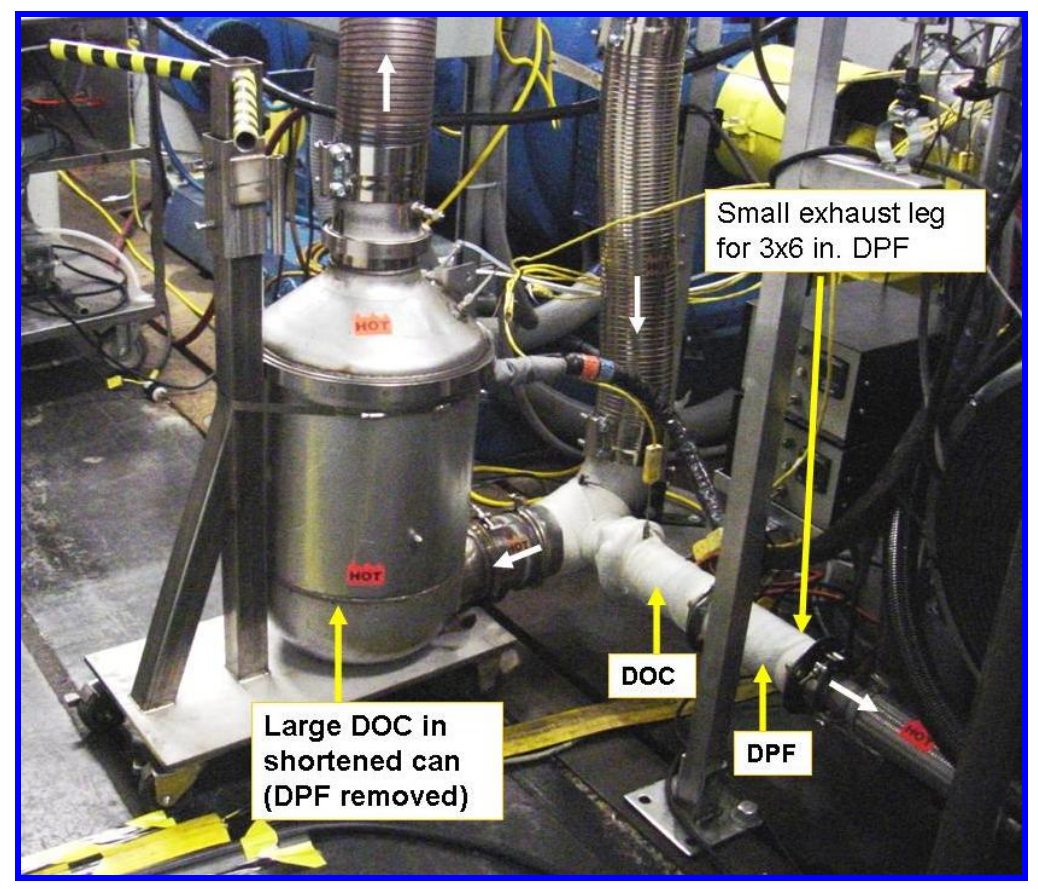

Figure 2.3 Small exhaust system branching off the main exhaust

Fig. 2.3 includes the small exhaust system branching off the main exhaust. The large DPF had been removed and only the large DOC is in place. The white arrows show the direction of exhaust flow.

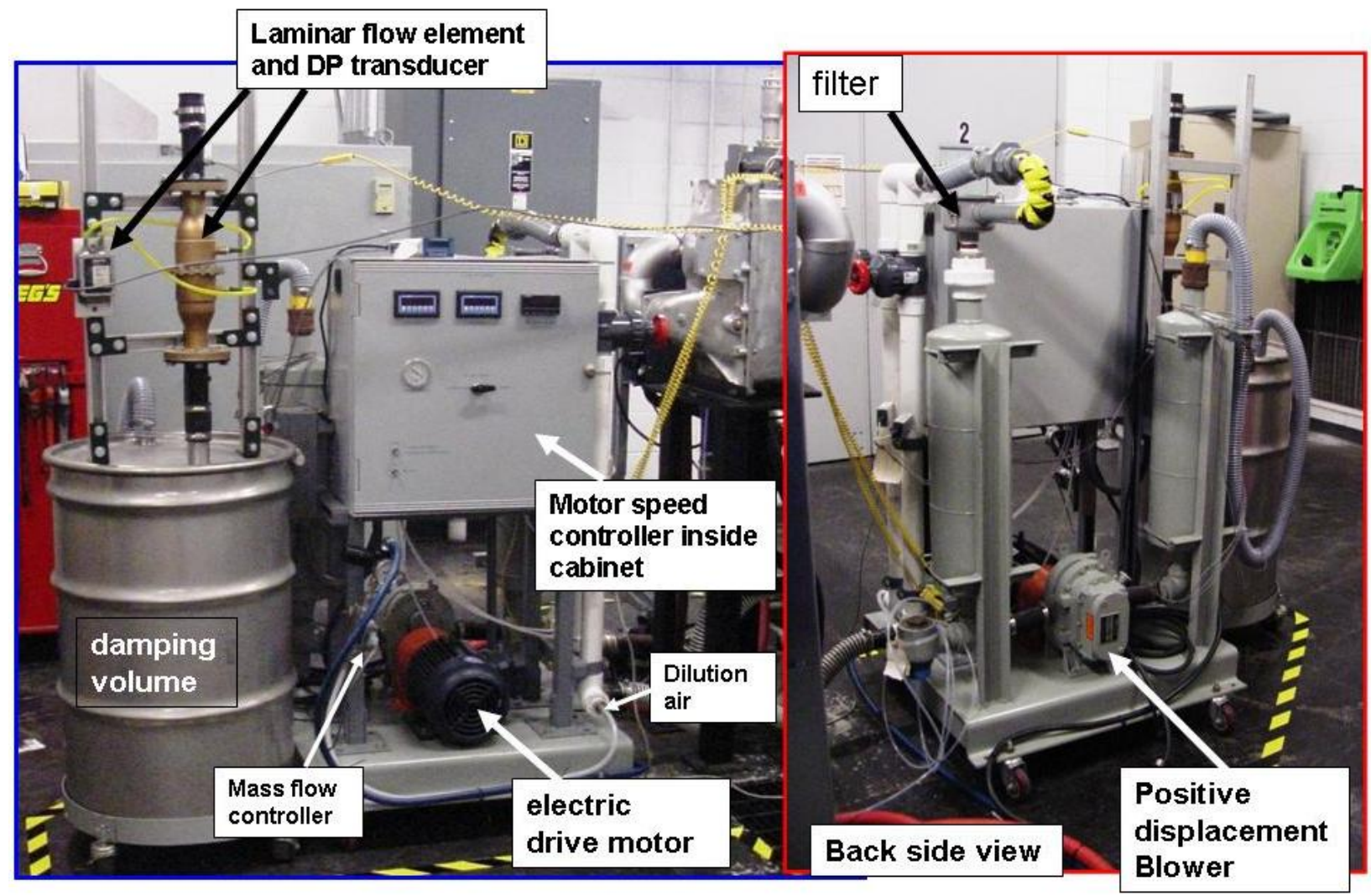

Figure 2.4 Front and back view of the blower system and flow measurement system. 


\subsection{Engine exhaust and PM characterization}

This section covers the characterization of exhaust gases and PM from the 2007 DDC engine.

The engine was operated at the set points selected as follows:

1) $1200 \mathrm{rpm}, 20 \%$ load,

2) $1500 \mathrm{rpm}, 40 \%$ load

3) $1800 \mathrm{rpm}, 100 \%$ load.

The PM was quantified in the ways listed below for the three chosen engine conditions.

1) Mass quantity was measured by standard filter methods.

2) AVL smoke meter - we found the smoke meter did not correlate accurately with the filter method but gave good trending. We decided that only the filter based numbers were reliable for reporting.

3) The PM SOF content was measured by a standard $\mathrm{CO} 2$ extraction method.

4) An SMPS (TSI Inc., Model 3934) instrument was also used to examine PM size distribution.

5) PM was also characterized to some extent by TEM imaging of PM collected on EM grids.

The details of the SMPS measurements are given in the following section. A brief summary of findings is given in Table 2.1.

Table 2.1 Exhaust soot characteristics at selected engine conditions.

\begin{tabular}{|c|c|c|c|}
\hline & PM & averaged & Volumetric \\
\hline ExxonMobil \& DDC Fuel & Conc. & SOF & $\mathrm{d}_{\mathrm{g}}$ \\
\hline Engine set-point & $(\mathrm{mg} / \mathrm{m} 3)$ & $(\%)$ & $(\mathrm{nm})$ \\
\hline $1200 \mathrm{rpm} @ 20 \%$ load & $9-14$ & 24.0 & 107 \\
\hline $1500 \mathrm{rpm} @ 40 \%$ load & $19-25$ & 24.9 & 155 \\
\hline $1800 \mathrm{rpm} @ 100 \%$ load & $54-67$ & 12.7 & 525 \\
\hline \multicolumn{4}{|c|}{ B20 Fuel } \\
\hline $1500 \mathrm{rpm} @ 40 \%$ load & $29-32$ & 14.0 & 146 \\
\hline
\end{tabular}

Note that $d_{g}$ is a volume weighted characteristic mean diameter discussed in the next section. Also SOF shown in this Table had much scatter in the data for each filter processed. The SOF is for soot collected before passing through the DOC.

\section{SMPS Results}

PM size distribution measurements were obtained for the 3 engine set-points outlined earlier. A TSI Inc. Scanning Mobility Particle Sizer (SMPS) was used to obtain size distributions in dilute exhaust. Results from the SMPS are given in Figures 2.5 and 2.6 and Tables 2.2 and 2.4. In Figure 2.5, the number-based diameter distributions are shown. This means the largest number of individual particles detected is represented by the peak of the curve, which is essentially a histogram. The curve peak values are near 50,60-65 and $70-80$ for the condition 1,2 and 3 respectively, showing size increasing as load (or power) increases. This agrees very well with the particle number based, mean diameter values given in Table 2.2.

Figure 2.6 illustrates a different way to look at the data. In this case the volumetric based diameter distribution is plotted. This volume based distribution is similar to a mass distribution, if the densities of the particles are uniform in size. The contrast between the different engine 
conditions becomes much more obvious for this metric. What is striking about Figure 2.6 and Table 2.3 (volume table) is how large the particles grow with increasing load. It appears that the use of EGR at the high power conditions can cause significant particle growth. The presence of these very large particles (agglomerates for this case) implies that a different type of soot cake may form under high power conditions than under lower power conditions which have higher numbers of smaller particles.

A small amount of data was taken at the $40 \%$ load condition with B20 fuel. The size distribution appeared to unchanged for B0 and B20 fuels.

It should be noted that in reality, the density of a diesel soot particle is a function of its mobility diameter. Thus, the larger particles formed at the high power condition may make a "fluffier" soot cake than an engine condition with fewer large particles. Of course this is conjecture based on limited data.

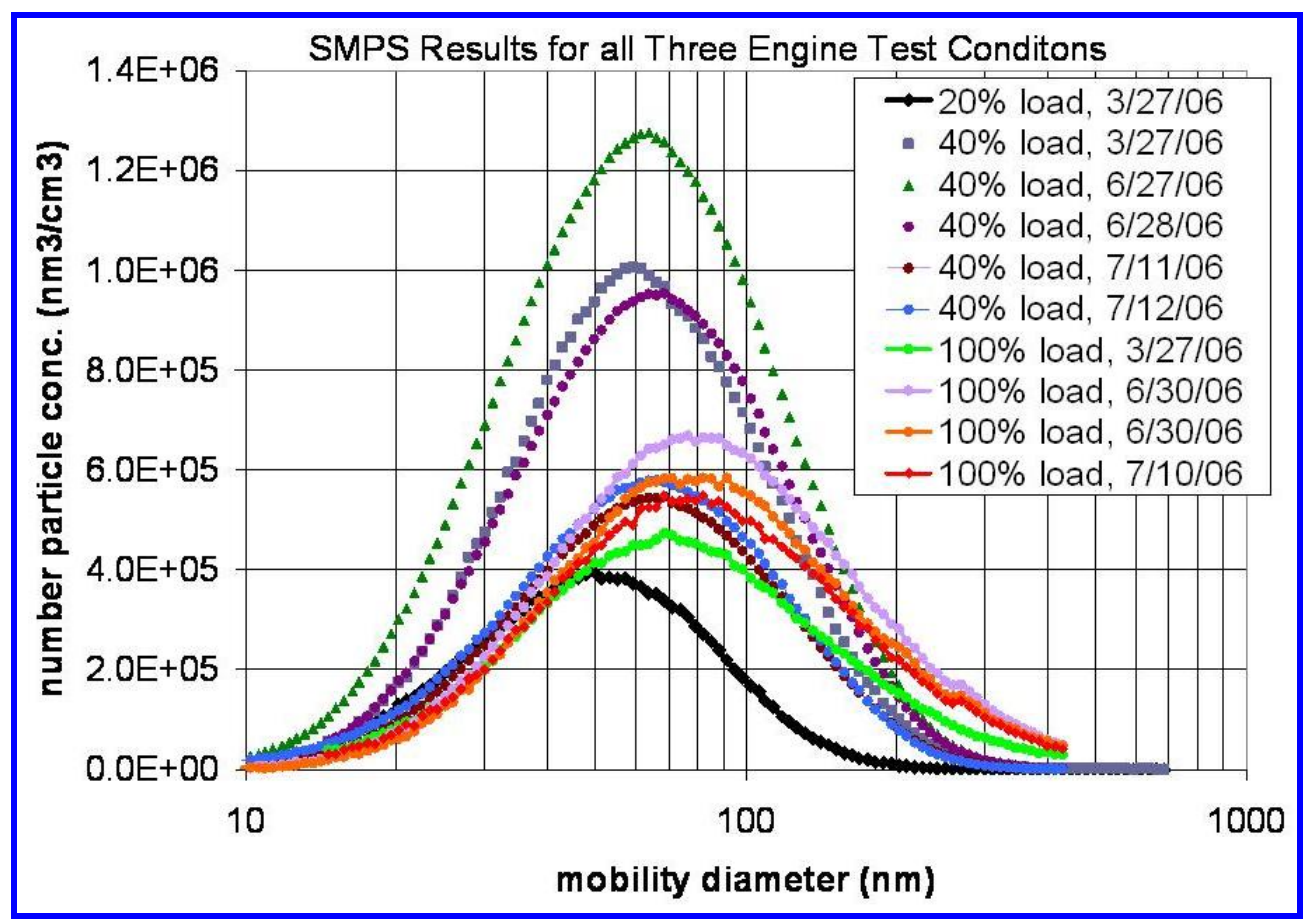

Figure 2.5 SMPS particle number based geometric mean mobility diameter

Figure 2.5 shows the average agglomerate size increased with load. 


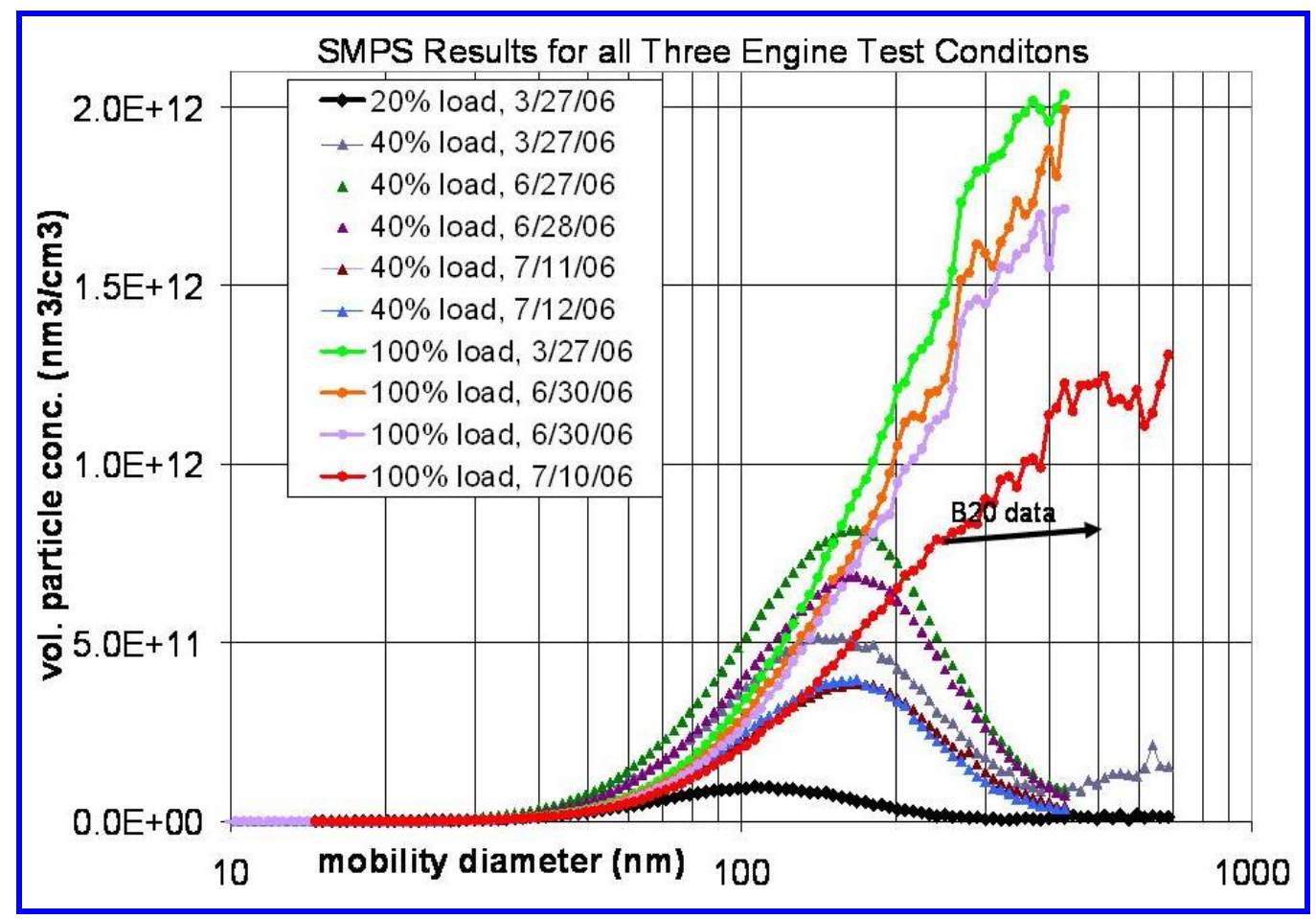

Figure 2.6 SMPS particle volume based geometric mean mobility diameter

Figure 2.6 shows a very distinct weighting towards larger agglomerates as load increases. Table 2.2 SMPS results for particle number concentration

\begin{tabular}{|c|c|c|c|c|c|c|c|c|c|}
\hline ID & $\underset{\left(\mathrm{mg} / \mathrm{m}^{3}\right)}{\mathrm{M}_{\text {total }}}$ & $\begin{array}{c}\mathrm{C}_{\text {total }} \\
\left(\# / \mathrm{cm}^{3}\right)\end{array}$ & $\begin{array}{c}\mathrm{d}_{\mathrm{g}} \\
(\mathrm{nm})\end{array}$ & $\begin{array}{c}\mathrm{C}_{\mathrm{Max}} \\
\left(\# / \mathrm{cm}^{3}\right) \\
\text { at } \mathrm{d}_{\mathrm{g}}\end{array}$ & $\sigma_{g}$ & $\mathrm{R}^{2}$ & Condition & $\begin{array}{l}\text { Dilution } \\
\text { ratio }\end{array}$ & \\
\hline Cond1(3/27) & 3.2 & $1.5 \mathrm{E}+07$ & & & & & 1 & 15.6 & Measured \\
\hline Cond2(3/27) & 19.5 & $4.0 \mathrm{E}+07$ & & & & & 2 & 15.6 & Measured \\
\hline Cond2(6/27) & 26.6 & $5.6 \mathrm{E}+07$ & & & & & 2 & 13.5 & Measured \\
\hline Cond2(6/28) & 22.1 & $4.1 \mathrm{E}+07$ & & & & & 2 & 13.7 & Measured \\
\hline Cond2(7/11) & 12.4 & $2.3 E+07$ & & & & & 2 & 19.4 & Measured \\
\hline Cond2(7/12) & 12.3 & $2.5 \mathrm{E}+07$ & & & & & 2 & 19.3 & Measured \\
\hline Cond3(3/27) & 44.8 & $2.2 \mathrm{E}+07$ & & & & & 3 & 15.6 & Measured \\
\hline Cond3_1(6/30) & 53.9 & $3.2 \mathrm{E}+07$ & & & & & 3 & 13.5 & Measured \\
\hline Cond3_2(6/30) & 47.2 & $2.8 \mathrm{E}+07$ & & & & & 3 & 20.2 & Measured \\
\hline Cond3(7/10) & 43.5 & $2.6 \mathrm{E}+07$ & & & & & 3 & 19.8 & Measured \\
\hline Cond1(fit;3/27) & 4.0 & $1.5 \mathrm{E}+07$ & 49.1 & $3.9 \mathrm{E}+05$ & 1.76 & 1.00 & 1 & 15.6 & Fitted \\
\hline Cond2(fit;3/27) & 21.2 & $4.0 \mathrm{E}+07$ & 60.4 & $1.0 \mathrm{E}+06$ & 1.79 & 1.00 & 2 & 15.6 & Fitted \\
\hline Cond2(fit;6/27) & 34.7 & $5.6 \mathrm{E}+07$ & 60.5 & $1.3 \mathrm{E}+06$ & 1.88 & 1.00 & 2 & 13.5 & Fitted \\
\hline Cond2(fit;6/28) & 28.1 & $4.1 E+07$ & 64.1 & $9.6 \mathrm{E}+05$ & 1.85 & 1.00 & 2 & 13.7 & Fitted \\
\hline Cond2(fit;7/11) & 15.7 & $2.3 E+07$ & 64.4 & $5.4 \mathrm{E}+05$ & 1.84 & 1.00 & 2 & 19.4 & Fitted \\
\hline Cond2(fit;7/12) & 16.8 & $2.5 E+07$ & 63.6 & $5.8 \mathrm{E}+05$ & 1.86 & 1.00 & 2 & 19.3 & Fitted \\
\hline Cond3(fit;3/27) & 31.7 & $2.2 \mathrm{E}+07$ & 70.5 & $4.6 \mathrm{E}+05$ & 2.01 & 1.00 & 3 & 15.6 & Fitted \\
\hline Cond3_1(fit;6/30) & 48.3 & $3.2 \mathrm{E}+07$ & 80.8 & $6.6 \mathrm{E}+05$ & 1.99 & 1.00 & 3 & 13.5 & Fitted \\
\hline Cond3_2(fit;6/30) & 40.8 & $2.8 \mathrm{E}+07$ & 80.1 & $5.9 \mathrm{E}+05$ & 1.98 & 1.00 & 3 & 20.2 & Fitted \\
\hline Cond3(fit;7/10) & 39.2 & $2.6 \mathrm{E}+07$ & 78.6 & $5.4 \mathrm{E}+05$ & 2.02 & 1.00 & 3 & 19.8 & Fitted \\
\hline
\end{tabular}


Table 2.3 SMPS results for volume weighted particle concentration

\begin{tabular}{|c|c|c|c|c|c|c|c|c|c|}
\hline ID & $\begin{array}{c}V_{\text {total }} \\
\left(\mathrm{ml} / \mathrm{m}^{3}\right)\end{array}$ & $\begin{array}{c}V_{\text {total }} \\
\left(\mathrm{nm}^{3} / \mathrm{cm}^{3}\right)\end{array}$ & $\begin{array}{c}\mathrm{d}_{\mathrm{g}} \\
(\mathrm{nm})\end{array}$ & $\begin{array}{c}\mathrm{V}_{\mathrm{Max}} \\
\left(\mathrm{nm}^{3} / \mathrm{cm}^{3}\right) \\
\text { at d } \mathrm{d}_{\mathrm{g}} \\
\end{array}$ & $\sigma_{g}$ & $\mathrm{R}^{2}$ & Condition & $\begin{array}{l}\text { Dilution } \\
\text { ratio }\end{array}$ & \\
\hline Cond1(3/27/07) & & & 108 & & & & & & \\
\hline Cond2(4/10/07) & & & 146 & & & & 2 & 14 & \\
\hline Cond1(3/27) & 3.2 & $3.3 \mathrm{E}+12$ & & & & & 1 & 15.6 & Measured \\
\hline Cond2(3/27) & 19.5 & $2.0 \mathrm{E}+13$ & & & & & 2 & 15.6 & Measured \\
\hline Cond2(6/27) & 26.6 & $2.8 \mathrm{E}+13$ & & & & & 2 & 13.5 & Measured \\
\hline Cond2(6/28) & 22.1 & $2.4 \mathrm{E}+13$ & & & & & 2 & 13.7 & Measured \\
\hline Cond2(7/11) & 12.3 & $1.2 \mathrm{E}+13$ & & & & & 2 & 19.4 & Measured \\
\hline Cond2(7/12) & 12.3 & $1.2 \mathrm{E}+13$ & & & & & 2 & 19.3 & Measured \\
\hline Cond3(3/27) & 44.8 & $4.5 \mathrm{E}+13$ & & & & & 3 & 15.6 & Measured \\
\hline Cond3_1(6/30) & 53.8 & $5.4 \mathrm{E}+13$ & & & & & 3 & 13.5 & Measured \\
\hline Cond3_2(6/30) & 47.2 & $4.7 \mathrm{E}+13$ & & & & & 3 & 20.2 & Measured \\
\hline Cond3(7/10) & 43.4 & $4.3 \mathrm{E}+13$ & & & & & 3 & 19.8 & Measured \\
\hline Cond1(fit;3/27) & 3.0 & $3.0 \mathrm{E}+12$ & 106.8 & $9.3 \mathrm{E}+10$ & 1.59 & 0.97 & 1 & 15.6 & Fitted \\
\hline Cond2(fit;3/27) & 18.5 & $1.8 \mathrm{E}+13$ & 150.0 & $5.0 \mathrm{E}+11$ & 1.71 & 0.94 & 2 & 15.6 & Fitted \\
\hline Cond2(fit;6/27) & 26.2 & $2.6 \mathrm{E}+13$ & 155.4 & $8.0 \mathrm{E}+11$ & 1.61 & 1.00 & 2 & 13.5 & Fitted \\
\hline Cond2(fit;6/28) & 21.8 & $2.2 \mathrm{E}+13$ & 159.8 & $6.7 \mathrm{E}+11$ & 1.61 & 1.00 & 2 & 13.7 & Fitted \\
\hline Cond2(fit;7/11) & 12.2 & 1.2E+13 & 158.4 & $3.8 \mathrm{E}+11$ & 1.60 & 1.00 & 2 & 19.4 & Fitted \\
\hline Cond2(fit;7/12) & 12.1 & $1.2 \mathrm{E}+13$ & 152.1 & $3.9 \mathrm{E}+11$ & 1.58 & 0.99 & 2 & 19.3 & Fitted \\
\hline Cond3(fit;3/27) & 45.1 & $4.5 \mathrm{E}+13$ & 613.2 & $1.2 \mathrm{E}+12$ & 2.63 & 1.00 & 3 & 15.6 & Fitted \\
\hline Cond3_1(fit;6/30) & 53.9 & $5.4 \mathrm{E}+13$ & 455.0 & $2.1 \mathrm{E}+12$ & 2.19 & 1.00 & 3 & 13.5 & Fitted \\
\hline Cond3_2(fit;6/30) & 47.4 & $4.7 \mathrm{E}+13$ & 531.9 & $2.0 \mathrm{E}+12$ & 2.34 & 1.00 & 3 & 20.2 & Fitted \\
\hline Cond3(fit;7/10) & 43.5 & $4.4 \mathrm{E}+13$ & 499.8 & $1.7 \mathrm{E}+12$ & 2.28 & 1.00 & 3 & 19.8 & Fitted \\
\hline
\end{tabular}

\subsection{Miniature DPF PM-loading experiments}

Miniature DPFs and DOC catalysts were used to carry out certain soot-loading experiments and other DPF testing. These included $3 \times 4$ inch DOC cores, $1 \times 3$ inch DPFs, and $3 \times 6$ inch DPFs. Photographs of these and their respective exhaust holders or cans are shown in Figure 2.7.
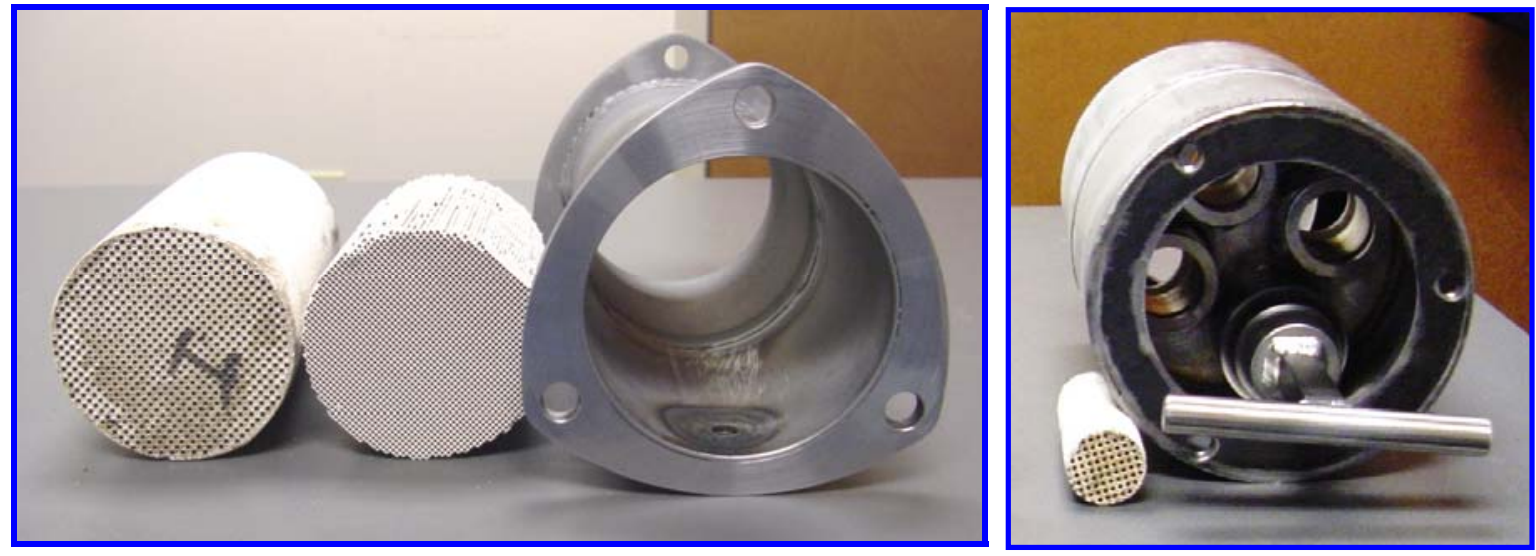

Figure 2.7 Miniature DPF and filter holder 
In Figure 2.7, from left to right; a $3 \times 6$ inch soot filter, a $3 \times 4$ inch DOC, and a holder "can" to be used to mount them into the exhaust. The filter and the DOC will each be fit into a separate holder. Further to the right are a $1 \times 3$ inch soot filter and a holder designed to mount up to $41 \times 3$ inch soot filters in an exhaust stream

The research goals include improved understanding and quantification of DPF loading behavior, including pressure drop $(\Delta \mathrm{P})$, soot distribution in the filters, soot layer density, soot density in pores and cracks (in the filter walls and washcoat), and resultant permeability of the soot deposits. The $3 \times 6$ inch DPFs were obtained for this purpose. The $1 \times 3$ inch DPFs were obtained mainly to use in bench flow reaction kinetic experiments.

\section{Soot-Loading $3 \times 6$ Inch Soot Filters}

The goal was to load a set of $3 \times 6$ soot filters using the 6-point test matrix (with the engine conditions discussed before) below as a guideline. $\Delta P$ data could be gleaned and soot-loaded DPFs could be examined by EM techniques to characterize soot distribution and a number of soot related properties. Table 2.4 is the initial test matrix for soot loading.

Table 2.4 Initial test matrix for soot filter loading

\begin{tabular}{|ll|}
\hline Engine condition & Soot loading level for characterization \\
1. 1200rpm, 20\%load & $1 \mathrm{~g} /$ /iter \\
2. $1500 \mathrm{rpm}, 40 \%$ load & $1 \mathrm{~g} /$ liter, $3 \mathrm{~g} /$ /iter, $5 \mathrm{~g} / \mathrm{liter}$ \\
3. $1800 \mathrm{rpm}, 100 \%$ load & $1 \mathrm{~g} /$ /liter, $3 \mathrm{~g} /$ /iter \\
\hline
\end{tabular}

A method of mounting the $3 \times 6$ inch filters in a can was developed during the course of the program. A ceramic fiber mat was found that works well, allowing the filters to be wrapped (two layer thick) and pressed tightly into the can without using tape or other material (which subsequently burns or vaporizes when exposed to the hot exhaust temperatures) to hold the mat in place. The loaded filters can be pressed back out of the cans after loading without damage and no evidence of soot leakage through the packing was ever observed (the downstream exhaust surfaces had virtually no carbon on them). Photographs of a loaded filter and the mat material are presented in Figure 2.8. 


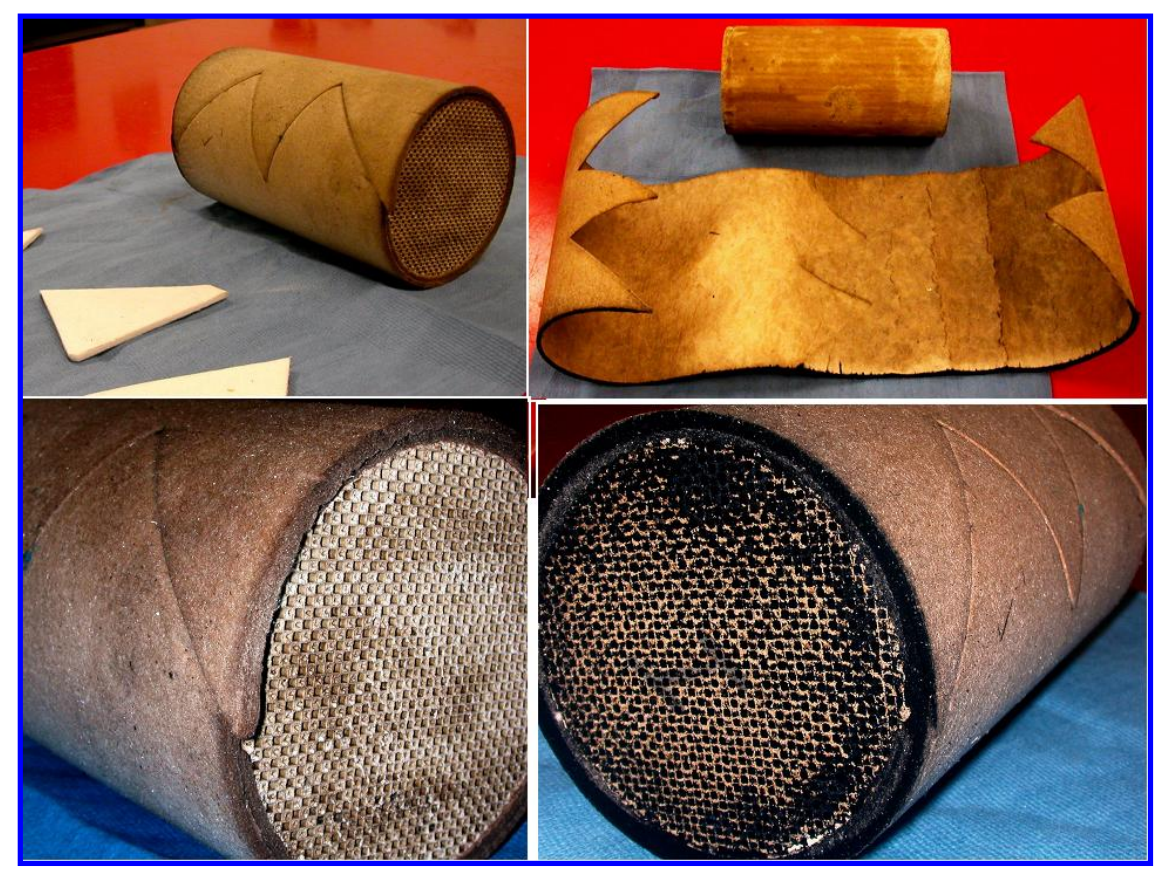

Figure $2.83 \times 6$ inch filter removed from the can after loading.

In Figure 2.8, the original color of the packing material is shown by the scraps in the upper left photograph. Inspection of the visible zig-zag seam in the packing material showed no evidence of PM deposits or any gas/PM bypassing of the filter. The inlet and outlet of the filter are shown in the lower photographs.

Soot was loaded onto DPFs using an ExxonMobil ULSD fuel. An additional eight DPFs were loaded with a standard ULSD supplied by DDC. Fuel property estimates for both fuels are given in Table 2.5. A test data summary for loading the soot filters is given in Table 2.6. The actual mass collected for the first filter (SG80415) loaded is very much in doubt, due to lack of understanding of the moisture problem at the ORNL facility at that time. The mass value of collected PM is certainly underestimated.

It became apparent that the soot filters can adsorb a significant mass of moisture which will inhibit accurate weighing. It was observed that a 3x6 inch DPF heated and weighed by this method can gain up to $1.5 \mathrm{~g}$ if left in the open air for a few days. Because it intends to measure soot quantities of a few tenths of a gram, this moisture problem is quite important.

Table 2.5 Properties of 2007 Certification Fuel (Haltermann) and ExxonMobil ULSD.

\begin{tabular}{|l|c|c|c|c|c|c|c|c|c|}
\hline Fuel & Sulfur & Aromatics & Olefins & $\begin{array}{c}\text { Paraffins } \\
\text { saturates }\end{array}$ & LHV & Cetane & carbon & hydrogen & $\begin{array}{c}\text { H:C } \\
\text { mole }\end{array}$ \\
\hline & ppm & wt. \% & wt. \% & wt. \% & btu/lb & number & wt. \% & wt. \% & ratio \\
\hline $\begin{array}{l}\text { ExxonMobil } \\
\text { ULSD, 05-2119 }\end{array}$ & 15 & 29.9 & 2.0 & 68.1 & 18345 & 50.5 & 86.62 & 12.93 & 1.78 \\
\hline $\begin{array}{l}\text { Paltermann Ltd., } \\
\text { UF1921LS10 }\end{array}$ & 11 & 29.5 & 2.2 & 68.3 & 18421 & 43.0 & 85.90 & 13.60 & 1.89 \\
\hline
\end{tabular}


Table 2.6 Summary of important quantities for experimental loading of $3 \times 6$ inch soot filters.

\begin{tabular}{|c|c|c|c|c|c|c|c|c|}
\hline \multicolumn{9}{|l|}{ Item or measurement } \\
\hline Test date & $6 / 21 / 06$ & $\begin{array}{l}6 / 27 \& \\
6 / 28 / 06\end{array}$ & $6 / 30 / 2006$ & 7/10/06 & 7/11/06 & 7/12/06 & $8 / 2 / 06$ & $\begin{array}{l}8 / 22 \& \\
8 / 23 / 06\end{array}$ \\
\hline Filter number & SG80415 & SG80411 & SG80414 & SG80413 & SG80407 & SG80408 & SG80409 & SG80403 \\
\hline Fuel & E-M & E-M & E-M & E-M & E-M & E-M & $\mathrm{DDC}$ & $\mathrm{DDC}$ \\
\hline Engine speed (rpm) & 1500 & 1500 & 1800 & 1800 & 1500 & 1500 & 1500 & 1200 \\
\hline Load (N-m) & 815 & 822 & 1590 & 1583 & 826 & 816 & 831 & 305 \\
\hline $\begin{array}{l}\text { Typical AVL smoke meter } \\
\text { reading }(\mathrm{mg} / \mathrm{m} 3)\end{array}$ & 42 & 31 & 140 & 130 & 31 & 33 & 32 & 11 \\
\hline $\begin{array}{l}\text { PM concentration from } \\
\text { standard filter method }(\mathrm{mg} / \mathrm{m} 3)\end{array}$ & -- & 22 & 59 & 54 & 20.7 & 19.4 & 20.3 & 9.9 \\
\hline Soluble organic fraction (\%) & & 18.8 & 12.2 & 9.4 & 13.7 & 26.4 & -- & -- \\
\hline DPF inlet temperature $\left({ }^{\circ} \mathrm{C}\right)$ & 368 & 347 & 364 & 358 & 345 & 356 & 346 & 282 \\
\hline DPF outlet temperature $\left({ }^{\circ} \mathrm{C}\right)$ & 353 & 344 & 370 & 362 & 336 & 342 & 324 & 256 \\
\hline DPF filtration time (minutes) & 115 & 567 & 40 & 18 & 225 & 92 & 42 & 420 \\
\hline DPF gas mass flow (g/min.) & 336 & 348 & 618 & 367 & 343 & 354 & 301 & 193.2 \\
\hline $\begin{array}{l}\text { Space Velocity at inlet } \\
\text { temperature }(1 / \mathrm{h})\end{array}$ & 52703 & 52797 & 96331 & 56667 & 51871 & 54487 & 45593 & 26238 \\
\hline Possible EM examination & NO & YES & YES & YES & YES & TBD & TBD & TBD \\
\hline measured mass gain $(\mathrm{g})$ & 0.14 * & 1.34 & 1.57 & 0.66 & 1.01 & 0.44 & 0.08 & 0.47 \\
\hline measured loading (g/liter) & 0.20 * & 1.93 & 2.26 & 0.95 & 1.45 & 0.63 & 0.12 & 0.68 \\
\hline estimated exposure (g) & 1.7 & 3.62 & 1.22 & 0.30 & 1.33 & 0.53 & 0.21 & 0.67 \\
\hline
\end{tabular}

\section{Table 2.6 (continued) Summary of important quantities for experimental loading} of $3 \times 6$ inch soot filters.

\begin{tabular}{|c|c|c|c|c|}
\hline \multicolumn{5}{|l|}{ Item or measurement } \\
\hline Test date & $9 / 8 / 06$ & $9 / 26 / 06$ & $10 / 6 / 06$ & $10 / 9 / 06$ \\
\hline Filter number & SG80404 & SG80410 & SG80401 & SG80400 \\
\hline Fuel & DDC & DDC & DDC & DDC \\
\hline Engine speed (rpm) & 1800 & 1500 & 1500 & 1500 \\
\hline Load (N-m) & 1551 & 808 & & \\
\hline $\begin{array}{l}\text { Typical AVL smoke meter } \\
\text { reading }(\mathrm{mg} / \mathrm{m} 3)\end{array}$ & 138 & 34 & 24 & 30 \\
\hline $\begin{array}{l}\text { PM concentration from } \\
\text { standard filter method }(\mathrm{mg} / \mathrm{m} 3)\end{array}$ & 55 & $\begin{array}{c}20 \\
\text { estimate }\end{array}$ & $\begin{array}{c}20 \\
\text { estimate }\end{array}$ & $\begin{array}{l}20 \\
\text { estimate }\end{array}$ \\
\hline Soluble organic fraction (\%) & -- & & & \\
\hline DPF inlet temperature $\left({ }^{\circ} \mathrm{C}\right)$ & 366 & 361 & 340 & 333 \\
\hline DPF outlet temperature $\left({ }^{\circ} \mathrm{C}\right)$ & 354 & 360 & 314 & 322 \\
\hline DPF filtration time (minutes) & 103 & 95 & 23 & 297 \\
\hline DPF gas mass flow (g/min.) & 603 & 404 & 349 & 340 \\
\hline $\begin{array}{l}\text { Space Velocity at inlet } \\
\text { temperature }(1 / \mathrm{h})\end{array}$ & 94288 & 62677 & 52351 & 50418 \\
\hline Possible EM examination & $\mathrm{NO}$ & TBD & YES & $\mathrm{NO}$ \\
\hline measured mass gain $(\mathrm{g})$ & 2.72 & 0.60 & 0.26 & 1.62 \\
\hline measured loading (g/liter) & 3.91 & 0.86 & 0.37 & 2.33 \\
\hline estimated exposure (g) & 2.85 & 0.64 & 0.13 & 1.68 \\
\hline
\end{tabular}

The second filter in Table 2.6 was heated slowly to dryness using heating tape and wrapping the filter in insulation. Thermocouples were placed near the geometric center and monitored 
until they exceeded $110^{\circ} \mathrm{C}$. This was dropped in favor of using a small oven and heating to $120^{\circ} \mathrm{C}$ for at least $2 \mathrm{hrs}$. Weighing is done while they are hot (before water re-adsorption). This is done both before and after the filter is loaded with soot.

\subsection{Pressure Drop Behavior}

\section{Pressure drop peaking behavior for the $40 \%$ engine load condition}

In the course of carrying out this work, unexpected $\Delta P$ behavior was observed when loading soot filters at the $1500 \mathrm{rpm}, 40 \%$ load point. The $\Delta \mathrm{P}$ appears to peak after loading the filter for about 40 minutes. Figure 2.9 gives the $\Delta \mathrm{P}$ results and other data for four filters loaded at the $1500 \mathrm{rpm}$ condition. Using the standard filter data mass results, it is estimated that the $3 \times 6$ inch DPF is exposed to about $5.2 \mathrm{mg} /$ minute of PM or about $0.21 \mathrm{~g}$ of PM during the first 40 minutes of loading. This would be a PM loading of about $0.29 \mathrm{~g} /$ liter for the DPF - a small amount of PM to make a large increase in $\Delta \mathrm{P}$. It was understood later that this is common but troublesome behavior for the heavily catalyzed filters. Figure 2.10 repeats the $\Delta P$ traces of Figure 2.9 , but they are all on the same plot for more clarity.

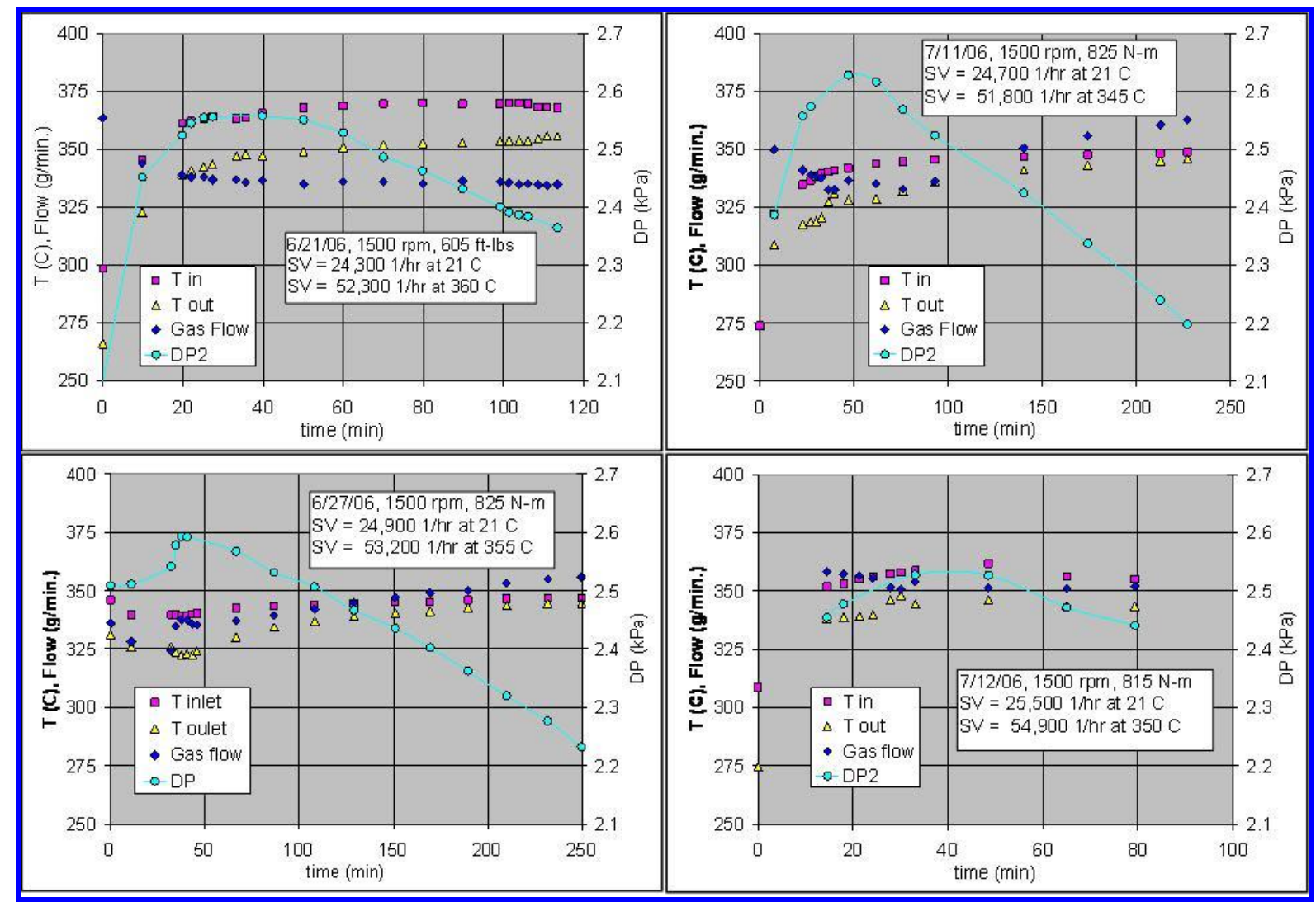

Figure 2.9 Pressure drop and other parameter behavior at $1500 \mathrm{rpm}$ and $40 \%$ load

Shown in Figure 2.9 are also gas temperatures and gas flow rate across for $3 \times 6$ inch filters while loading at the $1500 \mathrm{rpm}, 40 \%$ load set point. Note an apparent maximum in pressure drop is reached at about 40 minutes of PM loading. 
It should be noted that this is an interesting issue. The odd $\Delta \mathrm{P}$ behavior makes it virtually impossible to correlate DPF soot loading directly with measured $\Delta \mathrm{P}$. It was hoped that $\Delta \mathrm{P}$ could be used to select when to trigger regeneration. It is important to minimize how often regeneration occurs, but it can also be very destructive and lead to failures if regeneration occurs with too much carbon in the filter (thermal stress, uncontrolled burning, ash reacting with ceramics, etc.).

Some conjecture is offered for this result. The PM follows the open gas paths through the washcoat cracks and substrate pores and deposits there in the early minutes, increasing the $\Delta \mathrm{P}$ very steeply with time. After a time, a very permeable layer of soot bridges these gas paths through the crack and pore openings. Meanwhile, the soot already in the cracks and pores oxidizes due to NO2 attack, and the gas paths begin to "clear out" or "open up". New soot settles on the soot already bridging the gas paths but NO2 attacks keep this layer quite permeable. The effect of the gas paths clearing is greater than the $\Delta \mathrm{P}$ increase due to the growing soot layer, and so $\Delta \mathrm{P}$ declines. Later on the overall permeability becomes constant (the so-called balance point is reached) or begins to slowly decrease with time ( $\Delta \mathrm{P}$ increase) as the soot layer grows.

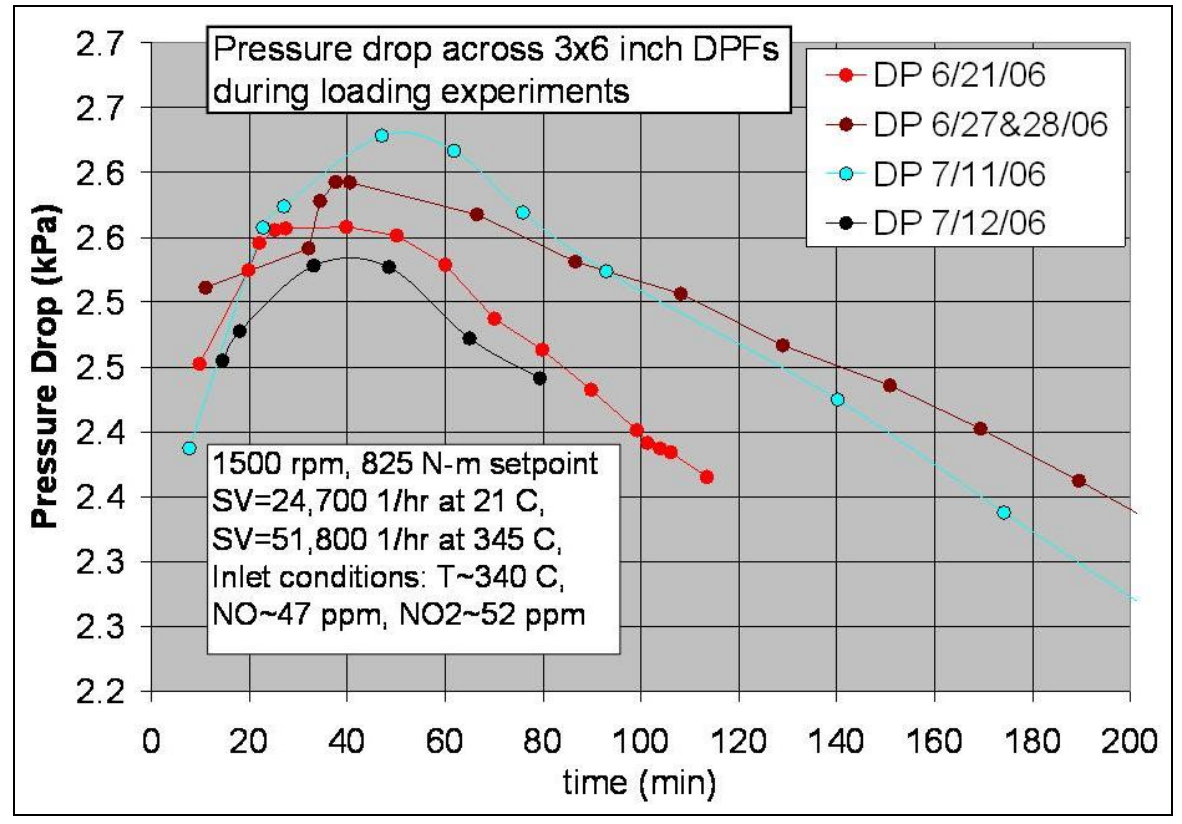

Figure 2.10 Repeat of pressure drop and other parameter behavior at 1500rpm and $40 \%$ load

\section{Soot loading and pressure drop at other conditions}

Soot loading tests were also carried out for the $1800 \mathrm{rpm}, 100 \%$ load condition and the 1200 $\mathrm{rpm}, 20 \%$ load condition. No $\Delta \mathrm{P}$ peak is seen at these conditions, like the one seen for the $40 \%$ load condition. Figure 2.11 gives results for the $100 \%$ load case, and pressure rises quickly and then slows and perhaps plateaus. 


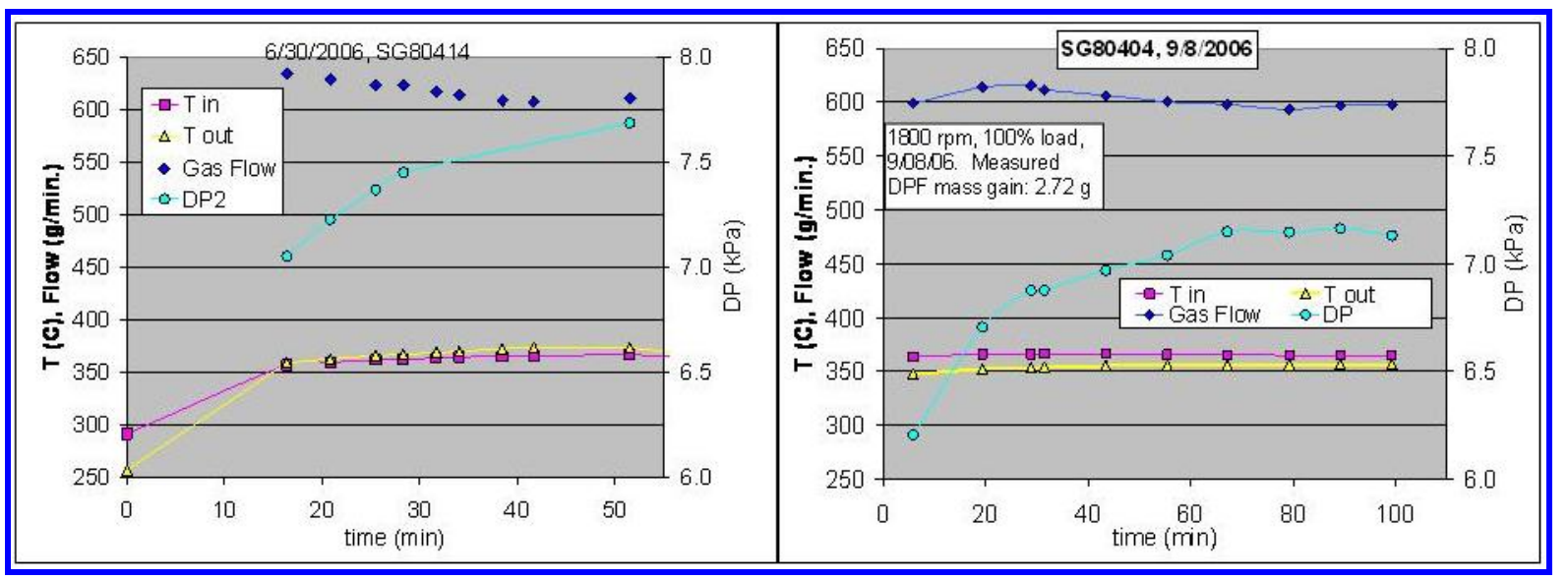

Figure 2.11 Pressure drop across for $3 \times 6$ inch DPFs at the $1800 \mathrm{rpm}, 100 \%$ load condition.

\section{$\underline{\text { Cold flow pressure drop tests }}$}

Cold flow tests were performed by flowing clean room temperature air through $3 \times 6$ inch DPFs at several flow rate levels while measuring $\Delta P$ across the DPF. These tests are fast and inexpensive and were thought to help the general understanding of permeability. The cold flow tests were applied to examine the permeability of clean DPFs, decreases in permeability due to soot loading, and to see if there are effects from DPF de-greening.

\section{$\underline{\text { Oven de-greening and DPF pressure drop test }}$}

Tests were performed by flowing air through fresh $3 \times 6$ inch soot filters at several flow rates to look at $\triangle \mathrm{P}$ across the DPF. Test results for two DPFs are shown in Figure 2.12, both before and after a de-greening process. The de-greening was done by oven heating the DPFs to above $600^{\circ} \mathrm{C}$ and holding this temperature for several hours. One reason these tests were performed was to see if the permeability increased some due to de-greening, but this is not the case for the de-greening method used. Measured $\Delta P$ is seen to increase very slightly (slight drop in permeability) after the heat treatment.

\section{Exhaust de-greening with oven regeneration}

The heat treating method may not actually mimic actual de-greening by hot exhaust exposure, particularly because exhaust gas contains significant water vapor and other gasses in quantities not found in air. A more valid de-greening method was tried by aging the DPFs in a high exhaust temperature stream and regenerating, if needed, in an oven.

Figure 2.13 depicts the set up used for the de-greening experiments. Two DPFs were installed in an attempt to de-green both simultaneously. Obviously the first DPF will soot-load and the second DPF will collect virtually no soot, but will be exposed to the hot exhaust. Heating tape was used to counter heat loss, keeping DPF temperatures near $375-400^{\circ} \mathrm{C}$, while operating the engine at the $1500 \mathrm{rpm}, 40 \%$ load condition. Nearly the same set-up as shown in Figure 2.13 is used for the cold flow tests, but only one DPF is installed and the DPF inlet is open to the room air (air is pulled through the DPF). 


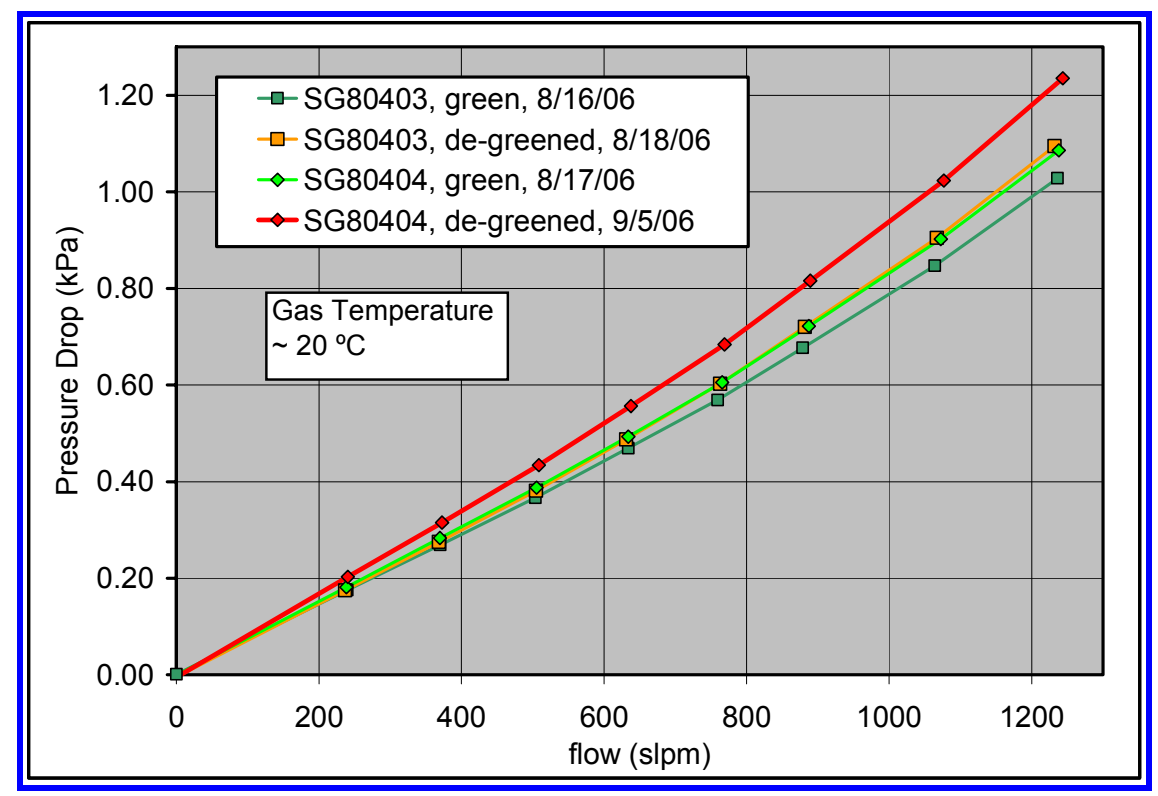

Figure 2.12 Results of cold flow testing of $3 \times 6$ inch DPFs

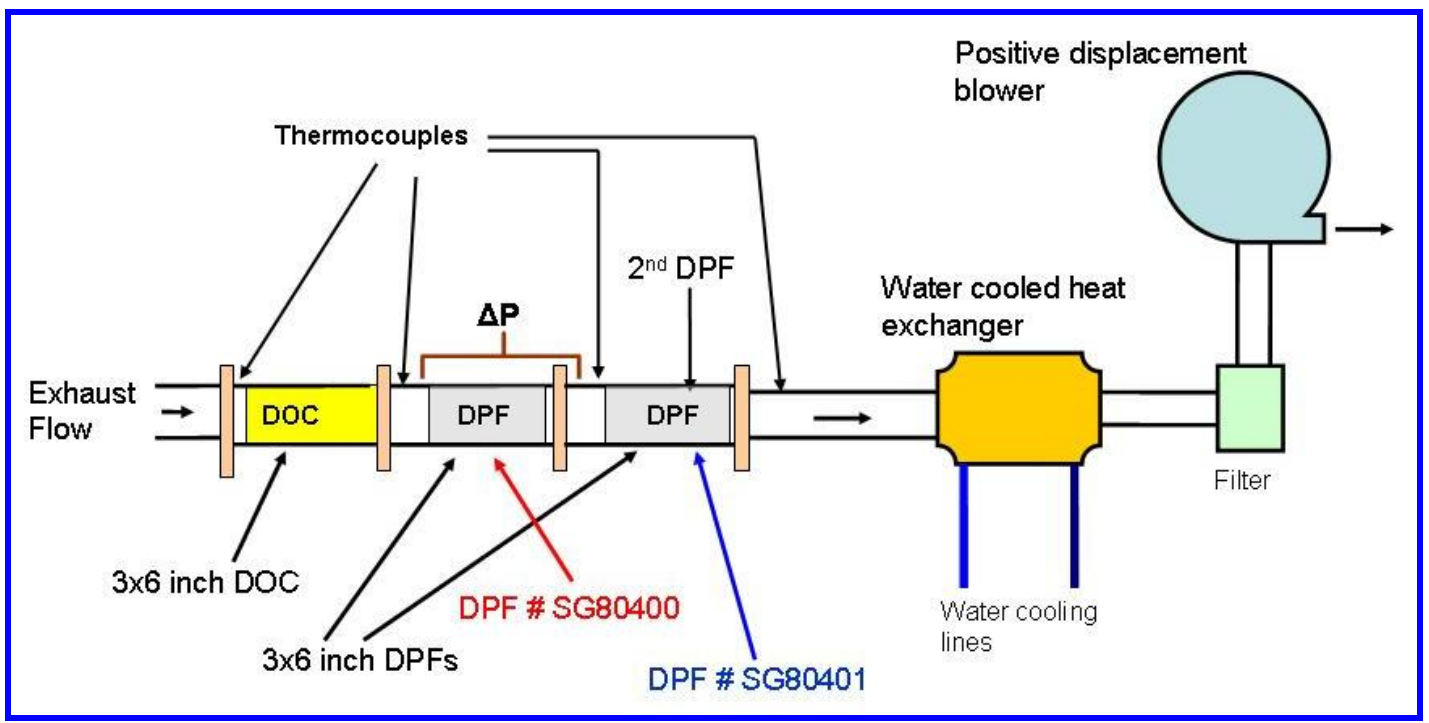

Figure 2.13 Schematic of exhaust leg for de-greening of 3x6 inch DPFs.

A description of the test sequence used to examine permeability changes due to more that 10 hours of de-greening follows. PM loading data was also collected in this test sequence.

1) Two unused DPFs numbered SG80400 and SG80401 were cold flow tested individually and then installed in the exhaust as shown in Figure 2.13. The results of the cold flow tests are shown in Figure 2.14, labeled as "green" DPFs.

2) The DPFs were exposed to exhaust at the $1500 \mathrm{rpm}, 40 \%$ load condition for 3 hours. DPF SG80400 was loaded with soot while SG80401 saw essentially no soot. Both DPFs were later cold flow tested, with SG80400 showing much higher $\Delta \mathrm{P}$ (see Figure 2.15) while 
SG80401 was virtually unchanged (this SG80401 data is not shown in Figures 2.14 or 2.15, but it lays on top of the other clean DPF data).

3) DPF SG80400 was oven regenerated (at $>600^{\circ} \mathrm{C}$ for $2 \mathrm{hrs}$ ) to burn off all the PM and later cold flow tested. These results were also identical to the earlier green-condition data.

4) Both DPFs were reinstalled (Figure 2.13). DPF SG80400 was then loaded with soot at the $1500 \mathrm{rpm}, 40 \%$ load condition for only 30 minutes. Because DPF SG80401 was installed behind the other DPF, it again saw no significant soot. DPF SG80400 was then removed and cold flow tested in its PM-loaded state and then reinstalled in the exhaust. This 30 minute loading was chosen for examination because that is near the peak $\Delta P$ seen in previous testing at the same engine set point. The cold flow results are shown in Figure 2.15 (red curve).

5) DPF SG80400 was placed back in the exhaust (no regeneration was done) in front of DPF SG80401, and soot loading was continued for another $\sim 7$ hours at the $1500 \mathrm{rpm}, 40 \%$ load condition. After this soot loading, both DPFs were removed and cold flow tested. The back DPF showed virtually no change. Again the results for SG80400 in this loaded state are included in Figure 2.15 (green curve).

6) Both SG80400 and SG80401 were oven regenerated, and cold flow tested. No difference in permeability was seen compared to the original "green" state, as shown in Figure 2.14.

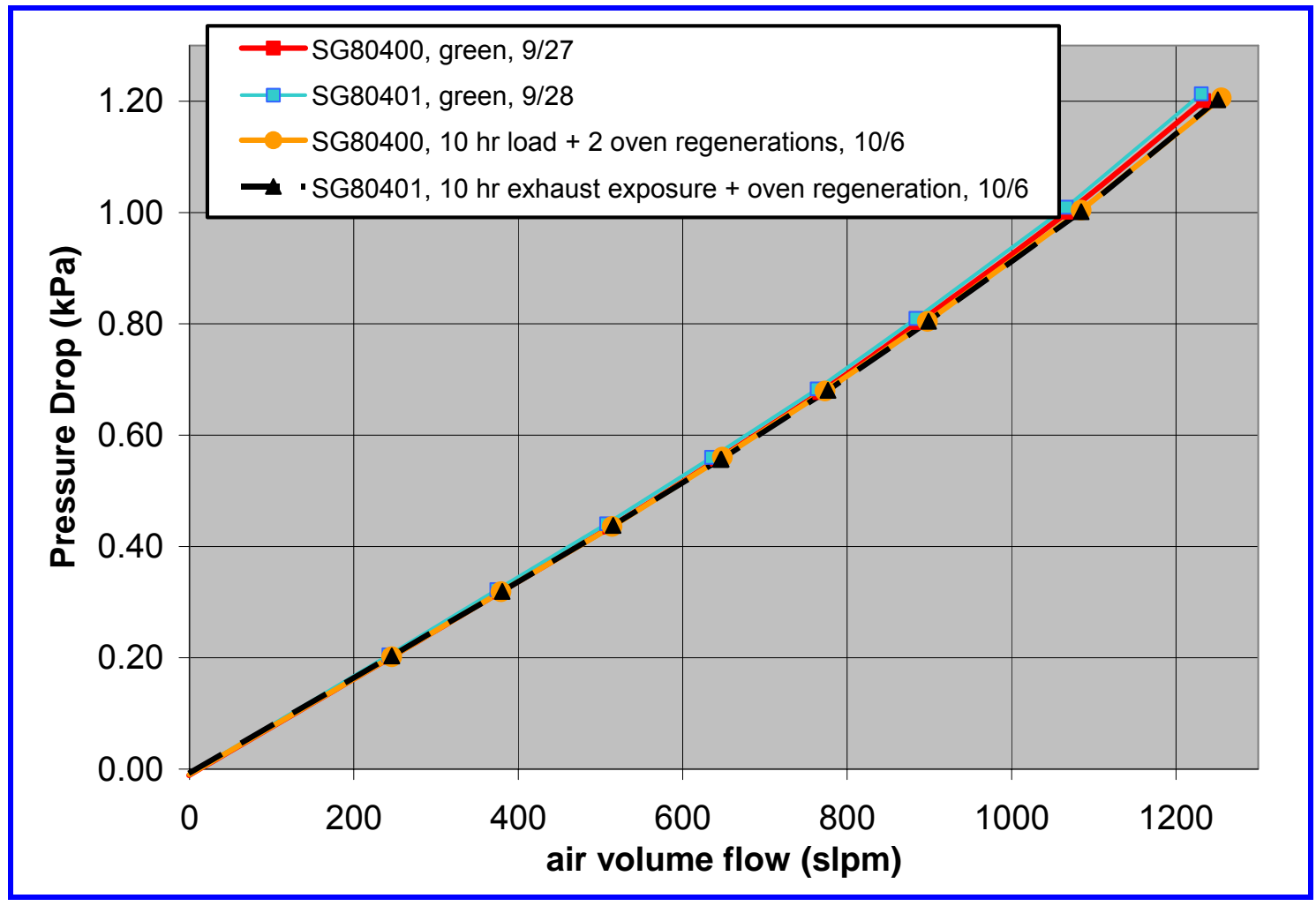

Figure 2.14 Results of cold flow testing of $3 \times 6$ inch DPFs 


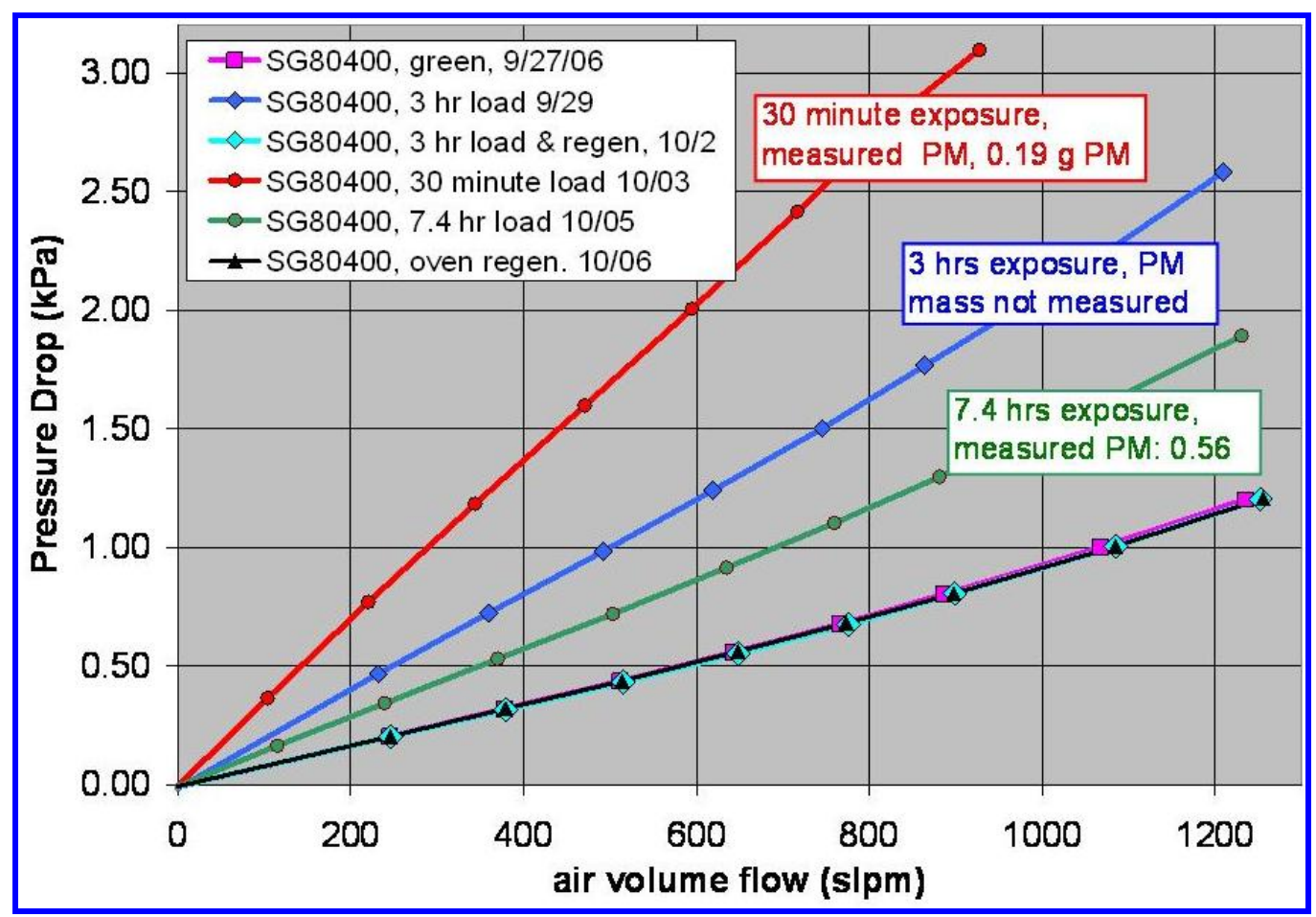

Figure 2.15 Cold flow testing results

Figure 2.15 shows changes in flow resistance with various loading times and/or PM loading of 3x6 DPF SG80400.

\section{$\underline{\text { Comparison of heavy and light washcoats }}$}

Another set of cold-flow results are given in Figure 2.16. This data shows the consistency of $3 \times 6$ inch DPFs tested. Also included is data from different lightly wash-coated cordierite filters which show higher permeability $(\sim 40 \%)$ than the heavily coated DPFs under study. This result would be expected, although it is difficult to conclude much due to the different origins of the DPFs. 


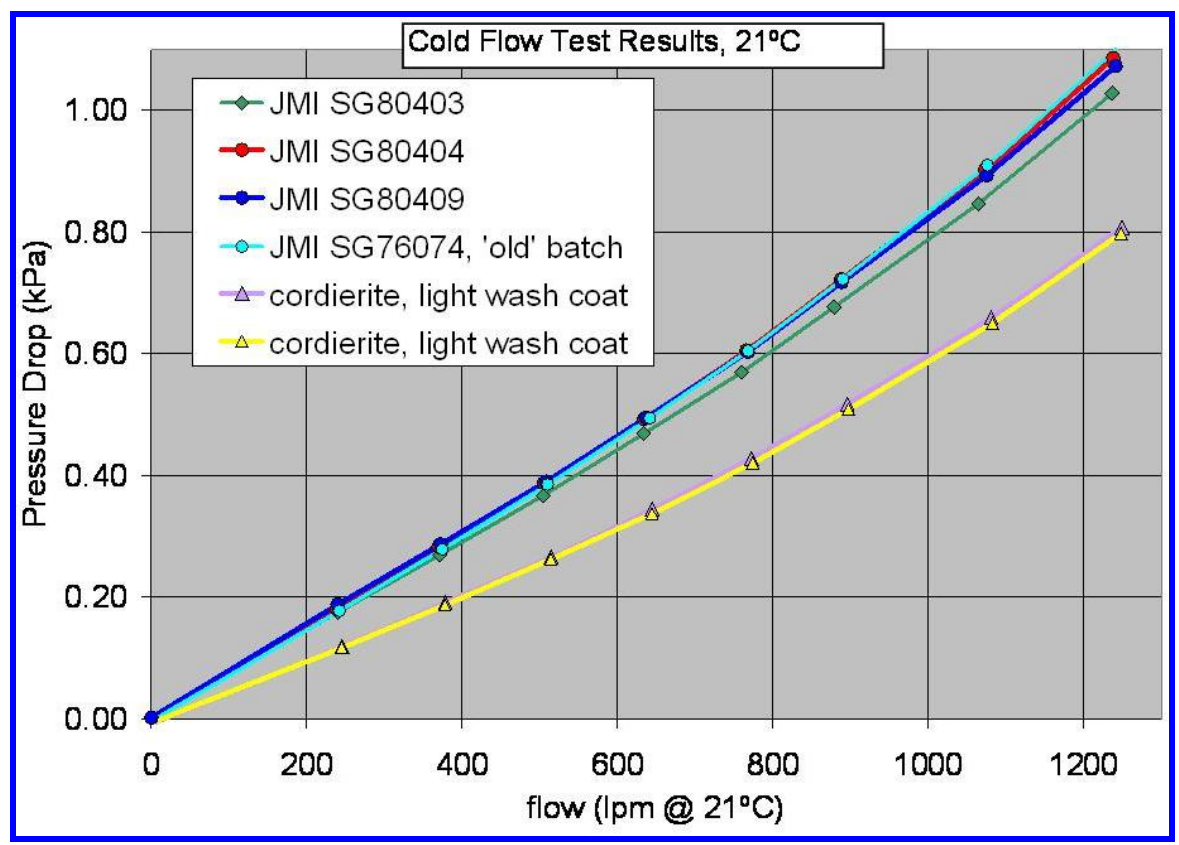

Figure 2.16 Cold flow result for several different 3x6 inch DPFs.

As indicated in Figure 2.16, the DPFs gave consistent results. Lightly coated cordierite DPFs are included for comparison.

\section{Observations and Conclusions}

\section{Soot-loading tests}

- For the $40 \%$ load engine condition, a $\Delta \mathrm{P}$ peak is seen at the $25-50$ minute region followed by a slow decrease in $\Delta P$. This is very repeatable in our test and this phenomenon is confirmed as problematic in actual commercial application.

- $\quad \Delta \mathrm{P}$ measurements follow a more expected pattern for the $20 \%$ and $100 \%$ engine load soot-loading experiments.

\section{Cold flow testing}

- Clean DPF permeability does not appear to be changed by de-greening.

- The cold flow tests agree with the trends seen for loading DPFs at the $1500 \mathrm{rpm} \mathrm{40 \%}$ engine load condition. $A \Delta P$ peak is seen in the initial 25-50 minute period followed by a slow decrease in $\Delta \mathrm{P}$. Figure 2.12 results show a much increased $\Delta \mathrm{P}$ compared to a clean DPF for the 30 minute loading time, and lower values for $3 \mathrm{hrs}$ and $7.4 \mathrm{hrs}$ of loading.

- Longer loading times show reduced $\Delta \mathrm{P}$. This is more evidence that the soot initially deposits in the cracks and pores, and is then being NO2-oxidized - but not replaced with more soot. The conjecture is that a very permeable soot layer forms after some time on the filter surface which bridges the pores in a way that does not allow more soot to enter the pores. 


\subsection{EM Characterization of a Soot-Loaded Un-Catalyzed Cordierite DPF}

A preliminary experiment was performed to develop and demonstrate the potential of certain Electron Microscopy (EM) techniques. An uncoated ( $3 \times 6$ inch) DPF was loaded for 5 hours on the Hatz engine, a single cylinder engine, to provide a sample for analysis purposes. This provided about 1 gram PM per liter of DPF. This DPF was then stabilized with epoxy and examined by Transmission Electron Microscopy (TEM) analysis as a preliminary check of our techniques. A very specialized epoxy embedding procedure is used which does not involve pulling a vacuum, so the particles are much less frequently disturbed or displaced from the DPF surface (as would typically be observed during standard metallographic preparation).

Figure 2.17 below shows typical cross-section images of the soot and the cordierite surface of the filter. This filter is uncoated and hence no washcoat is present. The sizes of the individual soot particles found were $8-70 \mathrm{~nm}$ and they stick together in very small agglomerates or link up as chains. The soot layer is very porous (all the "grey" areas between soot particles in the image are interconnected pores which have been filled in [embedded] with epoxy). The sample is a very thin cross-sectional slice through the intact cordierite and soot layer - produced by using diamond-knife ultramicrotomy. A more highly magnified photograph is seen in Figure 2.18, showing a cordierite pore contain soot particles.

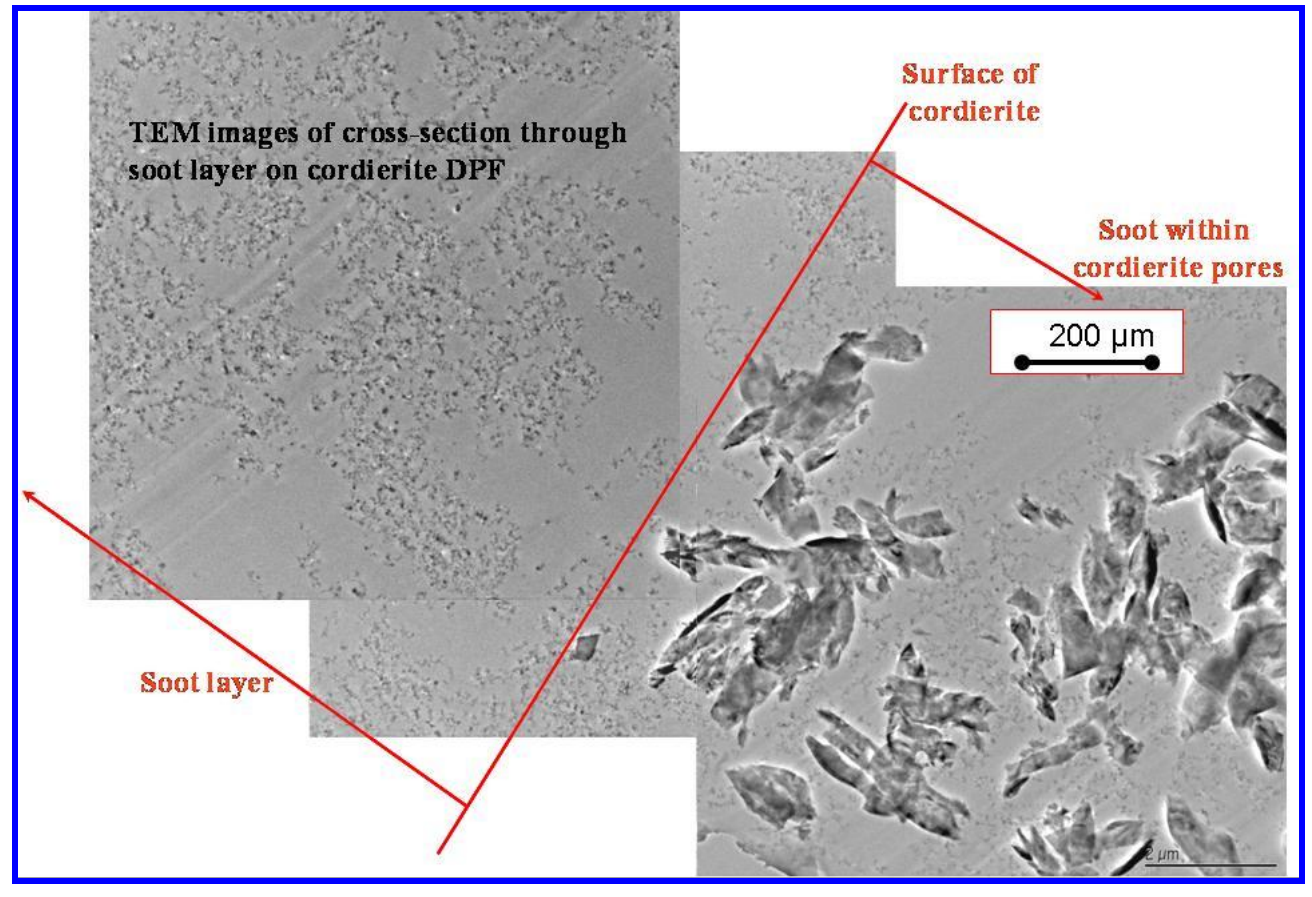

Figure 2.17 A composite from several overlapping images

Figure 2.17 shows the porous cordierite structure and the soot in the porous and the soot layer above the substrate. 


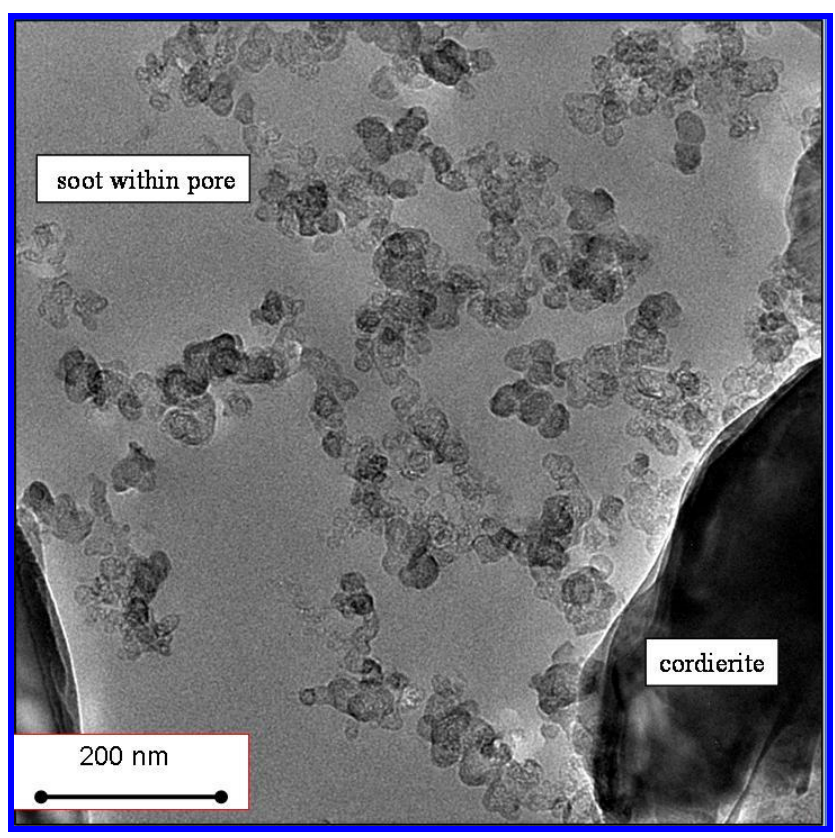

Figure 2.18 A highly magnified view of a pore containing soot particles from an uncatalyzed DPF.

Some particulate size characterization results were summarized for the Hatz engine PM. Although this Hatz engine PM data will not likely be studied in the future, these results serve as an example of sizing information that can be obtained through EM techniques. Figures 2.19, 2.20 and 2.21 describe the results of examining the $100 \%$ load Hatz engine PM at 3 engine speeds. The PM loading on the EM grids at $100 \%$ load had sufficient particles to do a good comparison. The experiments performed at lower engine loads had lower PM levels and the grids were apparently exposed for too short of a time period. The resultant sparsely populated grids have made such an analysis much more difficult.

In the discussion that follows, we distinguish between the "soot agglomerates" - the branched PM particles as shown in Figure 2.19, and the "soot particles" - the carbon spheroidal individual building blocks from which they are composed (and are also visible in Figure 2.19). 


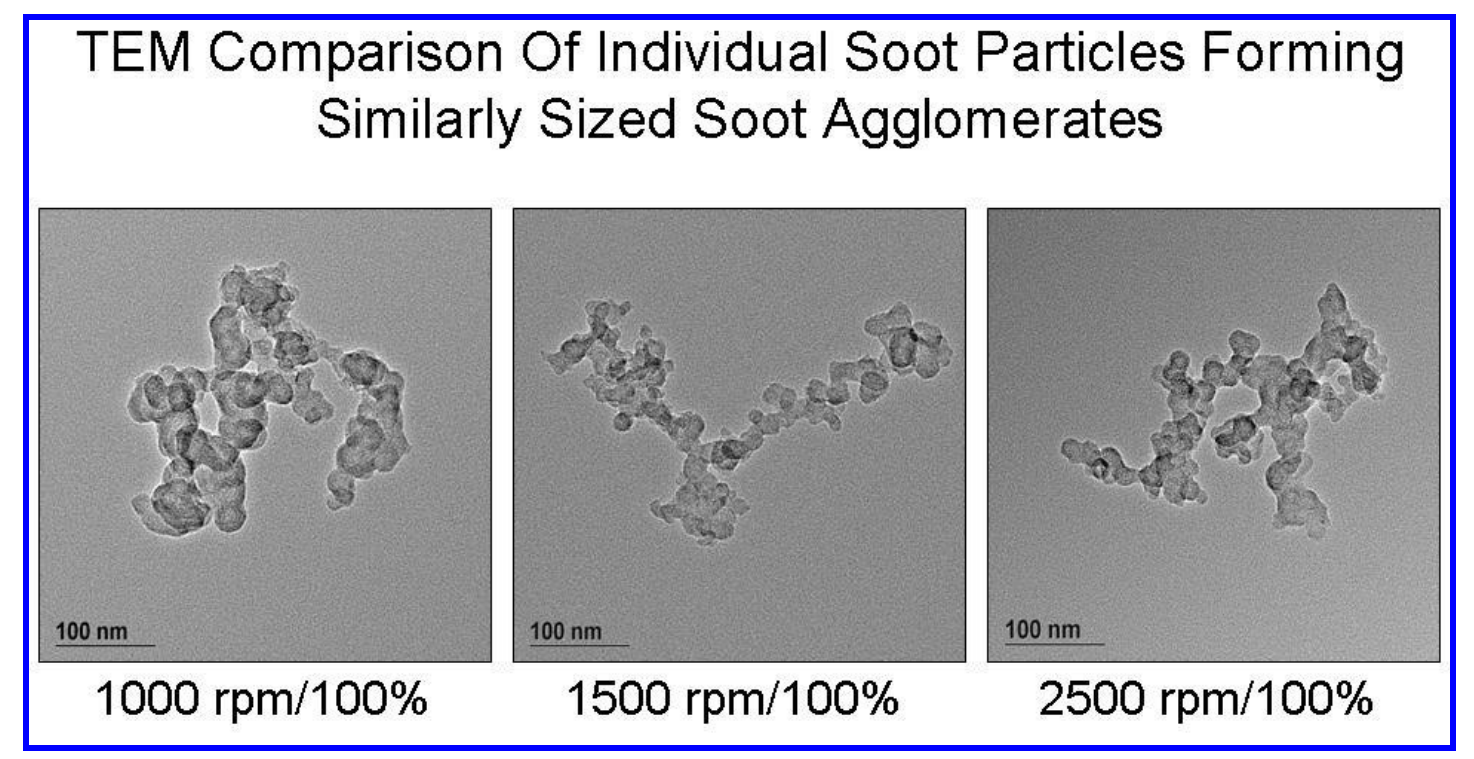

Figure 2.19 TEM comparisons of individual soot particles.

These TEM images in Figure 2.19 show the structure of the soot agglomerates, as aggregated particles composed of many smaller, rounded soot particles adhering together. The soot particles appear largest for the $1000 \mathrm{rpm}$ case.

Figures 2.20 and 2.21 summarize results from the detailed counting procedures of PM collected on EM grids. Results show the soot agglomerate particles from the Hatz engine at the 3 engine speeds appear to have little statistical size difference (Figure 2.21), but the basic soot particles they are "built" from appear larger at the $1000 \mathrm{rpm}$ set point (Figure 2.20). Soot gathered from the full-size DPF appears to be composed of yet smaller soot particles than any seen from the Hatz engine. The SMPS data indicates that the soot agglomerate particle sizes from the Hatz engine were significantly larger than those produced by the common-rail DDC Series 60 engine at $100 \%$ load points.
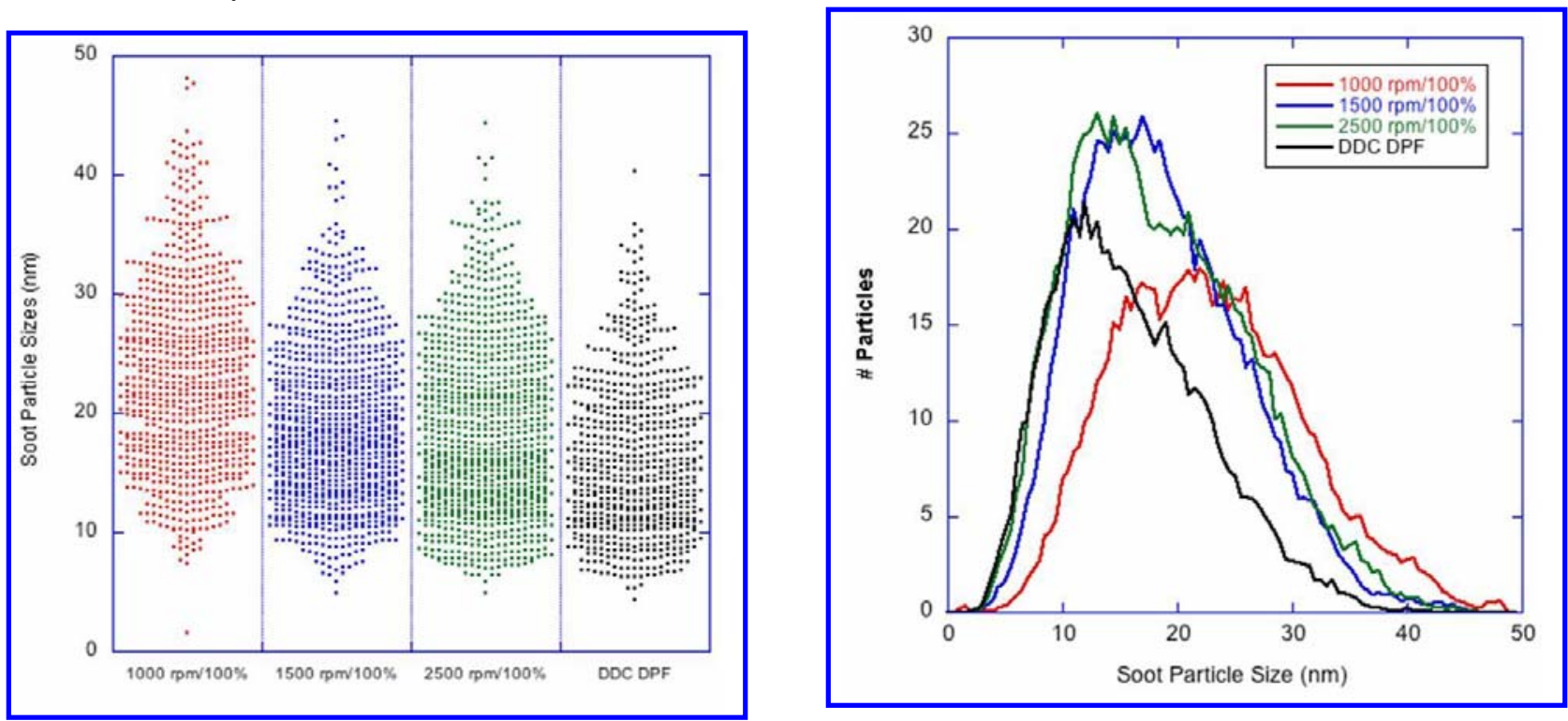

Figure 2.20 The results of soot particle size counts are shown in the above plots. 
The soot particle size is shown to drop with increased speed for the Hatz engine operating at $100 \%$ load. A data set is also included from soot taken from the (destructively tested) full-size DPF, and the particles were found to be smaller than those derived from the Hatz engine.

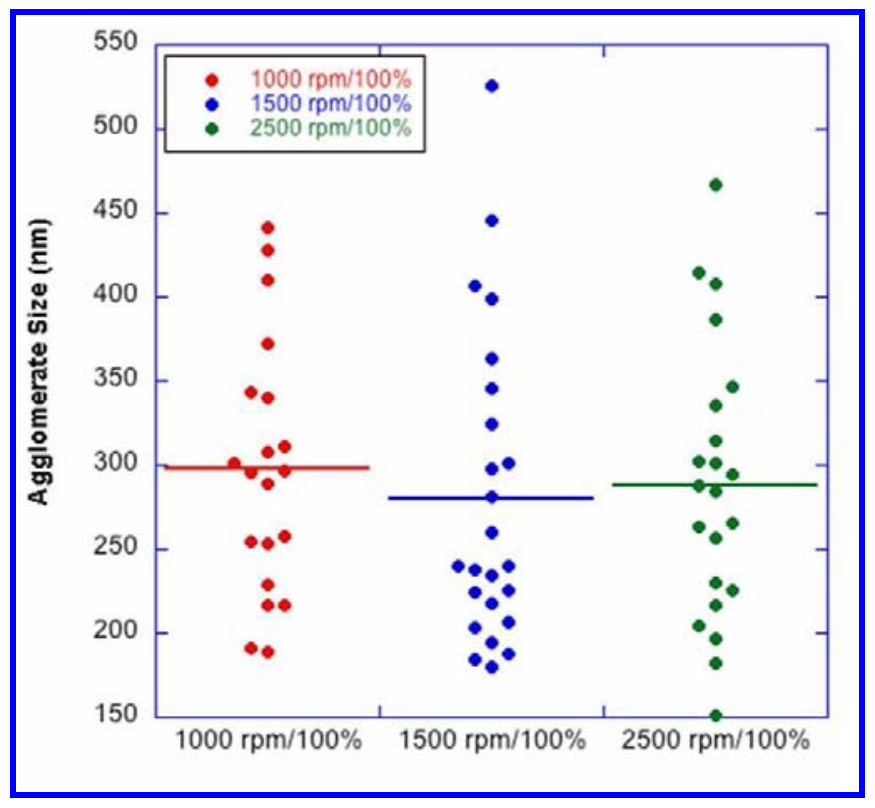

Figure 2.21 The soot agglomerate particles from the Hatz engine

It appears in Figure 2.21 to have no statistical size difference for the three speeds tested. The soot removed from the full-sized DPF has been handled, and any soot agglomerate sizing is likely to be invalid.

\section{Characterization of Soot Particles}

Soot consists of individual spheroidal particles, which are attached (stuck together) or agglomerated in irregular (fractal-like) shapes. The individual soot particles will be referred to as "fundamental particles" and attached soot particles as an "agglomerate". It was possible to collect size and shape information of soot particles, which were collected directly from the gas stream, using TEM. Soot that is collected on special TEM grids held in the gas stream, can be used to image and measure the fundamental particle size and the agglomerate size (and to gather agglomerate shape information). Soot collected from loaded DPFs can be used to examine fundamental soot particle size but not agglomerate information due to disturbing of the agglomerate size during post-loading handling.

As shown in Figure 2.22, the average fundamental particle size soot ranged of 13-17 $\mathrm{nm}$. PM collected at ORNL (operating the DDC Series 60 engine at $1800 \mathrm{rpm}, 100 \%$ load and $1500 \mathrm{rpm}$, $40 \%$ load) gave average soot particle diameters of 15 and $17 \mathrm{~nm}$, respectively. Soot collected from the loaded soot filter (first full-scale DPF with the ring crack) gave a value of $13 \mathrm{~nm}$. 


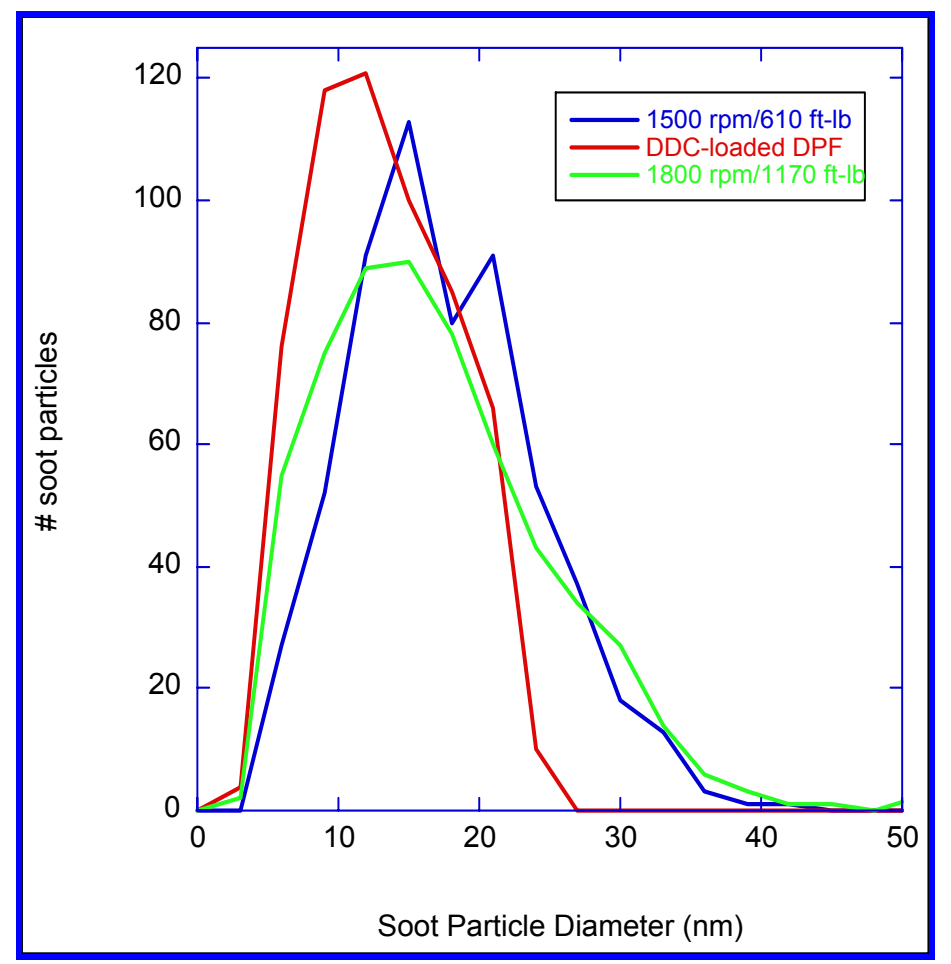

Figure 2.22 Individual soot particle diameters

Individual soot particle diameters in Figure 2.22 are measured from soot collected on carbon films inserted into the exhaust. Individual soot particle average diameters: DDC-loaded DPF $\sim 13 \mathrm{~nm}, 1800 \mathrm{rpm} / 1170 \mathrm{ft}-\mathrm{lb} \sim 15 \mathrm{~nm}, 1500 \mathrm{rpm} / 610 \mathrm{ft}-\mathrm{lb} \sim 17 \mathrm{~nm}$.

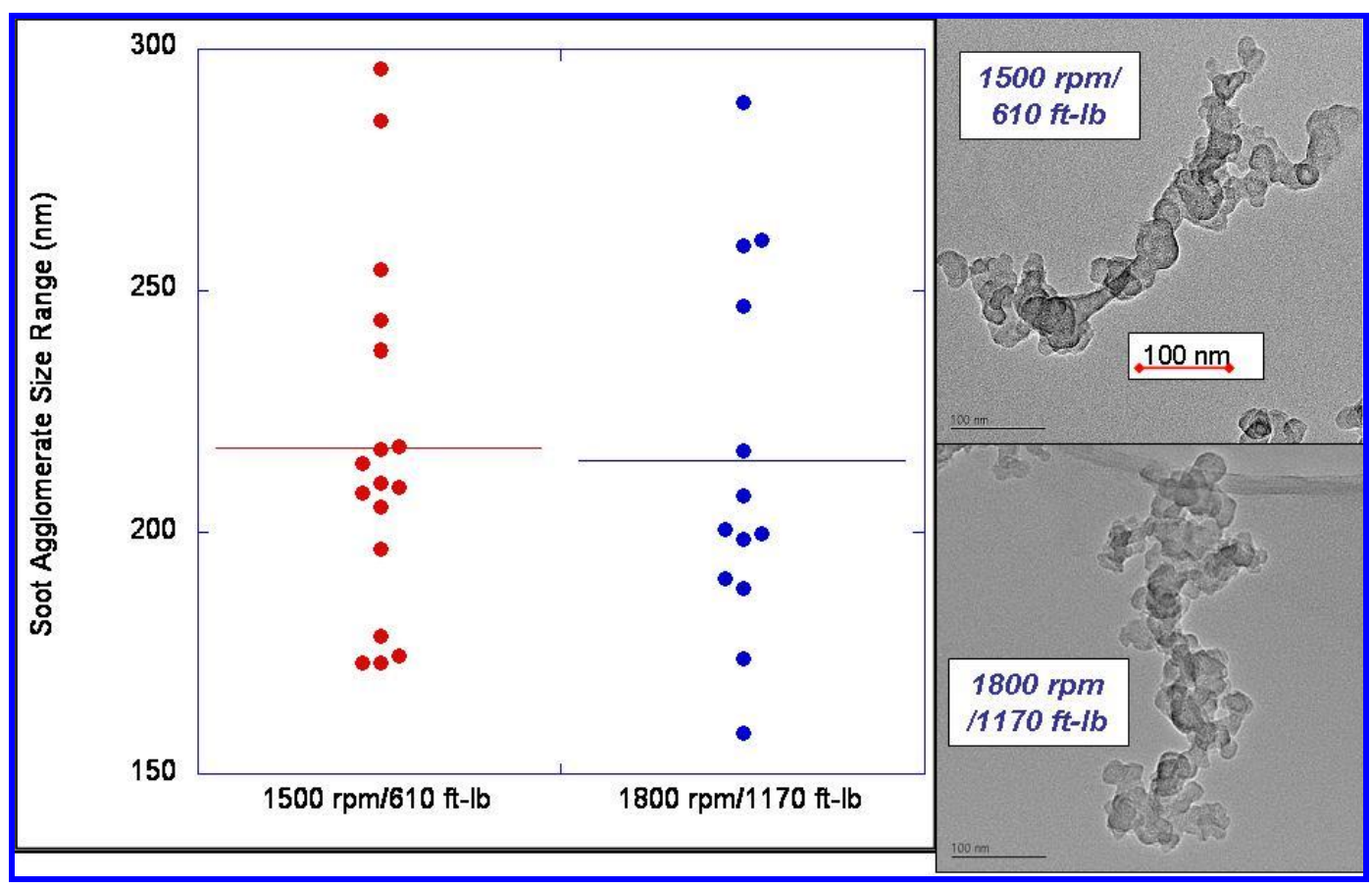

Figure 2.23 Soot agglomerate size and shape 
Soot agglomerate size and shape in Figure 2.23 is measured from soot collected on TEM grids during engine testing. Soot was not collected in-situ for DDC-loaded DPF, so agglomerate sizes could not be measured.

\subsection{Micro-structural characterization of soot and ash distribution}

This section examines results for one aged DPF. The findings gathered by applying EM characterization and other observations follow.

\subsubsection{DPF Sampling Methodology}

The full core was initially divided into 4 major cross-sections; A, B, C, and D as shown in Figure 2.24. Two cores were cut running the entire length (from the inlet face to the outlet face, 16" long continuous through the DPF) from the center and edge positions. Each core from each of the DPF cross-sections was then sectioned into $\sim 1 "$ individual cross-section samples and polished for analysis. A total of 44 samples were taken for the EM examination. In this way, a continuous sampling of changes to the inlet channel surfaces could be imaged and compositionally evaluated from the inlet to the outlet faces. Analyses included using the JEOL 8200 EPMA.

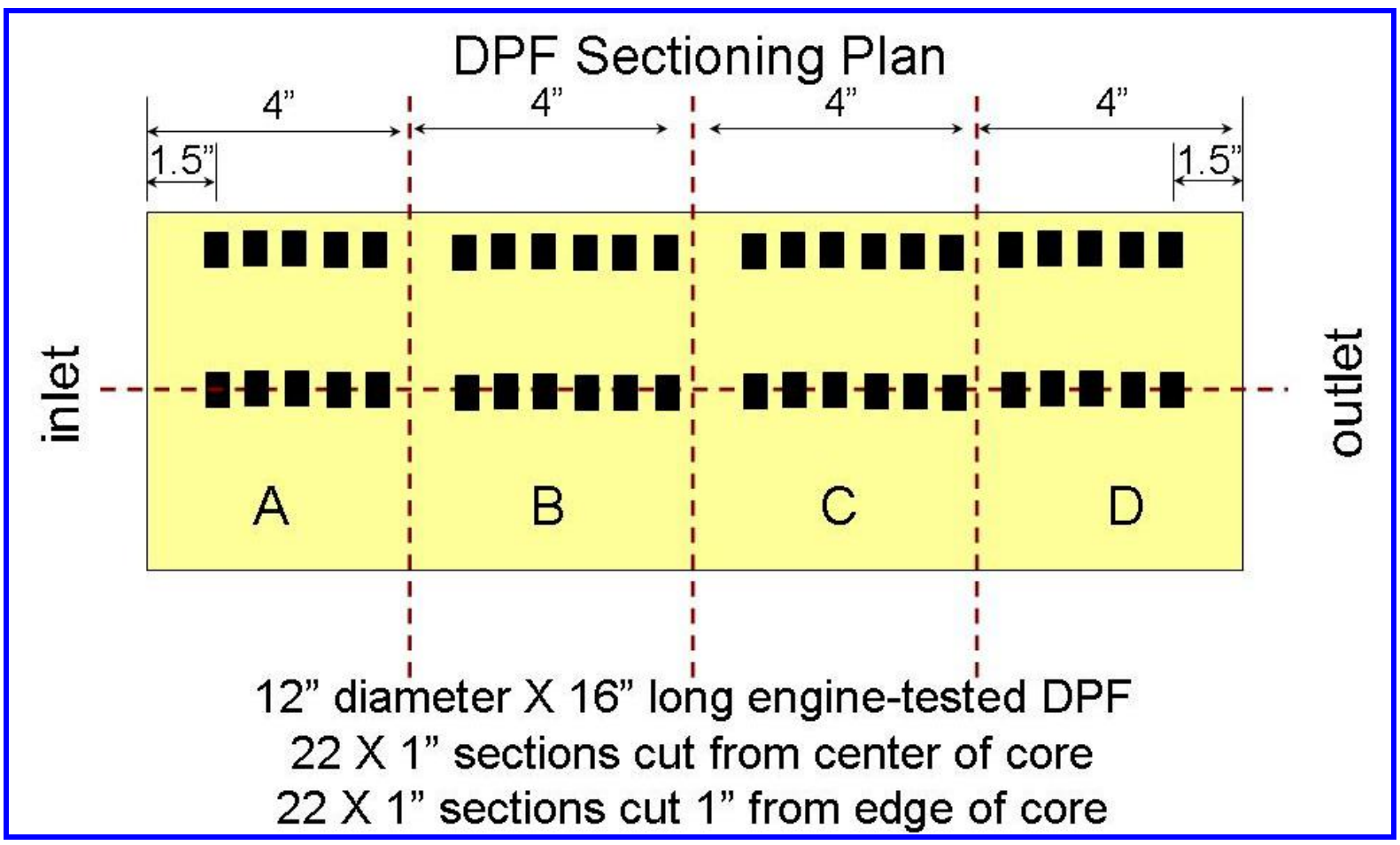

Figure 2.24 The DPF sectioning and sample positions

The DPF is 12 " diameter $\times 16$ " long. For EM study, $22 \times 1$ " sections were cut from center of core and 22 x 1 " were cut 1" from the outer circumference of core. Some additional samples were cut for the ICP effort. 
Samples were also cut as roughly 0.75 " cubes for ICP analysis and include samples removed from very near outlet face but not including the last 0.5 " portion containing the plugs.

\subsubsection{EM Based Characterization}

The findings and figures that follow are organized by progression through the key sections from the inlet face to the exit face. In general, the thickness of the soot and ash layer varied with position but no ash reaction or DPF damage was found in this filter.

The results from section $A$ are shown that the ash+soot layer was non-uniform, and the local layer thicknesses ranged from about 10 to $50 \mu \mathrm{m}$. The ash-related particles are isolated and composed of $(\mathrm{Zn}, \mathrm{Ca}, \mathrm{Mg}, \mathrm{S})$-phosphate. The highest concentration is in the near-surface regions of the soot layer

In Section B, the ash+soot layer thickness ranges from $\sim 25$ to $100 \mu \mathrm{m}$, and is non-uniformly distributed on inlet channel walls. All ash is found as isolated $(\mathrm{Zn}, \mathrm{Ca}, \mathrm{Mg}, \mathrm{S})$-phosphate particles. Particle morphology is depicted in Figure 2.25. The soot particles are seen to be turbostratic carbon in the size range of $\sim 25-40 \mathrm{~nm}$ and have no interaction with the ash. The ash consists of $(\mathrm{Zn}, \mathrm{Ca}, \mathrm{Mg}, \mathrm{S})$-phosphate particles in the size range of $\sim 100-350 \mathrm{~nm}$, and $(\mathrm{Zn}, \mathrm{Fe})$-phosphate particles with a size range of $\sim 25-40 \mathrm{~nm}$.

In section $\mathrm{C}$, the ash+soot layer is continuous on the sides of the inlet channel walls and is more uniform in thickness. The layers are on the order of $100 \mu \mathrm{m}$ thick on the side walls and about $200 \mu \mathrm{m}$ in the corners. All ash-related impurities still exist as isolated (Zn,Ca,Mg,S)-phosphate particles, and no reactions or interactions between the ash and washcoat are seen.

In the central region of the section $D$, the ash+soot layer is continuous and fairly uniform in thickness on sides and fills in the corners. Inlet channels become more clogged when moving closer to the outlet face of the DPF, and inlet channels are completely clogged around the outer edge. Examining the ash+soot particle morphology (Figure 2.26) gave the same results found for all regions examined. Only the thickness of the deposit changed along length of DPF, but the nature of this layer is fairly consistent.

Figure 2.27 gives a plot of the compositional makeup of the soot layer as a function of length along the DPF axis. Although the loading of ash+soot changes along the length of the DPF, because the layer thickens from inlet to outlet face, the elemental composition of the ash+soot layer remains nearly constant. There does seem to be more Si and Mg near the exit face of the $\mathrm{DPF}$, but the $\mathrm{Zn}, \mathrm{Ca}, \mathrm{Mg}$, and $\mathrm{S}$ (which is in phosphate form) all look fairly constant. 


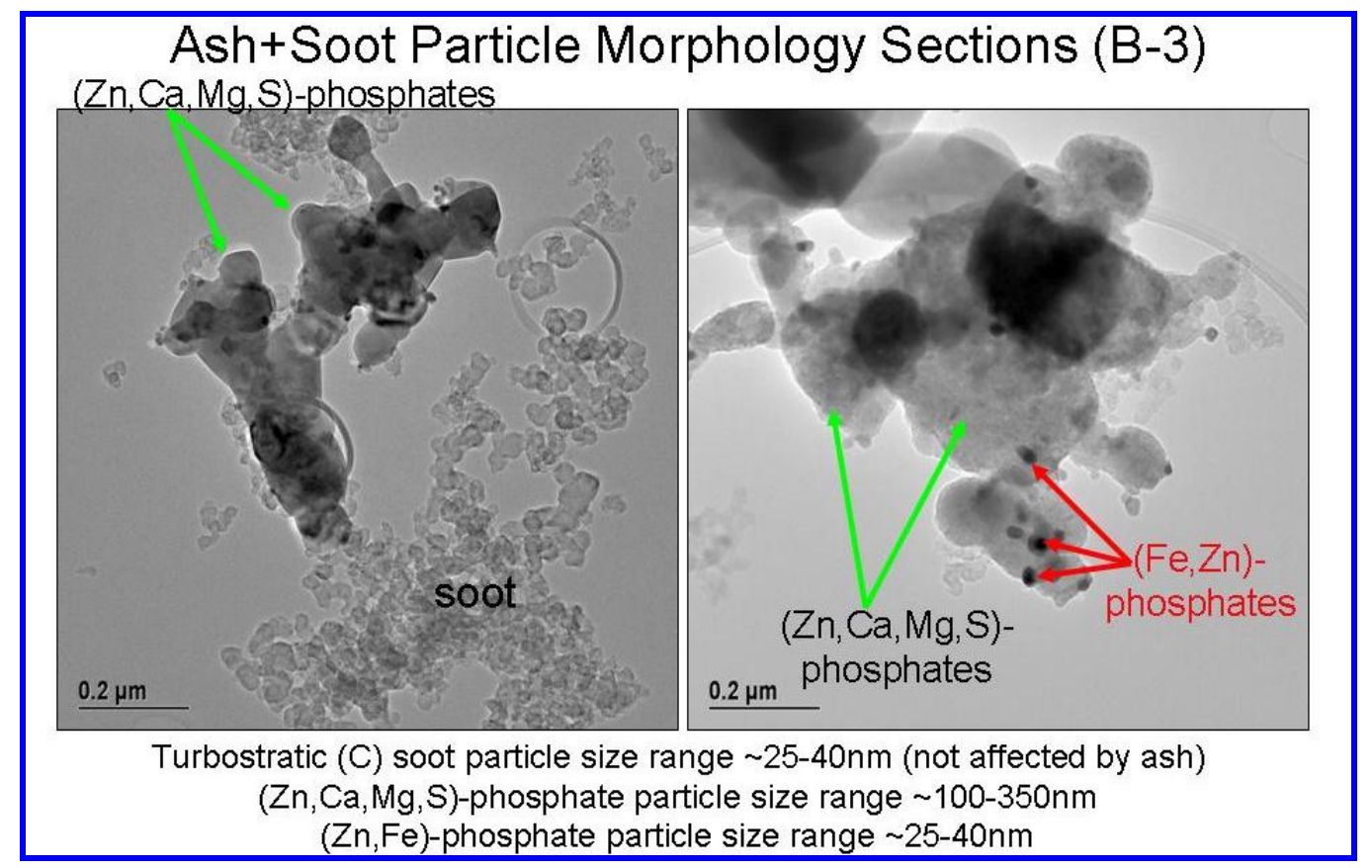

Figure 2.25 Ash+soot particle morphology for sections B-3.

No reaction was observed between the soot and ash particles in Section B.

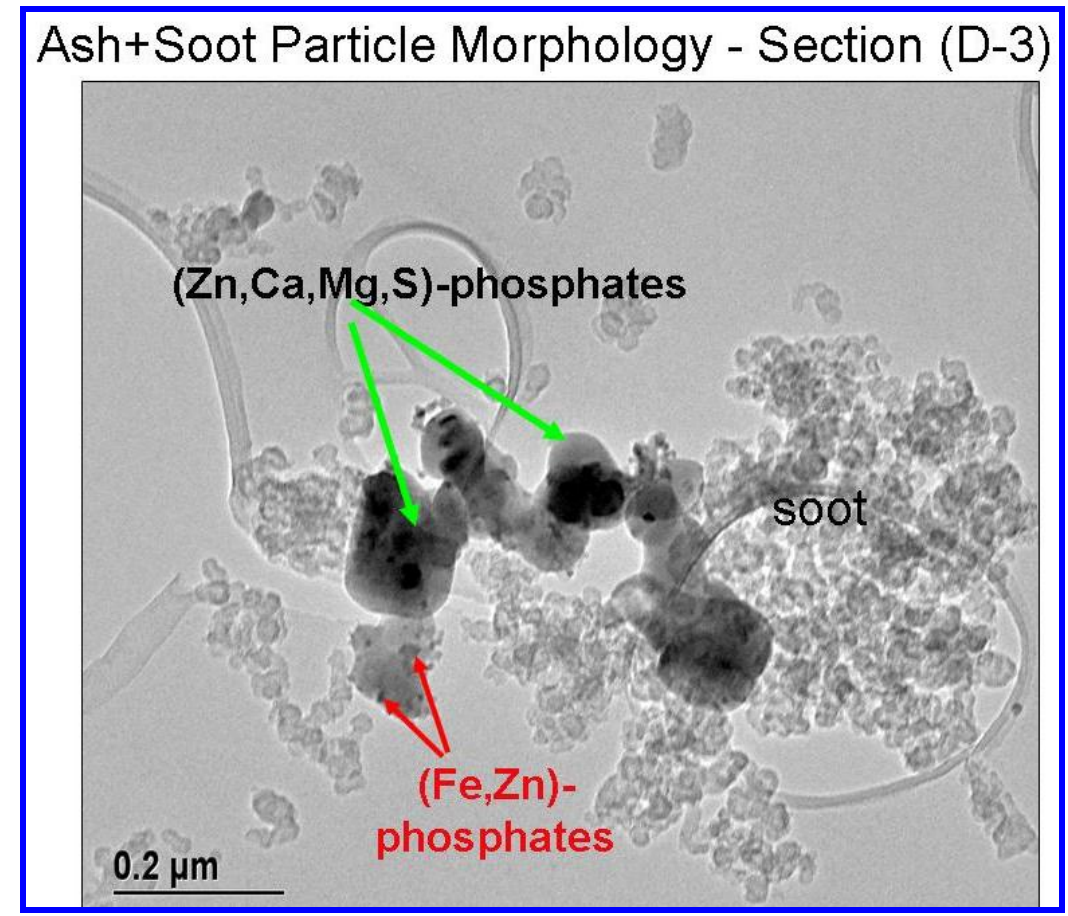

Figure 2.26 Ash+Soot particle morphology for section D-3. 
The nature of the particles shown in Figure 2.26 was found to be similar over the entire DPF. Again no interaction or reaction was observed between soot and ash particles, or the ash and washcoat.

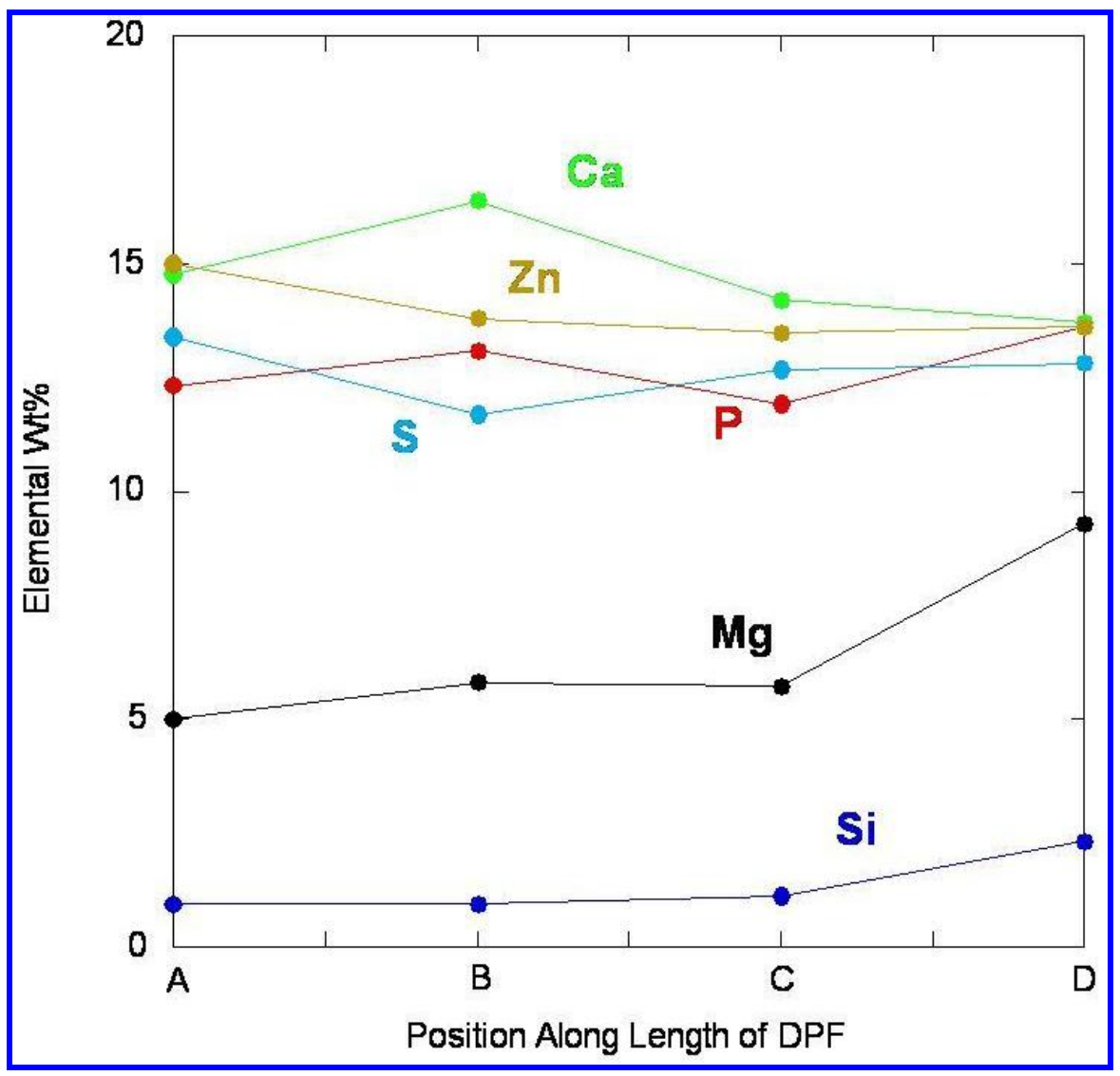

Figure 2.27 Compositional profiles "within" soot layer

Compositional profiles "within" soot layer are plotted as a function of length along the DPF in Figure 2.27. The loading profile changes along the length of the DPF since the ash+soot layer thickens from inlet to outlet face (and the number of phosphate particles increases), the actual elemental composition within the ash+soot layer remains nearly constant.

\section{Conclusions and observations}

- The composition and morphology of both soot and ash particles remain the same from inlet to outlet face of DPF, and only the thickness of the deposit changes. The density of the (ash+soot) layer does not change with increasing layer thickness and the localized composition within the deposit remains constant.

- The loading of ash constituents changes as a result of thickness only. The ash+soot layer became thicker towards the DPF exit and channels were very clogged near the outer circumference of section D. 
- The predominant "ash phase" is ( $\mathrm{Zn}, \mathrm{Ca}, \mathrm{Mg})$-phosphate with a minor phase of highlycrystalline (Fe,Zn)-phosphate. Sulfur is associated with primary phosphate phase, while Si is associated with soot particles.

- The presence of soot throughout the DPF implies it was operated for a period of time without regeneration before being removed from service for analysis.

\subsection{INDUCTIVE COUPLED PLASMA SPECTROSCOPY (ICP)}

Inductively coupled plasma (ICP) spectroscopy is an atomic emission technique used to analyze the elemental content of samples. This is a high production technique which requires nebulizing the sample into a plasma arc. For this to take place, the sample must be in solution form. Some samples, such as lube oil, are already solutions and are easily prepared for analysis. Other samples, such as metals or catalysts, must first be dissolved in a combination of acids to achieve a solution form. Catalysts are particularly difficult to dissolve because of their refractory nature and because of the variety of materials found in them. Successful analysis may result in quantifying many materials present in the catalyst (although not all metals can be analyzed by ICP) and also allows the measurement of ash or poisoning compounds. It should be noted that ICP measurements are generally considered to be within $\pm 20 \%$ (or better) without special standards and calibration. The actual samples used were small and contamination with loose ash or soot is possible.

The effort described in this section involved two endurance-tested, full sized DPFs. The first was exposed to excessive temperatures and suffered a ring crack failure. The second DPF included both the DOC and soot filter. It was only sent to the ICP laboratory for analysis.

\subsubsection{ICP Analysis of the First-Received Full-Sized DPF}

The first samples to be subjected to inductive coupled plasma spectroscopy (ICP) analysis were taken from the first large DPF. Samples were cut as described in Figure 2.24 at approximately 2, 6, 10 and 14 inches from the inlet plane of the DPF. The steps taken to perform this type of atomic emission spectroscopy are as listed below.

1. Samples of the DPF are ground up and dissolved in mixed acid solutions. The sample must be in liquid form for the ICP analyzer to perform. Different samples and elements require different procedures.

2. The liquid sample is nebulized into an inductively coupled high frequency field to form plasma.

3. Plasma emits characteristic wavelengths to each element and the calibration standards allow determination of the concentrations.

4. Results come out as mg per gram of sample, or weight ppm.

A problem with applying ICP to catalysts is that the dissolving process (digestion) may fail to completely dissolve refractory materials and some materials also form insoluble salts with certain acids (such as calcium fluoride). The remaining solids not only contain some of the metals, but can also bind other metal ions. This results in low concentration readings.

Accurate ICP results combined with lube oil quantity (released into the exhaust) and composition allows a lube oil mass balance to be performed as a diagnostic. Such mass balances have been conducted under ORNL's accelerated ash loading protocol project, which 
provided useful background for interpreting DDC results from field return DPFs. Little evidence for $\mathrm{Ca}, \mathrm{P}$, or $\mathrm{Zn}$ passing through the filter has been seen, but sulfur does pass through and can react with subsequent catalysts.

Results of the ICP work are shown in Figures 2.28 and 2.29 Slices are designated A to D with 1 near center of filter and -2 near edge of filter (see Figure 2.24). The distribution shows little ash in the front two slices, more in the third, and more still in the last slice. There is slightly more ash in the center than the edge samples. The longitudinal distribution, with ash concentrated in the ends of the channels, is characteristic of active regeneration.

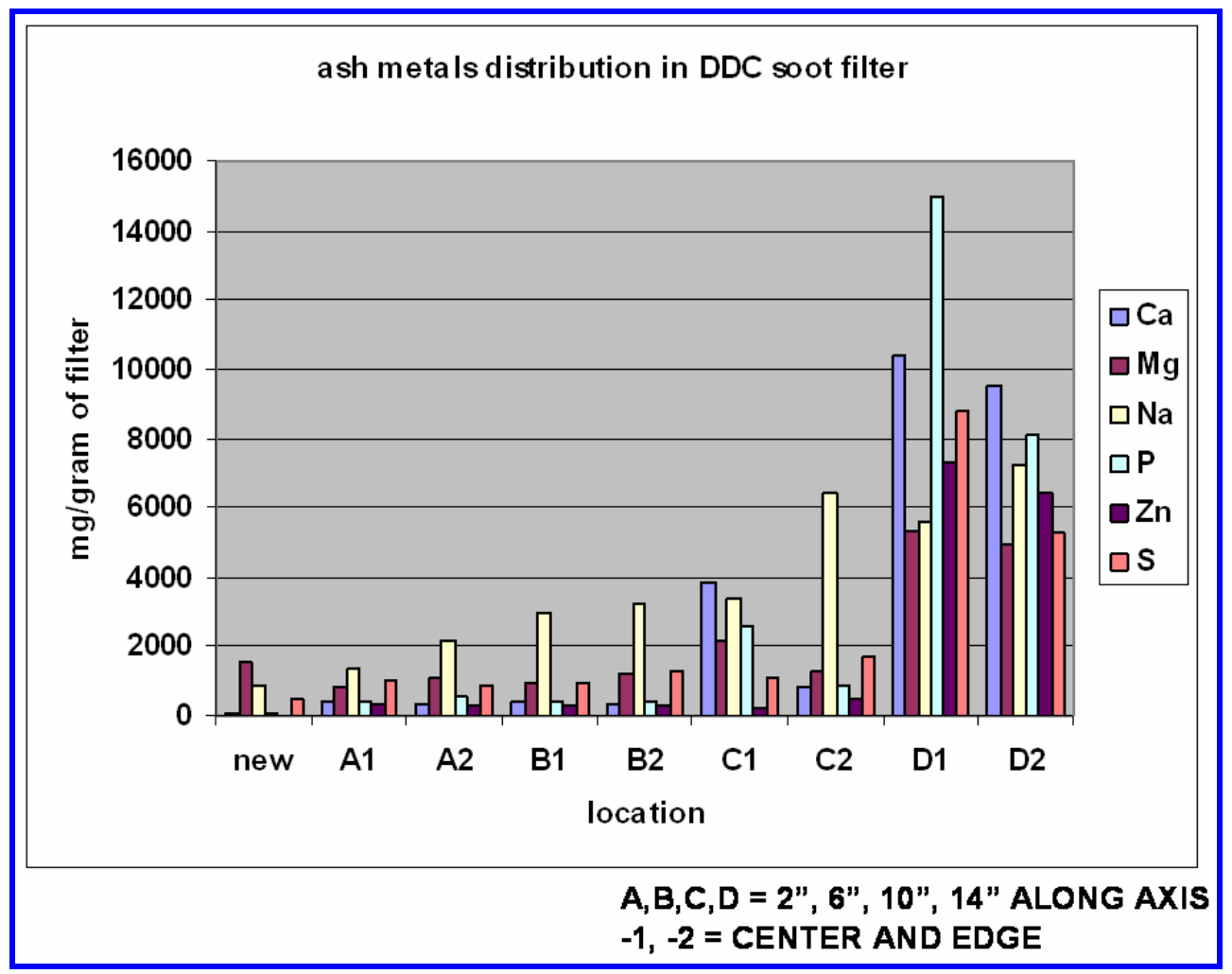

Figure 2.28 Detailed results of ICP analysis by sample location 


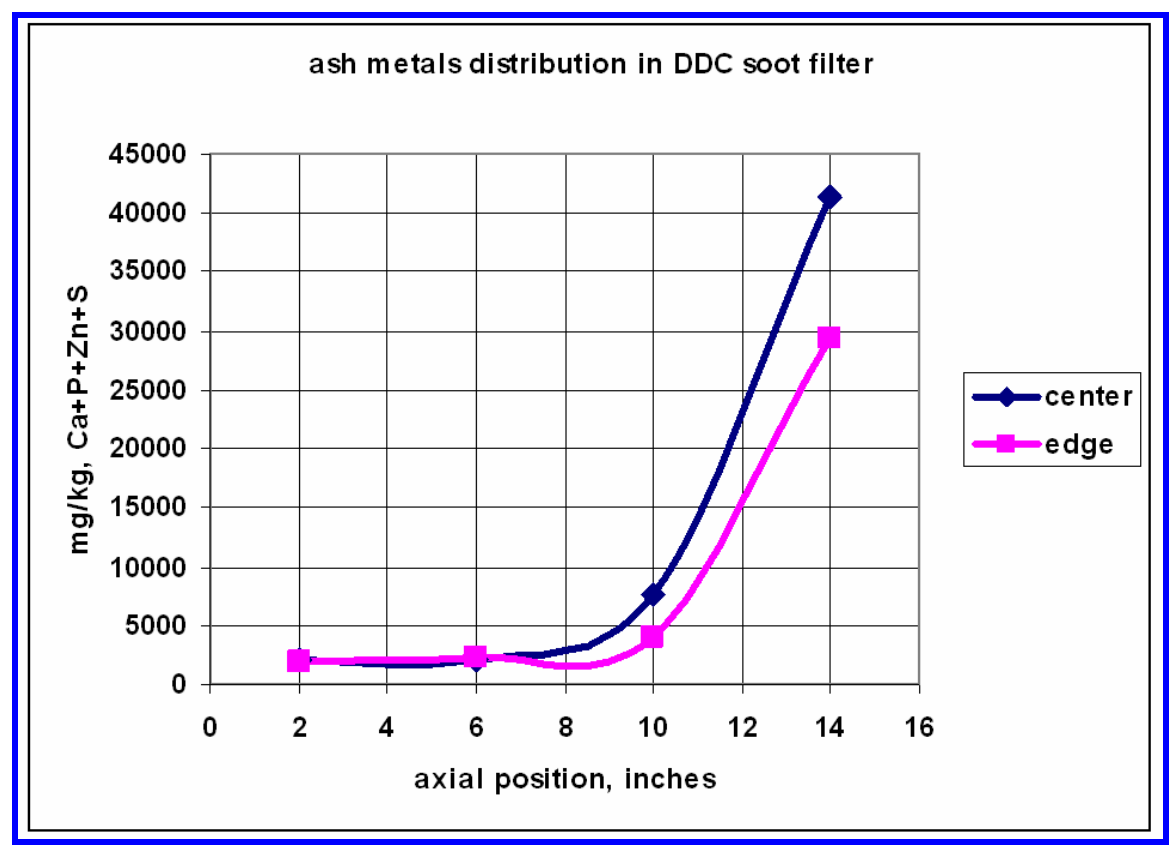

Figure 2.29 Results of ICP analysis shown as total ash metals as a function of axial position

The information from the durability test indicated that 17510 grams of lube oil were consumed and the filter weight increase was 232 grams. CJ4 oils have a maximum ash of $1 \%$, which could explain up to 175 grams of the filter weight increase. The filter also exhibited sodium, which is not used in heavy duty lube oils. About 69 grams of sodium were found, which can account for the total weight gain being larger than $175 \mathrm{~g}$. Sodium presence was also verified by electron microprobe tests. Possible sources of sodium could be an engine coolant leak into the exhaust or biodiesel fuel with excessive sodium content. A sodium source was not identified.

Additional filter samples were further analyzed by another ICP technique that uses high temperature fluxing with lithium metaborate before acid digestion. This technique is widely used in the minerals and mining industry and the results indicate the capability to quantify the substrate oxides of magnesia, alumina, and silica. Good recovery of refractory oxides is shown in Figure 2.30. 


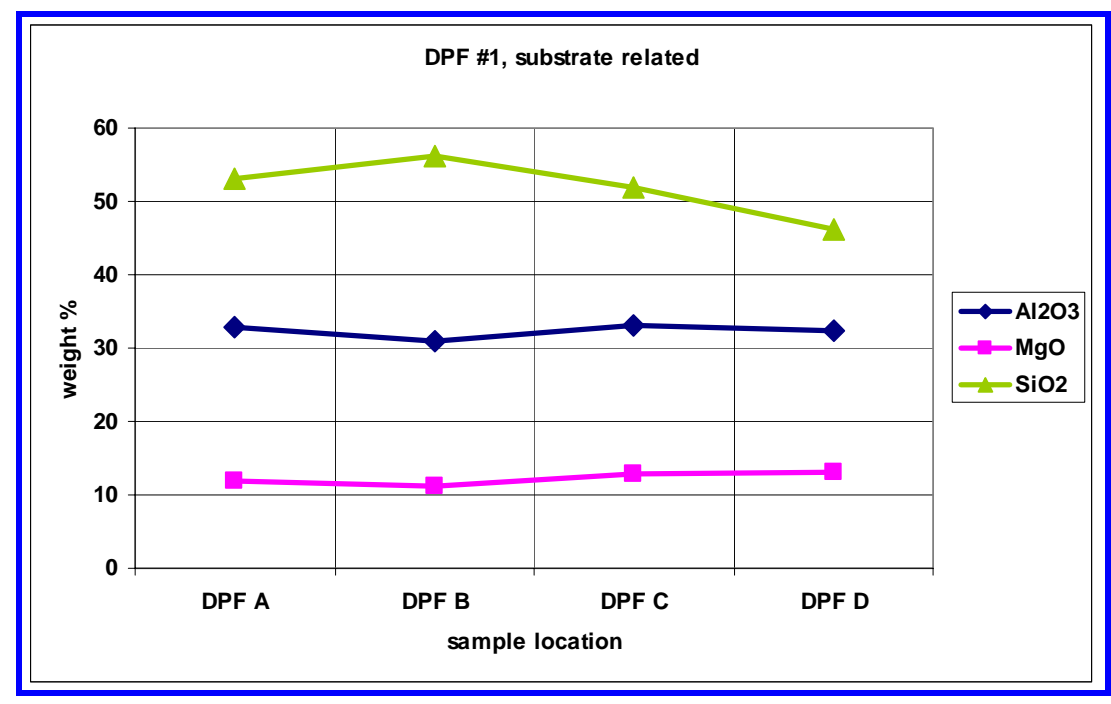

Figure 2.30 Measured refractory oxides are shown for four DPF

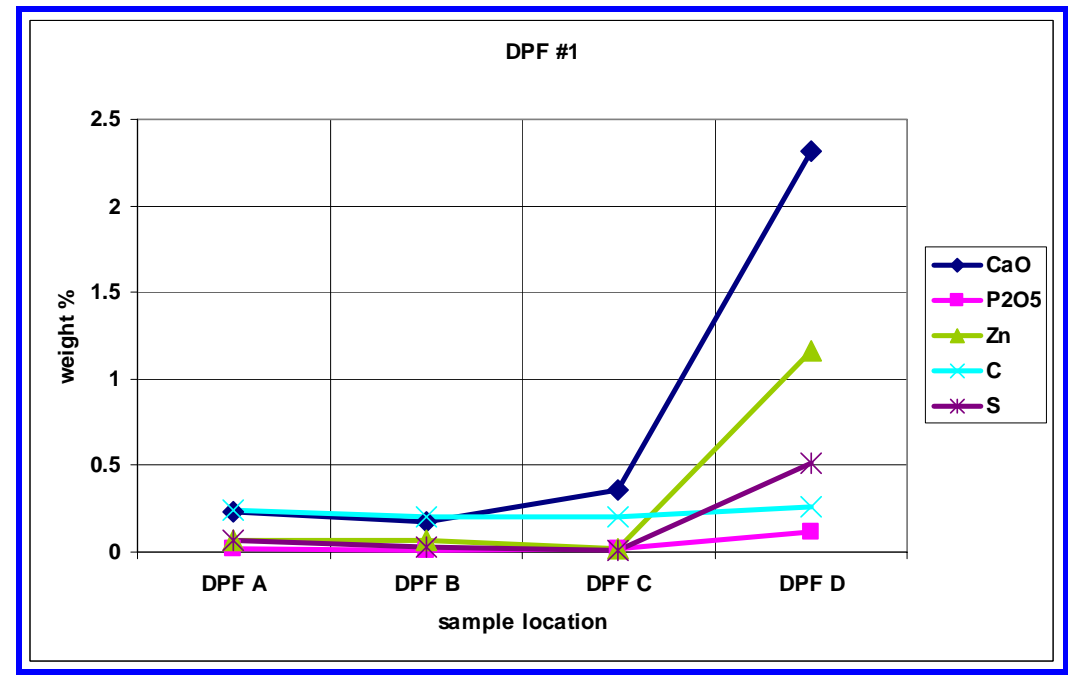

Figure 2.31 Distribution of lube oil related elements by DPF sample position.

In addition to ICP metals, measurements were made to quantify rare earths, precious metals, carbon, and sulfur. Figure 2.31 summarizes the measurements of $\mathrm{Ca}, \mathrm{P}, \mathrm{Zn}, \mathrm{C}$ and $\mathrm{S}$. Although $\mathrm{Ca}$ and $\mathrm{P}$ are reported as oxides, they are not necessarily oxides in the original samples. The distribution of these lube oil ash constituents is similar to that in Figures 2.28 and 2.29. The carbon is seen to be consistently at about 0.2 weight $\%$, which corresponds to about $1.1 \mathrm{~g} /$ liter soot loading.

The PGM results are given in Figure 2.32, and indicate that only Pd was found in the DPF. The concentration is slightly higher near the front of the filter. More measurements would be needed to define distribution of PGM and these results represent single measurements. 


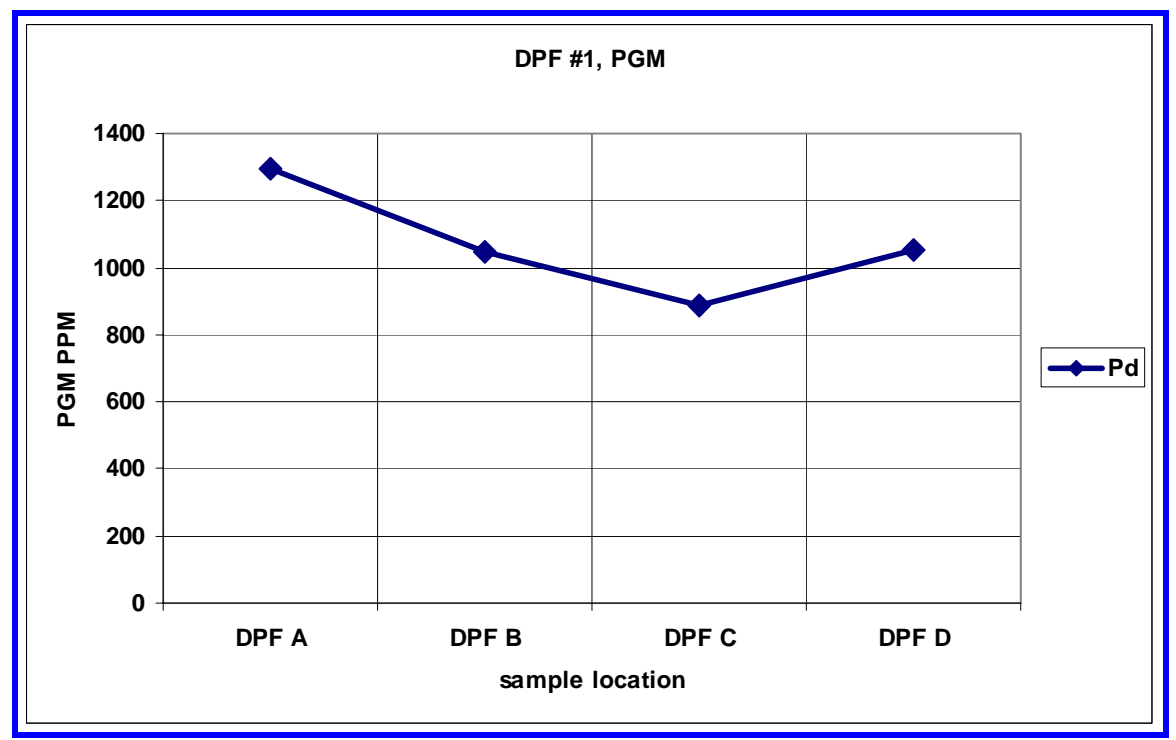

Figure 2.32 Distribution of Pd by DPF sample position.

\subsubsection{Comparison of ICP techniques applied to the first-received DPF}

Three different digestion techniques have been compared for their ability to measure materials of interest: nitric acid (HNO3), hydrofluoric acid (HF), and lithium metaborate fusion (liBor). Incomplete digestion of a sample leads to low concentrations being measured, either because the material of interest remains in solid form or because a dissolved material is selectively absorbed by remaining solids. This leads to the conclusion that the technique providing the highest measurement is probably the most representative. Unfortunately, none of the techniques have proven completely inclusive for all the materials of interest, as will be described in the remainder of this section. (Note that x-ray fluorescence (XRF) is an alternate technique for metals content of solids. This technique was not evaluated, since it is subject to matrix effects and requires a large number of calibration standards of similar composition to the samples being measured. In light of our results from ICP, however, it might be considered as an option.)

The first test of a digestion technique is the ability to measure the materials in the cordierite substrate, indicating the ability to completely digest the catalyst sample. Cordierite is composed of a crystalline compound with chemical formula $2 \mathrm{Al}_{2} \mathrm{O}_{3}-2 \mathrm{MgO}-5 \mathrm{SiO}_{2}$. This formula can be converted to equivalent weight percentages for $\mathrm{Al}, \mathrm{Mg}$, and $\mathrm{Si}$, although the theoretical numbers will be for cordierite only and are not corrected for any washcoat present. A comparison for the three digestion techniques is given in Table 2.7, which shows average concentration in weight ppm and standard deviation for a series of measurements. Clearly, the LiBor technique is the only one capable of complete measurement of the cordierite substrate. 
Table 2.7 Comparison of ICP results for cordierite using three digestion techniques

\begin{tabular}{|c|c|c|c|c|}
\hline (PPM WEIGHT) & $\begin{array}{c}\text { THEORETICAL (NOT } \\
\text { CORRECTED FOR } \\
\text { WASHCOAT) }\end{array}$ & HNO3 DIGESTION & HF DIGESTION & $\begin{array}{c}\text { LITHIUM } \\
\text { METABORATE } \\
\text { FUSION }\end{array}$ \\
\hline ALUMINUM & 185,000 & $13,200+-19,000$ & $61,000+-17,000$ & $171,000+-5,400$ \\
\hline MAGNESIUM & 83,000 & $2,100+1,900$ & $1,900+-2,400$ & $74,000+-5,100$ \\
\hline SILICON & 240,000 & $90+40$ & $303,000+-52,000$ & $242,000+-20,000$ \\
\hline
\end{tabular}

The second test of a digestion technique is the ability to measure poisoning or ash related materials on the catalyst. In this case, we are interested in lube oil related materials including calcium, zinc, sulfur, and phosphorous. A series of four samples were measured by the three techniques and the results are presented in Table 2.7. Samples were taken from the centerline, with $A, B, C$, and $D$ referring to axial quarter from the front of the substrate. If we apply the criteria of higher numbers being the most representative, then it appears that the LiBor technique provides the best analysis for calcium and zinc, but that HF digestion provides the best measurements for sulfur and phosphorous. It is possible that the high temperatures involved in the LiBor technique cause sulfur and phosphorous to be lost during sample preparation.

Table 2.8 Comparison of DPF sample results using three digestion techniques.

\begin{tabular}{|c|c|c|c|c|}
\hline ELEMENT & SAMPLE & HNO3 & HF & LiBor \\
\hline \multirow{4}{*}{ CALCIUM } & A1 & 398 & 15 & 1642 \\
\cline { 2 - 5 } & B1 & 415 & 36 & 1214 \\
\cline { 2 - 5 } & C1 & 3855 & 126 & 2570 \\
\cline { 2 - 5 } & D1 & 10400 & 889 & 16564 \\
\cline { 2 - 5 } & A1 & 326 & 98 & 700 \\
\cline { 2 - 5 } & B1 & 303 & 147 & 650 \\
\cline { 2 - 5 } & C1 & 186 & 612 & 168 \\
\hline \multirow{4}{*}{ ZINC } & D1 & 7309 & 4595 & 11600 \\
\cline { 2 - 5 } & A1 & 419 & 990 & 700 \\
\cline { 2 - 5 } & C1 & 302 & 946 & 300 \\
\cline { 2 - 5 } & D1 & 175 & 1093 & 100 \\
\hline \multirow{5}{*}{ SULFUR } & A1 & 3832 & 8794 & 5100 \\
\cline { 2 - 5 } & B1 & 298 & 436 & 80 \\
\cline { 2 - 5 } & C1 & 2491 & 2587 & 44 \\
\cline { 2 - 5 } & D1 & 7038 & 14969 & 528 \\
\hline
\end{tabular}

For complete catalyst analysis, it appears that the LiBor fusion technique provides the best sample preparation and the most representative analysis. For ash analysis work, calcium is recommended as the tracer metal, using the LiBor fusion for sample preparation. Calcium is present in the lube oil and is also the major element in ash. Additionally, it is not present in either the substrate or the washcoat, unlike magnesium or aluminum, making it ideal for calculating lube oil consumption or ash accumulation. Zinc can also be used for this purpose and is also best analyzed using the LiBor technique. Accurate measurements of sulfur and phosphorous are desired since they are major poisoning components which are lube oil derived. It appears that the LiBor technique is not the best technique for these elements, perhaps due to volatility during the fusion process. For sulfur and phosphorous, it appears that HF provides the highest numbers and hence, probably, the most representative. 


\subsubsection{ICP Analysis of the Second Full-Sized DPF}

The second endurance-tested DPF was analyzed here. Samples were cut along the axis at the centerline and at the outside of the filter for both the EM-based microstructural and the ICP evaluations similar to Figure 2.24. Samples were approximately 0.75 " cubes for ICP analysis and include samples removed at 2, 6, 10, 14 and 15 inches from the inlet face. These last samples are taken very near outlet face but exclude the portion containing channel plugs. In addition, samples were cut from the DOC. Samples were sent to the Saskatchewan Research Council Geoanalytical Laboratories for ICP analysis using the lithium metaborate fusion technique of preparation.

\section{Results for calcium}

The filter including both the DOC and DPF was sampled and analyzed at a total of 10 locations (first four are the DOC) and results are plotted in Figure 2.33. Only calcium is shown here, because it is considered most representative of all the ash related elements measured. The left hand graph indicates the total length of the bricks with inches 1 to 12 being the duel oxidation catalysts and inches 12 to 28 being the DPF. Data points indicate where measurements were taken. The right hand graph shows only the DPF data, re-plotted to the substrate 16 inch length.

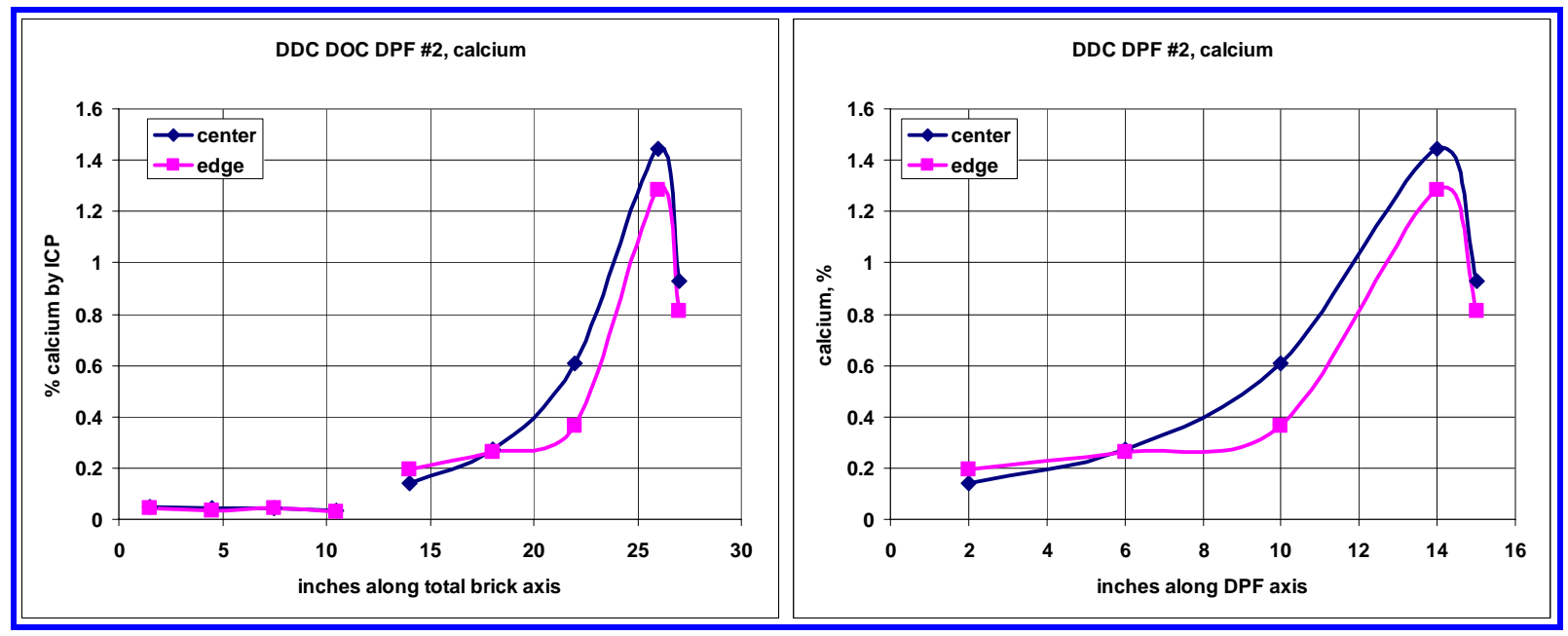

Figure 2.33 Calcium distribution for the DOC and DPF

In Figure 2.33 the DOC and DPF is in the left plot and only the DPF is in the right plot.

These graphs indicate the following: First, relative to the DPF, very little calcium is found in the oxidation catalyst bricks. Calcium is concentrated near the back of the DPF brick, indicating ash packing to the rear of the channels. Ash concentration or density is slightly higher on the centerline than on the edge, but is fairly well distributed. The first ash deposited in the channels (extreme right hand side) appears to be less dense than the ash deposited after it. This may be a packing phenomena, where later ash backs up more tightly. We have observed this in some of the samples we have analyzed for accelerated ash loading work. The ash being concentrated in the rear of the channels is readily observed in the samples, and the actual 
measurements confirm the visual observations. The measurements also give a relative indication of the ash packing density or number of channels filled.

\section{$\underline{\text { Results for lube oil related elements or compounds }}$}

The results for all the lubricant ash related compounds are shown in Figure 2.34. The lube oil related metals are concentrated at the back of DPF, with sample D position showing higher concentrations than sample $\mathrm{E}$. The high concentration of $\mathrm{P} 2 \mathrm{O} 5$ for both of the DOC position $\mathrm{C}$ samples is clearly seen: no explanation is available but note that each point was generated by a single measurement. Results for carbon are discussed near the end of this Chapter.

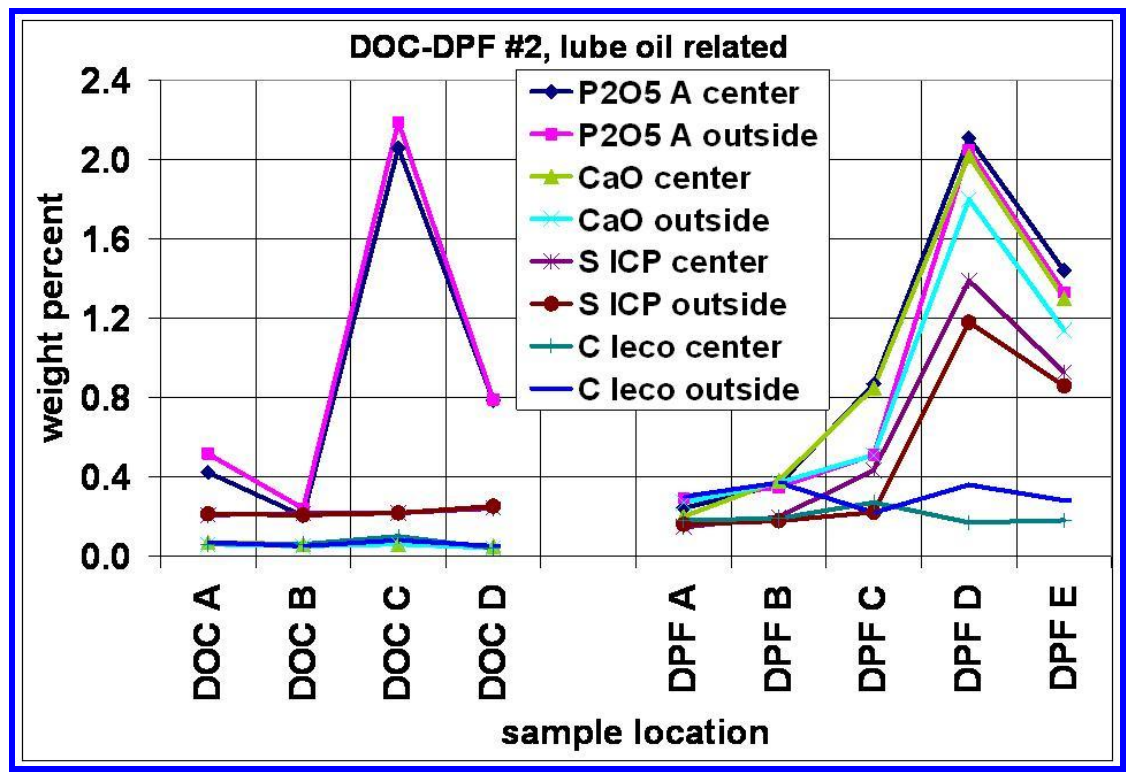

Figure 2.34 Results for all lube oil related elements for both the DOC and DPF.

Sulfur reported in Figure 2.34 is from the ICP technique, carbon from a combustion technique.

Substrate and alumina indicators, rare earth oxides and PGM

Results concerning the constituents of the substrate and alumina washcoat are given in Figure 2.35, for both the DOC and DPF. Note that theoretical cordierite contains $35 \% \mathrm{Al} 2 \mathrm{O} 3,51 \%$ $\mathrm{SiO} 2$, and $14 \% \mathrm{MgO}$. The differences between DOC and DPF indicate relative contribution of the washcoats compared to the substrates. 


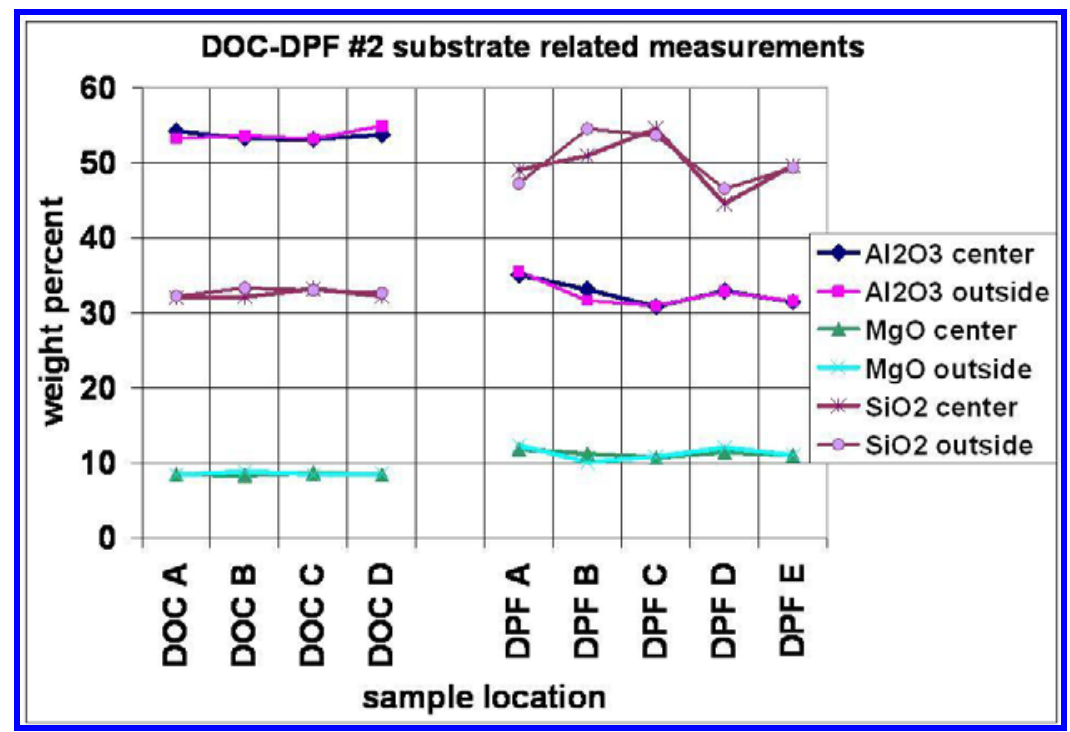

Figure 2.35 Distribution of $\mathrm{Al2O}, \mathrm{SiO2}$, and $\mathrm{MgO}$ in the DOC and DPF.

Results for the DOC and DPF measuring rare earths oxides are shown in Figure 2.36. It is seen that the DOC contains ceria, lanthia, and zirconia, but the DPF does not - except for the last sample at the very end of the DPF. It could indicate some DOC catalyst loss to DPF. More measurements and repeats would be needed to verify and quantify this finding.

The results examining PGM metals for the DOC are seen in Figure 2.37. The DOC appears to be $\mathrm{Pt} / \mathrm{Pd}$ formulation and it is well distributed. There was insufficient sample size remaining for the laboratory to complete the PGM analysis for the DPF.

This filter also showed considerable carbon based on an $\mathrm{O} 2$ burning analysis with $\mathrm{CO} 2$ emission measurement (LECO Corp. combustion test method, performed by SRCG lab). Figure 2.38 gives the carbon distribution by sample position for the DOC and DPF. The calculated total carbon mass indicated an averaged soot loading of $1.3 \mathrm{~g} / \mathrm{liter}$ of DPF. It appears that more carbon is near the outer perimeter of the DPF than near the center axis. 


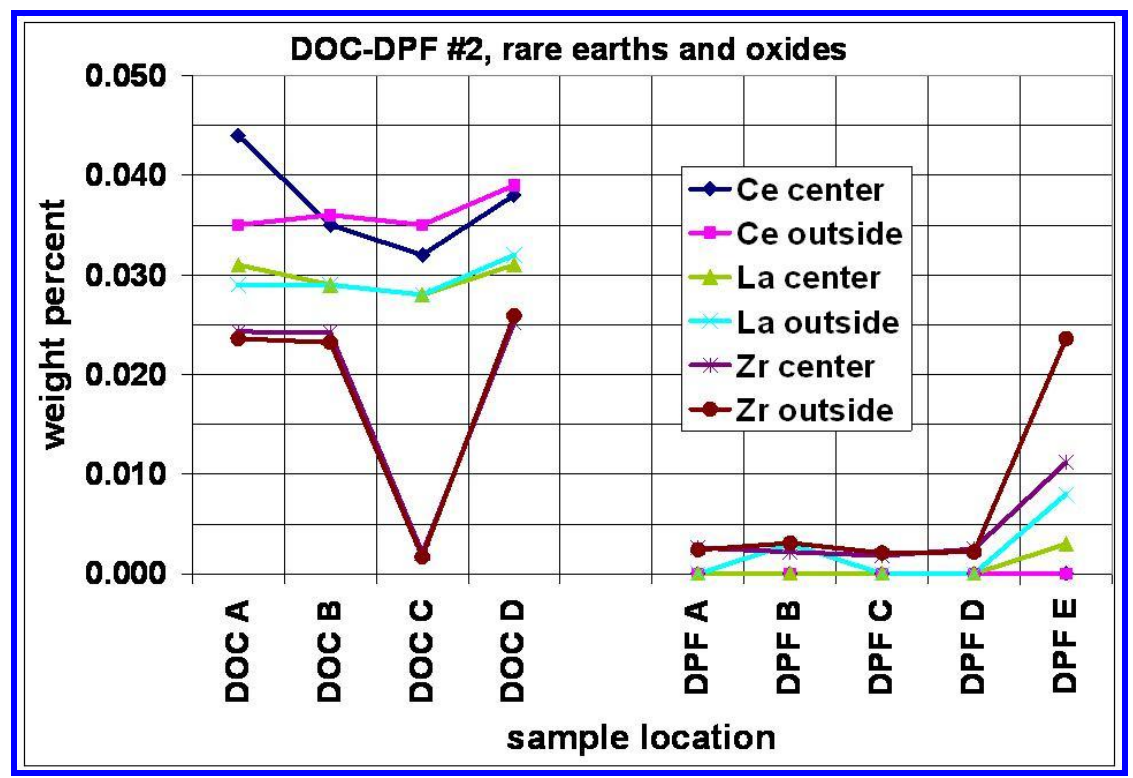

Figure 2.36 Distribution of Ce, La, and $\mathrm{Zr}$ is shown for the DOC and DPF.

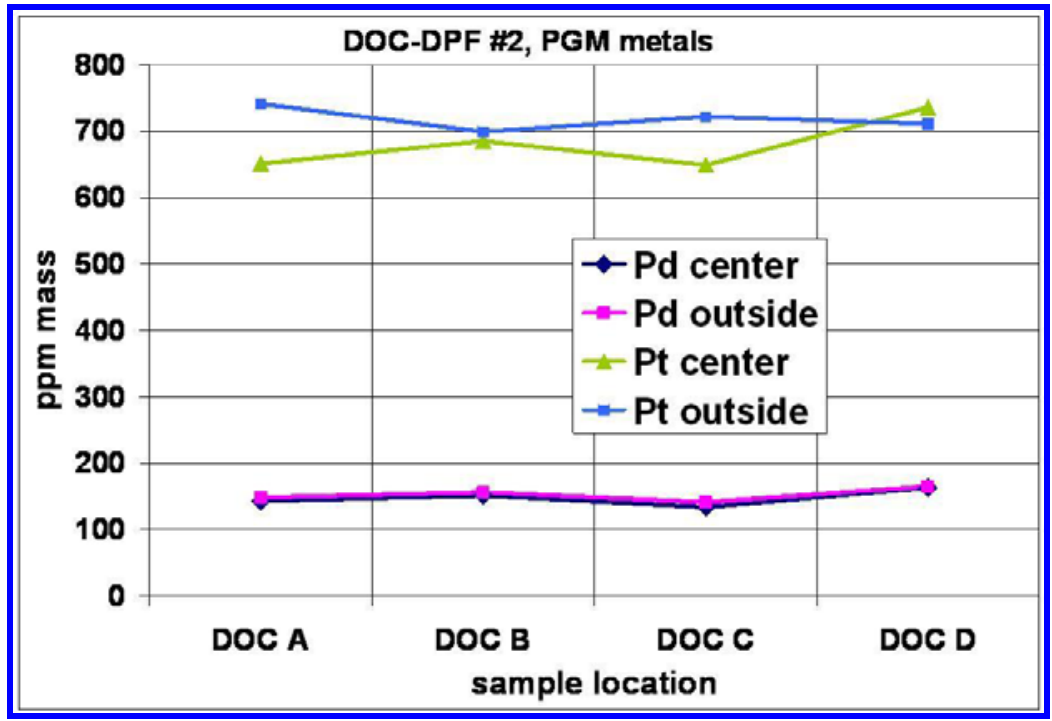

Figure 2.37 PGM metal measurements are shown for the DOC samples. Levels appear constant throughout the catalyst. 


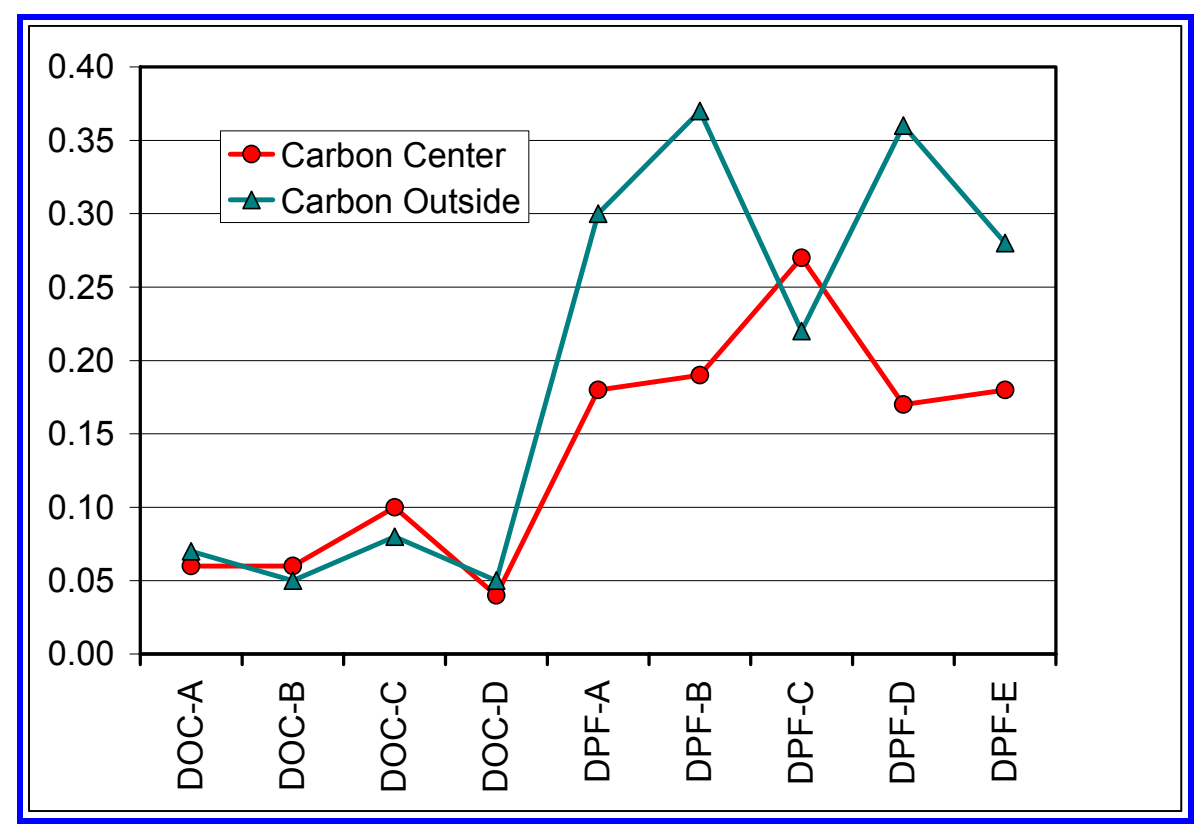

Figure 2.38 Distribution of carbon in the DOC and DPF is shown.

\section{General Conclusions and Observations}

- The ICP measurements can provide a quantitative picture of metals distribution in DOC and DPF components. It is important to note that refractory oxides are hard to digest and the technique can have $\pm 20 \%$ accuracy without special procedures.

- Measurements can be made as ppm (mass) or \% by weight and can be converted into $\mathrm{gm} / \mathrm{in}^{3}$ or $\mathrm{ft}^{3}$ with weight and size measurements.

- Lube oil related metals were found to be concentrated at the back of both DPFs examined, which is consistent with ash packing. These results are also consistent with the EM analysis results and information from visual inspection.

- Measurements can be used to calculate ash balances, if the oil consumption and formulation are available.

- ICP can provide data about catalyst formulation and distribution of washcoat and ash.

- A combustion based carbon measurement indicated an average soot loading of 1.1 and $1.3 \mathrm{~g} /$ liter for the first and second DPF respectively. 


\subsection{Summary for DPF soot layer characterization assessment}

\section{Soot-loading experiments}

- The three chosen DDC engine conditions used for PM generation show large differences in flow rate, temperature, NO and NO2 concentration, PM mass concentration, and particle agglomerate size distribution. Quite large particles were seen for the $100 \%$ load condition.

- Using a B20 fuel at the $40 \%$ load engine condition did not appear to change soot size distribution versus that derived from ULSD.

- When soot-loading a $3 \times 6$ inch DPF at the $40 \%$ load engine condition, a $\triangle P$ peak is seen at the 25-50 minute region followed by a slow decrease in $\Delta P$. This was very repeatable.

- $\quad \Delta \mathrm{P}$ measurements follow a more expected trend for the $20 \%$ and $100 \%$ engine load soot-loading experiments.

\section{$\Delta \mathrm{P}$ peaking phenomena}

- Evidence points to a "new" hypothesis concerning pressure drop for the DPFs. Starting with a clean DPF, soot initially deposits in the washcoat cracks and the cordierite pores that form the gas paths. This causes a very steep $\Delta P$ rise (permeability decrease) for a relatively short time. As more soot accumulates, layers form that bridge over the "entrances" to these gas paths, and prevent more soot from entering these crack and pore gas paths. The soot in the gas paths is continuously oxidized by NO2, which has the effect of "cleaning out" these gas paths. This can cause the $\Delta \mathrm{P}$ to actually drop as more soot is collected under certain exhaust conditions. Eventually the thickness of the soot layer will likely dominate and the $\Delta \mathrm{P}$ rises in some manner more consistent with the PM collection.

Cold flow testing

- $\quad$ Clean DPF permeability does not appear to be changed by de-greening.

- Cold flow test $\Delta \mathrm{P}$ results for clean and soot-loaded 3x6 inch DPFs agree with the trends measured during loading experiments at the $1500 \mathrm{rpm}, 40 \%$ engine load condition, and the $1800 \mathrm{rpm}, 100 \%$ load condition.

\section{EM examination of miniature DPFs}

- About $70-80 \%$ of the cordierite substrate pores (open to the surface of the inlet channels) are covered by washcoat. However, the washcoat is only partially bonded to the cordierite surface, which allows more gas paths to the cordierite pores and allows the DPF to have a reasonable permeability.

- Image analysis from samples of continuous soot layers gives porosity estimates near 75$80 \%$. It is hypothesized that the soot layer is not continuous, but regions bridge together as soot agglomerates continue to deposit and attach to existing agglomerates. This leaves voids such that the soot layer may be more open than the $80 \%$ porosity value estimated from continuous soot layer regions. 
- A set of $3 \times 6$ inch DPFs were soot-loaded at the $40 \%$ and $100 \%$ engine load conditions. Examination of soot loading distribution indicated that soot was fairly evenly distributed in these DPFs.

\section{Full-sized DPF examined by EM techniques}

- The composition and morphology of both soot and ash particles remain the same from inlet to outlet face of DPF, and only the thickness of the deposit changes. The density of (ash+soot) layer does not change with increasing layer thickness and the localized composition within the deposit remains constant.

- The loading of ash constituents changes as a result of layer thickness only. The ash+soot layer became thicker towards the DPF exit and channels were clogged near the outer circumference near the exit plane.

- The predominant "ash phase" is ( $\mathrm{Zn}, \mathrm{Ca}, \mathrm{Mg})$-phosphate with a minor phase of highlycrystalline (Fe,Zn)-phosphate. Sulfur is associated with the phosphate phase, while Si is associated with soot particles.

- No ash reactions were found in this DPF.

- The presence of soot throughout the DPF implies it was operated for a period of time without regeneration before being removed from service for analysis.

\section{$\underline{\text { ICP measurement results }}$}

- The ICP measurements can provide a quantitative picture of metals distribution in the DOC and DPF components. Refractory oxides are hard to digest and the technique can have low accuracy without special procedures.

- Lube oil related metals were found to be concentrated at the back of both DPFs examined, consistent with ash packing. These results are also consistent with the EM analysis results and information from visual inspection.

- Measurements can be used to calculate ash balances, if the oil consumption and formulation are available.

- ICP can provide data about catalyst formulation and distribution of washcoat and ash.

- A combustion based carbon measurement indicated an averaged soot loading of 1.1 and $1.3 \mathrm{~g} /$ liter for the first and second DPF respectively. 


\section{REFERENCES}

1. Detroit Diesel, "Diesel Engine Technology For Light Truck Markets," DE-FC05-97OR22606, Final Report to Department of Energy, April 2003.

2. Bolton, B., Chen, R., Hakim, N., and Oladipo, A. , "Breakthrough Diesel Engine Technology to meet Tier 2 and CO2 emissions reduction,", 2001 DEER Conference, August, 2001

3. Aneja, R., Bolton, B, Hakim, N, and Pavlova-MacKinnon, Z, "Attaining Tier 2 Emissions Through Diesel Engine and Aftertreatment Integration - Strategy and Experimental Results," 2002 DEER Conference, August, 2002

4. Aneja, R., Bolton, B, Oladipo, B., and Radwan, A," Advanced Diesel Engine and Aftertreatment Technology Development for Tier 2 Emissions," 2003 DEER Conference, August, 2003.

5. Zhang, H., and Balnaves, M., "Light Duty CIDI Engine Technology Development," Advanced Combustion Technologies, 2004 Annual Progress Report to, U.S. Department of Energy, November, 2004

6. Detroit Diesel, "Low Emissions Aftertreatment and Diesel Emission Reduction," DE-FC2699EE50575, Final Report to Department of Energy, February 2005 